\title{
Assessment of California Reformulated Gasoline Impact on Vehicle Fuel Economy
}

\author{
S. Aceves \\ R. Glaser
}

J. Richardson

January 1997

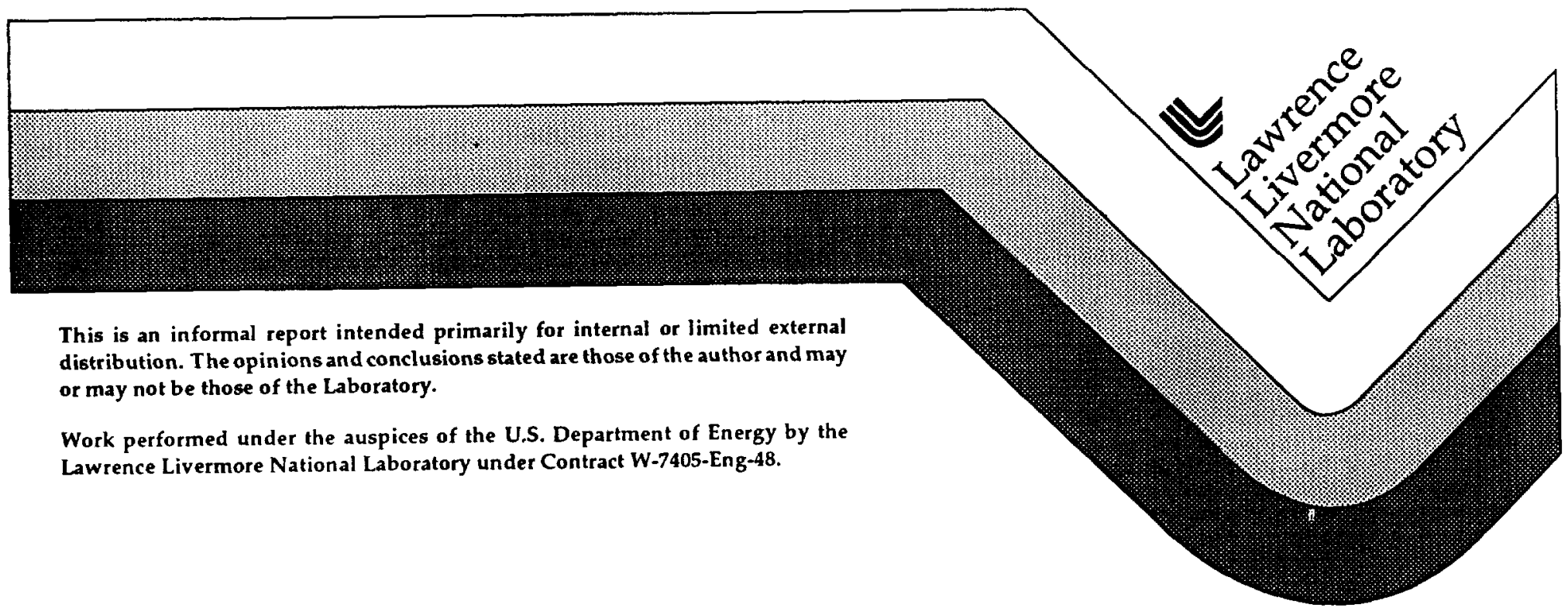




\section{DISCLAIMER}

This document was prepared as an account of work sponsored by an agency of the United States Government. Neither the United States Government nor the University of California nor any of their employees, makes any warranty, express or implied, or assumes any legal liability or responsibility for the accuracy, completeness, or usefulness of any information, apparatus, product, or process disclosed, or represents that its use would not infringe privately owned rights. Reference herein to any specific commercial product, process, or service by trade name, trademark, manufacturer, or otherwise, does not necessarily constitute or imply its endorsement, recommendation, or favoring by the United States Government or the University of California. The views and opinions of authors expressed herein do not necessarily state or reflect those of the United States Government or the University of California, and shall not be used for advertising or product endorsement purposes.

This report has been reproduced directly from the best available copy.

Available to DOE and DOE contractors from the Office of Scientific and Technical Information

P.O. Box 62, Oak Ridge, TN 37831

Prices available from (615) 576-8401, FTS 626-8401

Available to the public from the

National Technical Information Service

U.S. Department of Commerce

5285 Port Royal Rd.,

Springfield, VA 22161 


\section{ASSESSMENT \\ OF \\ CALIFORNIA REFORMULATED GASOLINE IMPACT ON \\ VEHICLE FUEL ECONOMY}

S. Aceves, R. Glaser, and J. Richardson

Lawrence Livermore National Laboratory

January, 1997 


\section{TABLE OF CONTENTS}

\section{Page}

ABSTRACT

$\begin{array}{ll}\text { INTRODUCTION } & 2\end{array}$

BACKGROUND 3

CARB Report 4

$\begin{array}{ll}\text { Additional Data Sets } & 7\end{array}$

$\begin{array}{ll}\text { Summary } & 9\end{array}$

STATISTICAL ANALYSIS OF CARB AND NEW DATA 11

$\begin{array}{ll}\text { Statistical Models for Mileage } & 11\end{array}$

- The Normal Model 11

- The Nonparametric Model 15

Statistical Analysis of Existing Data Sets $\quad 16$

Resolution of Results with Individual Mileage Records 21

$\begin{array}{lr}\text { ADDITIONAL FACTORS } & 29\end{array}$

CONCLUSIONS

ACKNOWLEDGMENTS $\quad 32$

REFERENCES

FIGURE CAPTIONS

$\begin{array}{ll}\text { FIGURES } & 36\end{array}$

APPENDIX 1. ANAL YZING THE CONTROL VEHICLE DATA 44

APPENDIX 2A. FUEL ECONOMY ANALYSIS OF SACRAMENTO 45 CITY FLEET

APPENDIX 2B. FUEL ECONOMY ANALYSIS OF SACRAMENTO COUNTY FLEET

APPENDIX 2C. FUEL ECONOMY ANALYSIS OF AUTO OIL FLEET: $\quad 57$ NORMAL MODAL

APPENDIX 2D. FUEL ECONOMY ANALYSIS OF AUTO OLL FLEET: $\quad 59$ NONPARAMETRIC MODEL 
APPENDIX 2E. FUEL ECONOMY ANALYSIS OF CARB FLEET:

APPENDDX 2F. FUEL ECONOMY ANALYSIS OF CARB FLEET: HIGHWAY DRIVING, NORMAL MODEL

APPENDIX 2G. FUEL ECONOMY ANALYSIS OF CARB FLEET: CITY DRIVING, NONPARAMETRIC MODEL

APPENDIX 2H. FUEL ECONOMY ANALYSIS OF CARB FLEET: HIGHWAY DRIVING, NONPARAMETRIC MODEL

APPENDIX 2I. FUEL ECONOMY ANALYSIS OF OKLAHOMA

69 FLEET: NORMAL MODEL

APPENDIX 2J. FUEL ECONOMY ANALYSIS OF OKLAHOMA DOE FLEET: NONPARAMETRIC MODEL 


\section{LIST OF TABLES}

Page

TABLE I. Typical Gasoline Parameters 3

TABLE II. Energy Content (BTU/gal) of Conventional Gasolines: EPA Data 4

TABLE III. Energy Content (BTU/gal) of 1990-1991 California Conventional 4 Gasolines: CARB Data

TABLE IV. CARB Test (with CaRFG) and Control (with Conventional Fuel) 5 Fleet Description and Corresponding Gasolines

TABLE V. Composition Analysis of Control Fuel 6

TABLE VI. CARB Dynamometer Fuel Economy Results 6

.TABLE VII. CSAA Average Fuel Economy Change with CaRFG 7

TABLE VIII. Automobile Club of Southern California Fuel Economy Results: 8 Reduction with CaRFG

TABLE IX. BDM-OK Fuel Economy Results: Percent Reduction with CaRFG 9 vs. Conventional Gasoline

TABLE X. Auto/Oil AQIRP Fuel Economy Results: Percent Reduction with CaRFG vs. Conventional Gasoline

$\begin{array}{ll}\text { TABLE XI. Summary of Literature Results } & 10\end{array}$

TABLE XII. Overview of Data Sets 16

TABLE XIII. Estimates of CaRFG Mileage Reduction Factor, $\delta \quad 18$

TABLE XIV. Assessing Consistency of CaRFG Mileage Reduction and 19 Energy Content Reduction

TABLE XV. Estimated $\sigma$ and Shapiro-Wilk Test of Normality P-Values 24

TABLE XVI. Probability Second Batch Gets Delta (\%) Lower Mileage Than

First Batch, Based on Number of Gallons in Each Batch, Difference in Intrinsic Fuel Economy from Batch to Batch, and Mileage Variation in Driving

TABLE XVII. Probability Second Batch Gets Delta (\%) Lower Mileage Than First Batch, Based on Number of Gallons in Each Batch, Difference in Intrinsic 26 Fuel Economy from Batch to Batch, and Mileage Variation in Driving 
TABLE XVIII. Expected Number of Motorists Recording Second Batch to

Get Delta (\%) Lower Mileage Than First Batch, Based on Number of Gallons in Each Batch, Difference in Intrinsic Fuel Economy from Batch to Batch, and Mileage Variation in Driving, Per One Percent of California Population Recording Mileage

TABLE XIX. Expected Number of Motorists Recording Second Batch to Get Delta (\%) Lower Mileage Than First Batch, Based on Number of Gallons in Each Batch, Difference in Intrinsic Fuel Economy from Batch to Batch, and Mileage Variation in Driving, Per One Percent of California Population Recording Mileage

TABLE XX. Vehicle Characteristics for Fuel Economy Sensitivity Analysis 29

TABLE XXI. Fuel Economy and Changes in Fuel Economy with respect to the Base Case "Average" Vehicle Described in TABLE XII. Results Obtained from HVEC

TABLE XXII. Average and Maximum Fuel Economy Reduction Resulting from Effects Listed 


\begin{abstract}
Fuel economy data contained in the 1996 California Air Resources Board (CARB) report with respect to the introduction of California Reformulated Gasoline (CaRFG) has been examined and reanalyzed by two additional statistical methodologies. Additional data has also been analyzed by these two statistical approaches. Within the assumptions of the analysis, point estimates for the reduction in fuel economy using CaRFG as compared to conventional, non-reformulated gasoline were $2-4 \%$, with a $95 \%$ upper confidence bound of $6 \%$. Substantial variations in fuel economy are routine and inevitable due to additional factors which affect mileage, even if there is no change in fuel reformulation. This additional analysis confirms the conclusion reached by CARB with respect to the impact of CaRFG on fuel economy.
\end{abstract}




\section{INTRODUCTION}

The introduction of Califomia Phase II Reformulated Gasoline (CaRFG) was initiated early in 1996 as part of a comprehensive regulatory program administered by the Air Resources Board (ARB) to reduce emissions from both on-road and off-road motor vehicles. Resultant emissions reductions are needed if California is to meet its obligations in the State Implementation Plan which is required by the amendments to the federal Clean Air Act. Under the ARB regulation, retail distribution of the new gasoline was required statewide on June 1, 1996.

In preparation for introduction of CaRFG, the ARB formed the California Reformulated Gasoline Advisory Committee consisting of more than 70 representatives from industry, public interest groups and government agencies in 1994. The function of the Committee is to advise the Board on issues concerning the compatibility of CaRFG with vehicles and equipment, the transition of CaRFG into the distribution and marketing systems and the public's acceptance of CaRFG. Of three subcommittees formed to research and monitor these issues, the Performance Subcommittee was given the task to help design fuel testing plans to evaluate the performance and compatibility of CaRFG in on-road motor vehicles, fuel storage systems and off-road vehicles and equipment.

The Performance Subcommittee, among other tasks, reviewed fuel economy data from test vehicles on the road and from laboratory chassis dynamometer vehicle tests to evaluate vehicle fuel economy trends for CaRFG in comparison to other gasolines. Their findings were published in March of 1996 in a report titled "CaRFG Performance and Compatibility Test Program", subtitled "Report of the Performance Subcommittee of the California Reformulated Gasoline Advisory Committee" with appendices.

The purpose of this current study, sponsored by the California Legislature and administered by the California Energy Commission, was to review and apply rigorous scientific and analytical skills to assess the reasonableness of data, procedures, and methodologies applied to reach CARB's conclusions regarding the impact of California Phase II gasoline on the fuel economy of vehicles in California. It was agreed that the following five tasks would constitute this current study:

(1) Identify and review the sources of data utilized by ARB staff for accuracy, completeness, and integrity. Identify sources of data that were not used and any new data that has become available since ARB published their findings. Review methods utilized by ARB staff for data aggregation and comparison with conventional gasoline, including statistical methods applied and the basis for rejection of data not utilized. If necessary, recompute fuel economy comparisons and resultant differences and compare with ARB findings.

(3) Incorporate new relevant data into the analysis, recompute fuel economy and compare results with Task (2) findings.

(4) Through a literature review, identify factors other than gasoline formulation (e.g., on-road driving habits, maintenance practices, climatic conditions, and others) which could explain fuel economy effects as reported by some California drivers. Compare these effects with the findings of Tasks (2) and (3).

(5) Prepare a final report of findings of the study. Include a quantitative estimate of the confidence in the fuel economy results.

Consequently, no new experimental or test program data were generated by this study, and thus no new fuel economy data was generated as a result of this study. 


\section{BACKGROUND}

The motivation for the development and introduction of reformulated gasoline is derived from the desire to reduce automobile emissions. Califormia Phase 2 Reformulated Gasoline (CaRFG) has specifications for the following fuel properties:

1. Reid vapor pressure (RVP)

2. Aromatic content

3. Olefin content

4. Oxygen content

5. $90 \%$ distillation temperature (T90)

6. $50 \%$ distillation temperature (T50)

7. Sulfur content

8. Benzene content

The introduction of additional oxygen-containing compounds into gasoline both effects the energy content and the physical/chemical properties of the gasoline. The effect of variations in gasoline composition has been the focus of considerable research and analysis by the Auto/Oil Air Quality Improvement Research Program (AQIRP), a consortium of major U.S. automakers and oil companies (Chrysler, Ford, General Motors, Amoco, ARCO, Ashland, BP America, Chevron, Conoco, Exxon, Marathon, Mobil, Philips, Shell, Sun, Texaco, Unocal, Elf France, Ethyl Corp., and UOP). Although the primary focus has been on the effect of fuel variations on emissions, some data has been reported on fuel economy in the SAE literature. [1,2] One of these studies by AQIRP, although not using CaRFG, does calculate, based on emission data and for a series of "older" (19831985 ) and "current" (1989) small fleets, a range of $-1.7 \%$ to $-4.9 \%$ reduction in variously defined fuel economies in using an MTBE oxygenated gasoline compared to conventional gasoline. [1] The MTBE gasolines are similar to but not identical to CaRFG. The quality of maintenance has been identified as a major component in aggregated vehicle emissions. [3]

Current gasoline is formulated to meet a number of specifications, related to engine performance, volatility and seasonal effects, performance, etc. Surprisingly, the energy content, which has been shown to be proportional to fuel economy, [1] is not explicitly specified. Octane is indicative of engine performance (i.e., the ability of the fuel to be used in high performance, high compression ratio engines without "knocking"), not energy content, and is satisfied by additives and fuel composition; gasolines of significantly different energy content can have identical octane ratings. Representative analysis and specifications for CaRFG, Federal RFG, and "conventional" gasoline are shown in Table I. [4-7] The energy values shown are measured for different batches of the appropriate.

TABLE I. Typical Gasoline Parameters

\begin{tabular}{|l|c|c|c|}
\hline \multicolumn{1}{|c|}{ PROPERTY } & CONVENTIONAL & FEDERAL RFG & CA RFG \\
\hline & & & \\
\hline RVP, psi & 8.7 & 7 & $6.8-7$ \\
\hline Aromatics, v \% & 32 & 27 & 22 \\
\hline Olefin, v \% & 9 & 8.5 & 4 \\
\hline Oxygen, wt \% & 0 & 2 & 2 \\
\hline T90, ${ }^{\circ} \mathrm{F}$ & 330 & 329 & 290 \\
\hline T50, ${ }^{\circ} \mathrm{F}$ & 220 & 210 & 200 \\
\hline Sulfur, ppm & 340 & 130 & 30 \\
\hline Benzene, v \% & 1.5 & 0.8 & 0.8 \\
\hline Energy, BTU/gal & $117,900-115,000$ & 115,600 & 111,400 \\
\hline
\end{tabular}


gasoline. The conventional properties are measured for a representative 1988 standard gasoline; the Federal RFG and CaRFG parameters are regulated specifications

However, gasoline composition has varied considerably over the years; hence "conventional" is an ambiguous term. The industry standard is 1988 conventional gasoline, but the composition of gasoline, not counting the introduction of oxygenated compounds, has varied considerably since 1988. [8] Furthermore, due to a desire for different summer and winter physical properties (e.g., vapor pressure), energy content shows a seasonal dependence. Finally, probably because it is not specified, energy content can vary considerably even within a given nominal gasoline seasonal composition. Table II shows averages and typical ranges for variation in energy content of conventional gasolines documented by the EPA. [9]

TABLE II. Energy Content (BTU/gal) of Conventional Gasolines: EPA Data

\begin{tabular}{|c|c|c|c|c|}
\hline & MINIMUM & MAXIMUM & AVERAGE & \% RANGE \\
\hline & & & & \\
\hline Summer & 113,000 & 117,000 & 114,500 & \pm 3.5 \\
\hline Winter & 108,500 & 114,000 & 112,500 & \pm 4.9 \\
\hline
\end{tabular}

Table III shows similar data in a survey of 1990-1991 California gasoline. [10]

TABLE III. Energy Content (BTU/gal) of 1990-1991 California Conventional Gasolines: CARB Data

\begin{tabular}{|c|c|c|c|c|}
\hline & MINIMUM & MAXIMUM & AVERAGE & \% RANGE \\
\hline & & & & \\
\hline Summer & 109,900 & 120,300 & 115,800 & $+3.9 \%$ to $-5.1 \%$ \\
\hline Winter & 110,900 & 114,300 & 117,700 & $\pm 3.0 \%$ \\
\hline
\end{tabular}

It is clear that a major source of on-road variability in fuel economy, in addition to all the variability in the driving conditions (e.g., wind, load, speed, air conditioning, reproducibility of fill-up - vida infra), is the expected variation in the energy content of ostensibly identical fuels.

\section{CARB Report}

The Air Resources Board, under the guidance of the Performance Subcommittee of the California Reformulated Gasoline Advisory Committee, evaluated the performance and compatibility of CaRFG in on-road motor vehicles, fuel storage systems, and off-road vehicles and equipment. These findings are presented in the recent CARB report. [10] This CARB report, with respect to fuel economy, presents results from fleet on-road trials, a small dynamometer study, and catalogues earlier fuel economy studies done by various sources. The CARB report also examines maintenance issues related to the use of CaRFG in the CARB on-road fleet study. Finally, the CARB report also presents industry-reported results with respect to materials compatibility and off-road vehicles.

1) On-road fleet study. Any sampling of a large population has to consider the level of fidelity with which the sampling represents the true population. In this case important factors include the vehicle type, age and mileage distribution, and driving patterns. The fleets chosen by CARB are representative of large industrial or government fleets; these are the only organizations which have fleets, but these fleets are not the most representative imaginable of the overall California vehicle population. Table IV lists salient characteristics of the fleets and corresponding gasoline energy content which participated in 
the study. More detailed characterization with respect to fleet and gasoline composition is in the CARB report.

TABLE IV. CARB Test (with CaRFG) and Control (with Conventional Fuel) Fleet Description and Corresponding Gasolines:

\begin{tabular}{|c|c|c|c|c|c|}
\hline \multirow[t]{2}{*}{ FLEET } & \multirow[t]{2}{*}{$\begin{array}{c}\text { TEST } \\
\text { VEHICLES }\end{array}$} & \multirow[t]{2}{*}{$\begin{array}{l}\text { CONTROL } \\
\text { VEHICLES }\end{array}$} & \multicolumn{2}{|c|}{$\begin{array}{c}\text { AVG FUEL ENERGY } \\
\text { BTU/GAL }\end{array}$} & \multirow{2}{*}{$\begin{array}{c}\text { FUEL } \\
\text { ECONOMY } \\
\text { CHANGE }\end{array}$} \\
\hline & & & $\overline{\mathrm{TEST}}$ & CONTROL & \\
\hline City of Sacramento & 106 & 81 & 110,400 & 115,500 & $-2.3 \%$ \\
\hline Sacramento County & 173 & 241 & 110,700 & 115,600 & $-2.4 \%$ \\
\hline CSU Fresno & 112 & 0 & 110,500 & None & $\overline{\mathrm{NA}}$ \\
\hline Bank of America & 20 & 10 & 110,300 & $113,700^{1}$ & $\mathrm{NA}^{2}$ \\
\hline GTE & 254 & 157 & 110,400 & $113,600^{\mathrm{I}}$ & $\mathrm{NA}^{3}$ \\
\hline Pacific Bell, North & 84 & 110 & 110,400 & 115,400 & $\mathrm{NA}^{3}$ \\
\hline Pacific Bell, South & 55 & 38 & 110,300 & $113,100^{I}$ & $\mathrm{NA}^{3}$ \\
\hline Caltrans & 25 & 0 & 110,200 & None & $\overline{\mathrm{NA}}$ \\
\hline TOTAL & 829 & 637 & 110,400 & & \\
\hline
\end{tabular}

1 Federal Reformulated Gasoline

2 Insufficient data to analyze

3 Auxiliary equipment used fuel from vehicle tank

Principle strengths and weaknesses are readily apparent from Table IV. A number of fleets containing a large number of vehicles were chosen. However, only two of the fleets resulted in useable data with respect to fuel economy (the other fleets did provide data concerning maintenance and hence materials compatibility). Even in those cases, some of the data was trimmed from the initial set on the basis of not being realistic (i.e., abnormal deviations in mileage, probably due to data entry error). The major reason for excluding six of the fleets was the use of auxiliary equipment, but three of the excluded fleets also used Federal RFG. Although that was the only gasoline available in southern California prior to the introduction of CaRFG, it does introduce additional ambiguity. Of the two fleets providing useable data, one consisted of police cars in the city of Sacramento, and the other contained $30 \%$ medium and heavy duty trucks in the county of Sacramento (the statewide percentage is only $8 \%$ ). Thus, neither fleet was exceptionally representative of the California state vehicle population nor did at least the city fleet represent "typical" driving patterns. Table $\mathrm{V}$ presents the fuel analysis from the conventional gasoline used as the control for the two Sacramento fleets.

It is apparent that the conventional fuel available in Sacramento for the two fleets was neither identical (e.g., the county gasoline was substantially oxygenated) nor representative of the industry standard, circa- 1988 conventional fuel. However, the energy contents were nearly identical and similar to that expected for industry standard gasoline.

The observations concerning the fidelity of the fleet representation of the Califomia vehicle population coupled with the variability of the control fuel merely illustrate the difficulty in doing a large, representative, on-road fuel economy study with control of potentially significant variables. The CaRFG was controlled in that there was a winter and summer composition, but each was a single homogenous batch from Phillips 66 . The "conventional" control fuels were sampled, but subject to the vagaries of commercial 
supply. Thus, not unexpectedly, there was significant variation in the composition of the eight measured parameters of the control fuel, thereby representing real world conditions; energy content was not one of the directly measured parameters.

TABLE V. Composition Analysis of Control Fuel

\begin{tabular}{|l|c|c|}
\hline \multicolumn{1}{|c|}{ PROPERTY } & $\begin{array}{c}\text { City of } \\
\text { Sacramento }\end{array}$ & $\begin{array}{c}\text { County of } \\
\text { Sacramento }\end{array}$ \\
\hline & & \\
\hline RVP, psi & 10.9 & 11.7 \\
\hline Aromatics, v \% & 24 & 24 \\
\hline Olefins, v \% & 10.2 & 10.4 \\
\hline Oxygen, wt \% & 0.2 & 1.9 \\
\hline T90, ${ }^{\circ} \mathrm{F}$ & 330 & 336 \\
\hline T50, ${ }^{\circ} \mathrm{F}$ & 199 & 188 \\
\hline S, ppm & 134 & 158 \\
\hline Benzene, v \% & 1.1 & 1.2 \\
\hline Energy, BTU/gal & 115,500 & 115,600 \\
\hline
\end{tabular}

The CARB conclusion with respect to the use of CaRFG, based on the two on-road fleet studies, was that about a $2.4 \%$ reduction in fuel economy would be expected. The variation about the fleet-average relative difference was $\pm 3 \%$. This is less than the relative difference in fuel energy content $(-4.3 \%)$.

2) CARB dynamometer study. CARB performed a limited dynamometer study using four vehicles (1995 Dodge Caravan, 1995 Ford Taurus, 1995 Chevrolet Lumina, and a 1995 Honda Accord LX) with three fuels (conventional, Federal RFG, and CaRFG). The results are summarized in Table VI. [10]

TABLE VI. CARB Dynamometer Fuel Economy Results

\begin{tabular}{|l|c|c|}
\hline \multicolumn{1}{|c|}{ VEHICLE } & $\begin{array}{c}\text { CaRFG vs. } \\
\text { Conventional }\end{array}$ & $\begin{array}{c}\text { Federal RFG vS. } \\
\text { Conventional }\end{array}$ \\
\hline & & \\
\hline Dodge & $-0.8 \%$ & $-2.0 \%$ \\
\hline Ford & $-3.7 \%$ & $-2.6 \%$ \\
\hline Chevrolet & $-5.0 \%$ & $-2.7 \%$ \\
\hline Honda & $-4.3 \%$ & $0.0 \%$ \\
\hline AVERAGE & $-3.5 \%$ & $-1.8 \%$ \\
\hline
\end{tabular}

3) Cited historical data. The CARB report cited the study by Battelle using a limited number of Federal Express on-road test data for delivery vans using a CaRFG and a conventional gasoline over a two year period. [2] The on-road data has quite a bit of scatter, no doubt due to the variability in the drive cycle plus some variation $(2.5 \%)$ in the RFG energy content during the test. The dynamometer results are, as expected, more tightly grouped. The on-road results for the change in fuel economy of CaRFG relative to "conventional" fuel available at that time in the South Coast Air Basin ranged from $+1 \%$ to $-7 \%$; the dynamometer results varied from $+1 \%$ to $-3 \%$. These results are per equivalent 
energy, however, and the CaRFG had 1 to $3 \%$ less energy/volume than the industry standard.

The CARB report also cites the Southeastern Wisconsin Fuel Efficiency Study, conducted jointly between the Wisconsin Department of Natural Resources and U.S. EPA. [10] This was a limited (eight vehicles) study comparing four fuels ("conventional" and three oxygenated RFG, although none were CaRFG). There was a $2.2 \%$ reduction in average fuel economy between the conventional fuel and the MTBE-containing RFG. The report does conclude the following: 1) for any vehicle using the same gasoline, mileage may vary by more than $10 \%$ between tests; 2 ) the drop in mileage between warm and cold weather was at least $5 \%$ for all four fuels, which is a greater drop than the difference in mileage among fuel types; 3 ) there are virtually no meaningful mileage differences among the three RFG used in the study that can be distinguished from the other factors that affect mileage.

Thus, based on its own on-road and dynamometer testing, plus cited external studies, CARB concluded "that use of CaRFG will reduce the average miles per gallon (fuel economy) by 1 to 3 percent. The 1 percent reduction results from comparing CaRFG to an oxygenated conventional gasoline; since oxygenates are already in widespread use in California, the 1 percent reduction is the expected average fuel economy change when CaRFG is introduced." [10]

\section{Additional Data Sets}

1) EPA. The US EPA reviewed the available literature from the perspective of the effect of oxygenates of fuel economy. An NRC report concluded that the fuel-economy penalty associated with the use of oxygenated fuels is approximately $2 \%$ to $3 \%$ and is related to changes in volumetric energy content. [11]

2) CA AAA Northern California. The California State Automobile Association

TABLE VII. CSAA Average Fuel Economy Change with CaRFG
\begin{tabular}{|c|c|c|}
\hline MONTH & $\begin{array}{c}\text { AVERAGE } \\
\text { MPG }\end{array}$ & \% CHANGE \\
\hline Apr 96 & 22.72 & \\
\hline Apr 95 & 23.01 & $-1.26 \%$ \\
\hline & & \\
\hline May 96 & 22.57 & $-0.53 \%$ \\
\hline May 95 & 22.69 & \\
\hline & & $-2.33 \%$ \\
\hline Jun 96 & 22.26 & \\
\hline Jun 95 & 22.79 & $-3.80 \%$ \\
\hline & & \\
\hline Jul 96 & 22.05 & $-1.60 \%$ \\
\hline Jul 95 & 22.92 & \\
\hline & & $-0.67 \%$ \\
\hline Aug 96 & 22.20 & $-1.70 \%$ \\
\hline Aug 95 & 22.56 & \\
\hline & & \\
\hline Sep 96 & 22.37 & \\
\hline Sep 95 & 22.52 & \\
\hline & & \\
\hline AVERAGE & & \\
\hline
\end{tabular}


(Northern California) compared their vehicle fleet fuel economy before and after the introduction of CaRFG; prior to the introduction of CaRFG, the fleet used conventional gasoline (i.e., non-oxygenated). They have summary data comparing average monthly fuel economy between equivalent time periods. These results are presented in Table VII. [12] The raw data which was the basis for these averages was not available.

3) CA AAA Southern California. The Automobile Club of Southern Califomia compared CaRFG to Federal RFG ("regular") using 3 vehicles under the Federal Test Procedure and Highway Fuel Economy Tests; thus, both urban and highway mileage data was obtained. [13] The three vehicles were a 1991 Plymouth Acclaim (2.5 liter 4 cylinder), a 1992 Plymouth Acclaim (2.5 liter 4 cylinder), and a 1989 Pontiac Bonneville (3.8 liter V6). Unfortunately, in this case the fuel economy with CaRFG was compared with Federal RFG, but "some of the constituents of CaRFG were present in the samples (of Federal RFG). This indicated that Chevron had already started (Feb 96) to convert their refinery by the time the most recent shipment of gasoline was delivered (to the Automobile Club of Southern Califomia)." These results are presented in Table VIII.

TABLE VIII. Automobile Club of Southem California Fuel Economy Results: Reduction with CaRFG

\begin{tabular}{|c|c|c|}
\hline VEHICLE & URBAN & HIGHWAY \\
\hline & & \\
\hline 91 Plymouth & $-3.3 \%$ & $-1.2 \%$ \\
\hline 92 Plymouth & $-3.2 \%$ & $-1.6 \%$ \\
\hline 89 Pontiac & $-0.8 \%$ & $-5.8 \%$ \\
\hline & & \\
\hline AVERAGE & $-2.4 \%$ & $-2.9 \%$ \\
\hline
\end{tabular}

4) State-wide gasoline sales and Caltrans total mileage. CARB has released statewide data documenting via gasoline tax receipts collected by the State Board of Equalization that 37.7 million gallons of 'gasoline (CaRFG) were consumed per day in Apr - Jul 96, compared to 36.9 million gallons per day in Apr-Jul 95 (a mixture of conventional (Northem California) and Federal RFG (Southern California)). [14] This increase of 2.2 $\%$ is compared to a Caltrans reported increase of 1.9 percent greater average daily traffic on state highways between Apr - Jul 96 compared to the same four months in 1995. Caltrans claims survey data, taken from 17 sites, is accurate to within 1 percent for total vehiclemiles on state highways. Thus, this data also supports the contention that the reduction in fuel economy attributable to the introduction of CaRFG is minimal.

5) Consumer Reports. Anecdotal data was provided by Consumer Reports; however, they refused to release the data from which they based their conclusions. They did describe the several different types of gasoline, where they are available, and concluded that there was "no meaningful differences in either acceleration or fuel economy between the various new fuels and the old-fashioned 1990 fuel." [15]

6) BDM-Oklahoma, for the Department of Energy. BDM-Oklahoma has compared $\mathrm{CaRFG}$ with a variety of fuels, including the 1988 industry average for conventional gasoline; this industry average is the US EPA reference fuel for RFG certification. [4] They tested five 1994 cars having an initial mileage ranging between 18,000 and 30,000 accumulated miles. After 30,000 additional accumulated miles on CaRFG, dynamometer tests were done using 2 driving cycles (FTP, the Federal Test Procedure, and US75, a modified cycle including more severe speeds and accelerations). These specific results are 
summarized in Table IX. Further data was provided and was analyzed in more statistical detail (vida infra ). This data also illustrates the potential effect variation in driving cycle will have on mileage.

TABLE IX. BDM-OK Fuel Economy Results:

Percent Reduction with CaRFG vs. Conventional Gasoline

\begin{tabular}{|c|c|c|}
\hline VEHICLE & FTP & US75 \\
\hline & & $-2.6 \%$ \\
\hline 94 Honda Accord & $-4.0 \%$ & $-2.3 \%$ \\
\hline 94 Toyota Camary & $-5.9 \%$ & $-5.3 \%$ \\
\hline 94 Nissan Maxima & $-5.7 \%$ & $-4.4 \%$ \\
\hline 94 Ford Taurus & $-3.6 \%$ & $0.1 \%$ \\
\hline 94 Chevy Lumina & $-3.8 \%$ & \\
\hline & & $-3.5 \%$ \\
\hline AVERAGE & $-4.6 \%$ & \\
\hline
\end{tabular}

7) Auto/Oil AQIRP. The Auto/Oil AQIRP performed a dynamometer test evaluation of CaRFG vs. conventional gasoline (i.e., industry average, non-oxygenated, representing 1988 national average composition, and measured to have $3 \%$ higher volume energy density than CaRFG). A preliminary report [10] of these results was included in the CARB report (Appendix 41), and a public document has been issued. [5] Detailed statistical analysis has been performed on this data (vida infra). The test fleets consisted of seven 1983-1985 vehicles, ten 1989 vehicles, and six 1994 vehicles; both passenger cars and light duty trucks were included in the test fleet composition. The reported conclusions from this FTP test of 23 vehicles are summarized in Table X.

TABLE X. Auto/Oil AQIRP Fuel Economy Results: Percent Reduction with CaRFG vs. Conventional Gasoline

\begin{tabular}{|c|c|}
\hline FLEET & \% REDUCTION \\
\hline & \\
\hline $1983-1985$ & $-1.9 \%$ \\
\hline 1989 & $-2.6 \%$ \\
\hline 1994 & $-3.6 \%$ \\
\hline
\end{tabular}

Summary. Table XI summarizes all the cited data which quantitatively measured the reduction in fuel economy due to the use of CaRFG. This table contains both data referenced to and obtained by CARB, as well as data unavailable to CARB at the time their report was published. Despite the variability in the reference vs. test fuel, the variations in the type of test, the variations in the vehicles, and the inherent variations in on-road driving conditions, all of the literature values, both before and after the CARB report, indicate a reduction in mileage due to the introduction of $\mathrm{CaRFG}$ which would be approximately 2 to $4 \%$. As with any on-road mileage parameter, there is significant scatter in the data, so larger (and smaller) reductions are expected in a certain fraction of all measurements. 
TABLE XI. Summary of Literature Results

\begin{tabular}{|l|c|}
\hline FUEL ECONOMY STUDY & $\begin{array}{c}\text { REDUCTION DUE TO } \\
\text { CaRFG }\end{array}$ \\
\hline Auto/Oil AQIRP Emission & -1.7 to $-4.9 \%$ \\
\hline CARB On-road & $-2.3 \%$ \\
\hline CARB Dynamometer & $-1.8 \%$ \\
\hline Battelle On-road & +1 to $-7 \%$ \\
\hline Battelle Dynamometer & +1 to $-3 \%^{2}$ \\
\hline Wisconsin & $-2.2 \%$ \\
\hline EPA & -2 to $-3 \%$ \\
\hline AAA Northern California & $-1.7 \%$ \\
\hline AAA Southem California & -2 to $-3 \%$ \\
\hline California Gasoline Use & 0 to $-1 \%$ \\
\hline Consumer Reports & Insignificant \\
\hline BDM-OKDOE & -3.5 to $-4.6 \%$ \\
\hline Auto/Oil AQIRP Dynamometer & -1.9 to $-3.6 \%$ \\
\hline
\end{tabular}

1 Oxygenated but not CaRFG

${ }^{2}$ Compared per energy equivalent

${ }^{3}$ Oxygenated RFG but not CaRFG

${ }^{4}$ Federal RFG (not CaRFG) 


\section{STATISTICAL ANALYSIS OF CARB AND NEW DATA}

Statistical Models for Mileage

Two statistical models will be developed to quantify the effect of CaRFG on fuel economy. The first model is based on large sample considerations and will be called the normal model. The second model uses relaxed assumptions and will be called the nonparametric model.

\section{The Normal Model.}

Gasoline fuel theory and experimentation support the contention that a reduction in energy content causes a proportionate reduction in fuel economy. [1] It is reasonable therefore to model mileage multiplicatively. Consider a particular vehicle and fuel type. We assume the model,

$$
T=\mu \varepsilon,
$$

where $\mathrm{T}$ (a random variable) denotes the measured number of miles traveled with one gallon of fuel, $\mu$ (a parameter) is the mean mpg, and $\varepsilon$ (a random variable) has mean 1 and standard deviation $\sigma$. The parameters $\mu$ and $\sigma$ depend on such things as the vehicle, the fuel, and the manner of driving, and are unknown. The paramieter $\sigma$ in particular characterizes variation in mileage due to changes in speed, terrain, route, traffic, weather, number of passengers, energy content, and so on.

Consider $\mathrm{N}$ gallons of fuel: $\mathrm{T}_{1}, \ldots, \mathrm{T}_{\mathrm{N}}$ are generated, and $X=(1 / N) \Sigma T_{j}$

is the measured fuel economy (mpg). Regard $\mathrm{T}_{1}, \ldots, \mathrm{T}_{\mathrm{N}}$ as a random sample. Since $\mathrm{T}$ has mean $\mu$ and standard deviation $\mu \sigma$, it follows from large sample statistics that for sufficiently large $N, \log X$ is approximately normally distributed with mean $\log \mu$ and standard deviation $\sigma / \sqrt{N}$. [16] For brevity, denote this distribution as $\mathcal{X}(\log \mu, \sigma / \sqrt{N})$. The size of the sample is effectively the total volume of gasoline, $\mathbf{N}$ gallons, and since a volume is infinitely divisible, the approximate normality of $X$ is achieved if the sum $\Sigma T_{j}$ can be viewed as arising additively from a large number of relatively small and uniform contributions. For selected vehicles with extensive mileage data, the approximate normality conjecture can (and will in this report) be tested statistically, but for limited data, as in the dynamometer experiments, normality will be an untested assumption. [For this reason, an alternative model with no claim of normality will be developed.]

Compare now the vehicle's mileage for two scenarios. In scenario 1 , fuel 1 (namely, conventional fuel) will be used; in scenario 2, fuel 2 (CaRFG) will be used. Ideally the only systematic difference between the scenarios is the fuel formulation difference. In dynamometer testing professional drivers replicate a rigid EPA protocol. In CARB on the road testing scenario 1 represents a 5 month time period in 1994, and scenario 2 represents the same 5 month period in 1995; hopefully, driving patterns and external factors "average out" over the comparable 5 month periods.

Adopt the model $\mathrm{T}=\mu \varepsilon$ for scenario 1 and the model $\mathrm{T}=\mu \theta \varepsilon$ for scenario 2, where

$$
\theta=1-\delta \text {, }
$$

and $\delta$ is the fuel economy reduction factor for CaRFG. For example, if $\delta=0.03$, then CaRFG reduces mileage on the average by $3 \%$ relative to conventional fuel for this vehicle. If the vehicle uses $\mathrm{N}$ gallons in scenario 1 and $\mathrm{X}$ is the measured mileage, and if the vehicle uses $\mathrm{M}$ gallons in scenario 2 and $\mathrm{Y}$ is the measured milegge, then $\log \mathrm{X}$ is approximately $\mathcal{N}(\log \mu, \sigma / \sqrt{N})$, and $\log Y$ is approximately $\mathcal{N}(\log \mu \theta, \sigma / \sqrt{M})$.

We are interested in $\delta=1-\theta$ but not $\mu$. The nuisance parameter $\mu$ is eliminated by considering

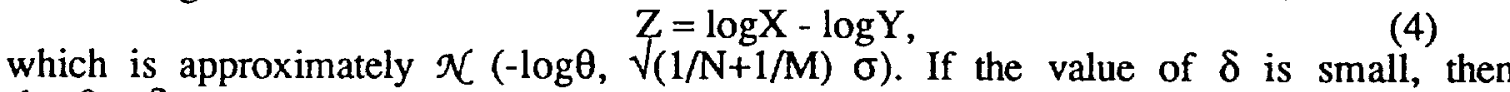
$-\log \theta \approx \delta$.

In applications mileage data from several vehicles are assimilated. Consider a 
collection of $k$ vehicles and the corresponding data $Z_{1}, \ldots, Z_{k}$, where for vehicle $i$ there are $N_{i}$ gallons for scenario 1 and $M_{i}$ gallons for scenario 2 . The $Z$ 's are independent, with $Z_{i}$ being distributed approximately as $\mathcal{N}\left(-\log \theta_{i}, \sqrt{ }(1 / N+1 / M) \sigma_{i}\right)$.

The intrinsic effects of CaRFG on mileage, measured by $\delta_{i}=1-\theta_{i}$, need not be the same for each vehicle, nor should the variability parameters $\sigma_{i}$ necessarily be the same either. However, the available data preclude estimating differences in the $\delta_{i}$ and $\sigma_{i}$, because of limited replication in dynamometer testing and unreliable individual fill-up data in on the road testing. It is necessary then to make these assumptions:

- common underlying $\sigma$

- common reduction factor $\delta$.

Thus, the relative variation in mileage is assumed to be same for all vehicles, i.e., $\sigma_{i} \equiv \sigma$, and the fuel effect is isolated in a single parameter and assumed to be the same for all vehicles, i.e., $\delta_{\mathrm{i}} \equiv \delta$. By making these assumptions it is possible to develop maximum likelihood estimates of the parameters $\delta$ and $\sigma$ as well as corresponding confidence bounds and intervals for $\delta$. In essence these inferences apply to the corresponding means of the distributions of $\delta$ and $\sigma$ over the population of all California vehicles.

For the Sacramento City and Sacramento County CARB data sets, there were. control vehicles as well as test vehicles. For the control vehicles conventional fuel was used in both 1994 and 1995. The above modeling can be used for the control vehicles with the interpretation that $\delta$ represents the mean change proportion in mpg from 1994 to 1995 . In fact, however, it may safely be assumed that $\delta=0$ for each control population, since as shown in Appendix 1, hypothesis tests of $\delta=0$ are accepted at the usual levels of significance. Consequently the use of the control vehicle data is merely to help in the estimation of the parameter $\sigma$.

We now develop the maximum likelihood estimates of $\delta$ and $\sigma$ for the normal model. First consider the CARB on the road testing programs. Assume the following data: - $\log$ mileage differences $Z_{1}, \ldots, Z_{Q}$ based on $Q$ test vehicles; for vehicle $i, N_{i}$ gallons for scenario 1 (conventional fuel) and $M_{i}$ gallons for scenario 2 (CaRFG)

- Log mileage differences $W_{1}, \ldots, W_{c}$ based on $C$ control vehicles; for vehicle $j, K_{j}$ gallons for scenario 1 (conventional fuel) and $\mathrm{L}_{\mathrm{j}}$ gallons for scenario 2 (also conventional fuel).

Thus, $Z_{\mathrm{i}}$ is distributed as $\mathcal{N}\left(\beta, V_{r_{i}} \sigma\right)$, where

and

$$
\beta=-\log (1-\delta)
$$

and $W_{j}$ is distributed as $\mathcal{N}\left(0, V_{s_{j}} \sigma\right)$, where

$$
r_{i}=1 / N_{i}+1 / M_{i}
$$

The likelihood function is therefore

$$
s_{j}=1 / K_{j}+1 / L_{j} \text {. }
$$

$$
L=\prod_{i=1}^{Q} \frac{1}{\sigma \sqrt{2 \pi r_{i}}} \exp \left\{-\frac{1}{2 r_{i} \sigma^{2}}\left(z_{i}-\beta\right)^{2}\right\} \prod_{j=1}^{c} \frac{1}{\sigma \sqrt{2 \pi s_{j}}} \exp \left\{-\frac{1}{2 s_{j} \sigma^{2}} w_{j}^{2}\right\}
$$

which is maximized by

$$
\hat{\beta}=\frac{\sum_{i} z_{i} / r_{i}}{\sum_{i} 1 / r_{i}}
$$

and

$$
\hat{\sigma}^{2}=\frac{1}{Q+C}\left[\sum_{i} \frac{1}{r_{i}}\left(z_{i}-\hat{\beta}\right)^{2}+\sum_{j} \frac{1}{s_{j}} w_{j}^{2}\right]
$$

In on the road testing a vehicle is observed in normal operating conditions over a period of time. Fuel economy, i.e., the number of miles driven relative to the number of gallons 
pumped, is the measured variable. In dynamometer testing, on the other hand, a fixed driving protocol over a fixed distance is employed, and fuel consumption, i.e., the number of gallons consumed over this distance, is the measured variable. Thus, it is appropriate to use the multiplicative model,

$$
T^{*}=\mu^{*} \varepsilon^{*},
$$

where $T^{*}$ (a random variable) denotes the measured number of gallons consumed in one mile of driving, $\mu^{*}$ (a parameter) is the mean gpm, and $\varepsilon^{*}$ (a random variable) has mean 1 and standard deviation $\sigma^{*}$. The development for the reciprocal quantity gpm follows in analogous fashion to the previous development for mpg. Consider $\mathrm{N}^{*}$ miles of driving: $\mathrm{T}_{1}{ }^{*}, \ldots, \mathrm{T}_{\mathrm{N}}{ }^{*}$ are generated, and

$$
X^{*}=\left(1 / N^{*}\right) \Sigma T_{j}^{*}
$$

is the measured fuel consumption ("gallonage", gpm). Regarding $T_{1} *, \ldots, T_{N} *$ as a random

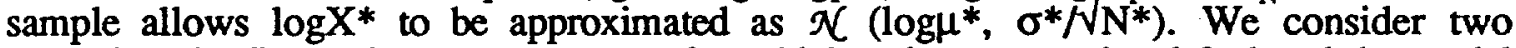
scenarios, the first a dynamometer test of a vehicle using conventional fuel and the model eq. (11), the second a replicated dynamometer test of the same vehicle but with CaRFG as fuel, i.e., $T^{*}=\mu^{*} \theta^{*} \varepsilon^{*}$, where

$$
1 / \theta^{*}=1-\delta,
$$

and $\delta$ (precisely as before) is the fuel economy reduction factor for CaRFG. If the vehicle is driven $N^{*}$ miles in scenario 1 and $X^{*}$ is the measured gallonage, and if the vehicle is driven $\mathrm{M}^{*}$ gallons in scenario 2 and $\mathrm{Y}^{*}$ is the measured gallonage, then $\log \mathrm{X}^{*}$ is approximately $\mathcal{X}\left(\log \mu^{*}, \sigma^{*} / \sqrt{N^{*}}\right), \log \mathrm{Y}^{*}$ is approximately $\mathcal{N}\left(\log \mu^{*} \theta^{*}, \sigma^{*} / \mathrm{NM}^{*}\right)$, and

$$
\mathrm{Z}^{*}=\log \mathrm{Y}^{*}-\log \mathrm{X}^{*}
$$

is approximately $\mathcal{N}\left(\log \theta^{*}, \sqrt{ }\left(1 / \mathrm{N}^{*}+1 / \mathrm{M}^{*}\right) \sigma^{*}\right)$.

Assume the following dynamometer test data:

- $\log$ gallonage differences $Z_{1}^{*}, \ldots, Z_{Q}{ }^{*}$ based on $Q$ test vehicles; for vehicle $i$, $\mathrm{N}_{\mathrm{i}}^{*}$ miles for scenario 1 (conventional fuel) and $\mathrm{M}_{\mathrm{i}}^{*}$ miles for scenario 2 (CaRFG).

Under assumptions of a common gallonage variation parameter $\sigma^{*}$ and a common fuel economy reduction factor $\delta, Z_{i}^{*}$ is distributed as $\mathcal{N}\left(\beta, \sqrt{r_{i}}{ }^{*} \sigma^{*}\right)$, where

$$
\beta=-\log (1-\delta)
$$

and

The likelihood function is therefore

$$
r_{i}^{*}=1 / N_{i}^{*}+1 / M_{i}^{*} \text {. }
$$

$$
L=\prod_{i=1}^{Q} \frac{1}{\sigma^{*} \sqrt{2 \pi r_{i}^{*}}} \exp \left\{-\frac{1}{2 r_{i}^{*} \sigma^{* 2}}\left(z_{i}^{*}-\beta\right)^{2}\right\}
$$

which is maximized by

$$
\hat{\beta}=\frac{\sum_{i} z_{i}^{*} / r_{i}^{*}}{\sum_{i} 1 / r_{i}^{*}}
$$

and

$$
\hat{\sigma}^{* 2}=\frac{1}{Q} \sum_{i} \frac{1}{r_{i}^{*}}\left(z_{i}^{*}-\hat{\beta}\right)^{2} .
$$

Confidence limits for $\delta=1-\mathrm{e}^{-\beta}$ may be constructed from $\hat{\beta}$ and its standard error. The estimated variance of $\hat{\beta}$ is

$$
\operatorname{vâr}(\hat{\beta})=\hat{\sigma}^{2} / \sum_{i} \frac{1}{r_{i}}
$$

for the on the road (mpg) development eqs. (1) through (10), and is 


$$
\operatorname{vâr}(\hat{\beta})=\hat{\sigma}^{* 2} / \sum_{\mathrm{i}} \frac{1}{\mathrm{r}_{\mathrm{i}}}
$$

for the dynamometer (gpm) development eqs. (11) through (19); the associated standard errors are the square roots. Thus, an approximate level $100(1-\alpha) \%$ confidence interval for the on the road $\beta$, according to large sample statistics [16], is given by

$$
[\underline{\beta}, \bar{\beta}]=\hat{\beta} \pm z_{\frac{\varepsilon}{2}} \hat{\sigma} / \sqrt{\sum_{i} \frac{1}{r_{i}}} \text {, }
$$

where $\hat{\beta}$ is defined in eq. (9) and $z_{\gamma}$ is derived from the equation

$$
\Phi\left(\mathrm{z}_{\gamma}\right)=1-\gamma
$$

with $\Phi$ denoting the standard normal cumulative distribution function. Similarly, an approximate level $100(1-\alpha) \%$ upper confidence bound for $\beta$ is

$$
\tilde{\beta}=\hat{\beta}+z_{\alpha} \hat{\sigma} / \sqrt{\sum_{i} \frac{1}{r_{1}}} \text {. }
$$

Since $\delta=1-\mathrm{e}^{-\beta} \approx \beta$ for small $\delta$, the point estimate eq. (9), confidence interval eq. (22), and upper bound eq. (24) apply approximately to the CaRFG mileage reduction factor $\delta$. However, for best precision the following point estimate, confidence interval, and upper bound are recommended:

and

$$
\begin{aligned}
& \hat{\delta}=1-\mathrm{e}^{-\hat{\beta}}, \\
& {[\underline{\delta}, \bar{\delta}]=\left[1-\mathrm{e}^{-\underline{\beta}}, 1-\mathrm{e}^{-\bar{\beta}}\right],}
\end{aligned}
$$

$$
\tilde{\delta}=1-e^{-\bar{\beta}}
$$

The corresponding results for the dynamometer situation are obtained in obvious fashion: eqs. (25), (26), and (27) are valid based on the point estimates eqs. (18) and (19) along with the definition eq. (16).

The reduction in fuel economy (mpg) due to CaRFG is expected to be consistent with the reduction in energy content (BTU/gal). Let $\delta_{0}$ denote the proportionate reduction in energy content; it is desired to test whether the mileage reduction factor $\delta$ is no more than $\delta_{0}$. Formally, we wish to test the hypothesis

$\mathrm{H}_{0}: \delta \leq \delta_{0} \quad$ (the CaRFG mileage reduction is no more than expected from the

against the alternative energy content reduction)

$\mathrm{H}_{1}: \delta>\delta_{0} \quad$ (the CaRFG mileage reduction is more than expected from the energy content reduction)

An appropriate test procedure may be made based on the above normal asymptotics. The $\mathrm{P}$-value, or significance, of the observed data is the probability that the maximum likelihood mileage reduction estimate, $\hat{\delta}$, would exceed the observed measured value, if the actual reduction factor were $\delta_{0}$. This quantity is most conveniently calculated in terms of $\hat{\beta}$ and $\beta_{0}=-\log \left(1-\delta_{0}\right)$ as

$$
P=1-\Phi\left(\frac{\hat{\beta}-\beta_{0}}{\text { S.E. }(\hat{\beta})}\right)
$$

where S.E. $(\beta)$ is the square root of the estimated variance, eq. (20) or (21). The P-value gives the probability of a measured mileage reduction at least as high as observed, if the true CaRFG mileage reduction is no more than expected from the energy content reduction. In essence $P$ measures the plausibility of the observed data in the context of the hypothesis $\mathrm{H}_{0}$ being true. Formally, $\mathrm{H}_{0}$ is accepted at level of significance $\alpha$ if $\mathrm{P} \geq \alpha$. 


\section{The Nonparametric Model.}

The validity of the normal model in analyzing mileage (or gallonage) data depends on the ability to treat, in log space, miles driven (or gallons consumed) as the sum of a large number of relatively small and uniform contributions. Limited by the existing experimental data we find it necessary in addition to assume the mileage reduction effect is the same for all vehicles and the relative variation in mileage (or gallonage) is the same for all vehicles. Although (as will be demonstrated later) examination of residuals reveals the Auto Oil dynamometer test data to conform to all the normal model assumptions, such is not the case for the CARB on the road test data. This may be the result of certain vehicles having different duties and therefore different driving profiles from one year to the next. We introduce here an alternative, nonparametric formulation which does not assume normality or constant relative variation. on the model

A nonparametric approach which does not make assumptions of normality is based

$$
\mathrm{Z}_{\mathrm{i}}=\beta+\mathrm{e}_{\mathrm{i}} \text {, }
$$

where as before $Z=\log X-\log Y$, and $\beta=-\log (1-\delta)$, but the $e_{i}$ are independent with distributions continuous and symmetric about 0 , and not necessarily the same. In effect each $Y_{i}$ is distributed as $(1-\delta) X_{i}$, but the distributions may vary from vehicle to vehicle. We are assuming as before that the mileage reduction effect is the same for each vehicle, i.e., $\delta_{i} \equiv \delta$, but we are no longer assuming a common relative variation in mileage, i.e., that $\sigma_{i} \equiv \sigma$.

The maximum likelihood inferences presented earlier for the normal model have well-founded nonparametric counterparts. [17] The Hodges-Lehmann point estimator of $\beta$ is the sample median, $\beta_{h}$, of the collection of all $B=Q(Q+1) / 2$ averages of Z-pairs. That is, denote the ordered values of $\left\{\left(Z_{i}+Z_{j}\right) /, i \leq j\right\}$ as $U^{(n)} \leq \cdots \leq U^{(B)}$. Then, if $B$ is odd, say $B=2 b+1$, we have

and if $B$ is even, say $B=2 b$, we have

$$
\hat{\beta}_{h}=U^{(b+1)} \text {, }
$$

$$
\hat{\beta}_{h}=\left[U^{(b)}+U^{(b+1)}\right] / 2 \text {. }
$$

The associated nonparametric estimate, $\hat{\delta}_{\mathrm{h}}$, of $\delta$ is given by

$$
\hat{\delta}_{\mathrm{h}}=1-\mathrm{e}^{-\hat{\boldsymbol{\beta}}_{\mathrm{t}}} \text {. }
$$

Tukey confidence intervals and upper confidence bounds based on inverting the Wilcoxon signed rank test are functions of the U's. In particular, a level $100(1-\alpha) \%$ confidence interval for $\beta$ is given by

$$
\left[\underline{\beta}_{h}, \bar{\beta}_{h}\right]=\left[U^{\left(C_{s}\right)}, U^{\left(B+1-C_{e}\right)}\right] \text {, }
$$

and a level $100(1-\alpha) \%$ upper confidence bound for $\beta$ is given by

$$
\tilde{\beta}_{h}=U^{\left(B+1-C_{2 a}\right)} \text {, }
$$

where the integers $C_{\alpha}$ and $C_{\alpha 2}$ may be extracted from tables in [17] for $Q \leq 15$. For larger $\mathrm{Q}$ (as in the CARB on the road applications), a large sample approximation is adequate:

$$
\mathrm{C}_{\alpha} \approx \mathrm{Q}(\mathrm{Q}+1) / 4-\mathrm{z}_{\alpha / 2}[\mathrm{Q}(\mathrm{Q}+1)(2 \mathrm{Q}+1) / 24]^{1 / 2}
$$

The corresponding confidence limits for $\delta$ are obtained from eqs. (33) and (34) by applying the transformation

$$
\delta=1-e^{-\beta} .
$$


The nonparametric analog of the test whether the mileage reduction factor $\delta$ is no more than the value $\delta_{0}$ consistent with the energy content reduction is the Wilcoxon signed rank test. [17] This procedure investigates the ranks of the absolute differences $\left|Z_{i}-\beta_{0}\right|$, where $\beta_{0}=-$ $\log \left(1-\delta_{0}\right)$. Let $R_{i}$ denote the rank of $\left|Z_{i}-\beta_{0}\right|$ in the joint ranking from least to greatest of $\left\{\left|Z_{1}-\beta_{0}\right|, 1 \leq \mathrm{i} \leq \mathrm{Q}\right\}$. Let $\mathrm{H}^{+}$denote the sum of those ranks for which $Z_{i}-\beta_{0} \geq 0$, i.e., there is evidence that the mileage reduction is excessive. The hypothesis $\mathrm{H}_{0}$ is accepted if $\mathrm{H}^{+}$is sufficiently small. Implementation of the Wilcoxon signed rank test and the associated calculation of P-values may be carried by using existing statistical software [19] or by using tables in [17] if $Q \leq 15$.

The control group of vehicles in the on the road CARB study is obviated nonparametrically by testing the hypothesis $\mathrm{H}_{0}: \beta=0$ against $\mathrm{H}_{1}: \beta \neq 0$. See Appendix 1 .

All nonparametric inferences developed above in terms of mileage and $Z$ [eq. (4)] have obvious analogs in terms of gallonage and $Z^{*}$ [eq. (14)]. Thus, nonparametric point estimates and confidence limits for the dynamometer testing are obtained by substituting $Z^{*}$ for $Z$ in eqs. (30) through (34).

Statistical Analysis of Existing Data Sets

Table 1 provides an overview of the 13 data sets available for study of the effect of CaRFG on fuel economy. Of these, ten involve on the road tests and three involve dynamometer tests. Only two of the on the road data sets, Sacramento City and Sacramento County, provide data suitable for statistical analysis. The reasons for rejection of the road

TABLE XII. Overview of Data Sets

\begin{tabular}{|l|c|c|c|l|}
\hline \multicolumn{1}{|c|}{ DATA SET } & TESTING & DEPTH & VEHICLES & \multicolumn{1}{|c|}{ COMMENTS } \\
\hline Sacramento City & $\mathrm{R}$ & 2 & 122 & culled data 187->122 \\
\hline Sacramento County & $\mathrm{R}$ & 2 & 110 & culled data 414-->110 \\
\hline Auto Oil AQIRP & $\mathrm{D}$ & 2 & 32 & most representative data set \\
\hline CARB & $\mathrm{D}$ & 2 & 4 & city and highway results \\
\hline Oklahoma DOE & $\mathrm{D}$ & 2 & 5 & most recent study \\
\hline Wisconsin & $\mathrm{R}$ & 0 & 8 & vehicles combined; fed ffg \\
\hline Battelle & $\mathrm{R}$ & 0 & 30 & dedicated vehicles \\
\hline CSU Fresno & $\mathrm{R}$ & 1 & 112 & mostly poor quality data \\
\hline Bank of America & $\mathrm{R}$ & 0 & 30 & poor quality data \\
\hline GTE & $\mathrm{R}$ & 0 & 411 & auxiliary equipment used \\
\hline Pacific Bell, North & $\mathrm{R}$ & 0 & 194 & auxiliary equipment used \\
\hline Pacific Bell, South & $\mathrm{R}$ & 0 & 93 & auxiliary equipment used \\
\hline Caltrans & $\mathrm{R}$ & 0 & 25 & irrelevant data \\
\hline
\end{tabular}


Testing $\quad \mathrm{R}=$ on the road testing, $\mathrm{D}=$ dynamometer testing

Depth of Statistical Analysis 2 = point \& confidence estimates, 1 = point estimate only, $0=$ no estimates

Vehicles number of vehicles in the study

data sets have been published by the ARB $[10,18]$ and are summarized below.

CSU Fresno. Only 14 of 112 vehicles in the study had mileage data for both conventional fuel and CaRFG; of these only one vehicle had at least 1000 miles driven with each fuel. The normal model point estimate for the 14 vehicles is $\hat{\delta}=0.027$ [refer to eq. (25)]; the nonparametric point estimate is $\hat{\delta}_{\mathrm{h}}=0.016$ [refer to eq. (32)]. The vehicles are not typical, as mileages as low as $3 \mathrm{mpg}$ were reconded.

Bank of America. Test vehicles were at times fueled with commercially available gasoline, thus invalidating the comparison.

GTE, Pacific Bell North, and Pacific Bell South. Vehicles often performed maintenance and repair work on telephone systems, during which auxiliary equipment such as generators were powered by fuel from the gas tank.

Caltrans. This 25 vehicle fleet consisted of heavy-duty highway work vehicles operating under unusual conditions. The mileage data were therefore not relevant.

Wisconsin Department of Natural Resources. Federal reformulated gasoline rather than CaRFG was used in this study. Individual vehicle mileage calculations are unavailable. The average reduction in fuel economy between conventional and federal reformulated gasoline was reported to be 0.028. [10]

Battelle. In this study Federal Express delivery vans were dedicated to either conventional fuel or CaRFG. Thus, the change in fuel economy due to CaRFG for any given van could not be measured.

The Sacramento City data set consists of mileage records for a fleet of 187 Sacramento city police vehicles. Most of the vehicles were Ford Crown Victorias. There were 81 control vehicles and 106 test vehicles. The time periods studied were March to August in both 1994 and 1995. The control vehicles used conventional fuel throughout, and the test vehicles used only conventional fuel in 1994 and only CaRFG in 1995. The raw data identifying each vehicle and recording its fill-up history (gallons dispensed and odometer readings) are available on the ARB website. [20] The fill-up histories were beset with considerable inconsistencies, omissions, and inaccuracies. For purposes of statistical analysis obviously erroneous portions of mileage data were deleted by CARB for a given vehicle whenever anomalies such as negative or absurd mileages occurred. [21] Furthermore, 51 vehicles (i.e., 15 control and 36 test vehicles) were removed from consideration because the 1995 mileage differed so enormously (by $40 \%$ or more) from the 1994 mileage that the difference could not plausibly be attributed to random variation or a change in fuel formulation. A reason for such dramatic change could be a change in the type of duty for the vehicle. [21] Our analysis further reduced the collection of treatable vehicles to 122 ( 61 control and 61 test vehicles) by eliminating those whose distance driven in either year was less than 1000 miles. It was felt that a vehicle needs to have at least 1000 on the road miles for the many variables in driving conditions to average out to allow a viable comparison.

An identical protocol of culling was applied to the Sacramento County data set, which consists of mileage records for a fleet of 414 vehicles (241 control and 173 test vehicles) operated by county employees. These were mostly passenger cars, vans, and light duty trucks. The same time periods as the Sacramento City's were studied. The raw mileage data are available on the ARB website. [20] Our culled collection of treatable vehicles, restricted to vehicles with at least 1000 miles driven in each year and having a change in gas mileage from 1994 to 1995 of no more than $40 \%$, consists of 50 control and 60 test vehicles. 
The results of applying the statistical estimation methods of the previous section to the Sacramento City and Sacramento County data sets are presented in Table XIII. The normal model point estimates of the CaRFG mileage reduction factor, $\delta$, are obtained from eqs. (9) and (25); the normal confidence intervals are obtained from eqs. (9), (10), (22), and (26); and the normal upper confidence bounds are obtained from eqs. (9), (10), (24), and (27). The nonparametric results are based on the $\log$ differences, $Z$, of eq. (4). The nonparametric point estimates are obtained from eqs. (30), (31) and (32); the nonparametric confidence intervals are obtained from eqs. (33) and (36); and the nonparametric upper confidence bounds are obtained from eqs. (34) and (36). All calculations were performed with Microsoft Excel spreadsheets, which are displayed in Appendix 2.

TABLE XIII. Estimates of CaRFG Mileage Reduction Factor, $\delta$

Normal Model

\begin{tabular}{|l|c|c|c|}
\hline DATA SET & $\delta$ & $\begin{array}{c}90 \% \text { CONFIDENCE } \\
\text { INTERVAL }\end{array}$ & $\begin{array}{c}\text { 95\% UPPER } \\
\text { CONF. BOUND }\end{array}$ \\
\hline Sacramento City & .021 & $(.009, .033)$ & .033 \\
\hline Sacramento County & .037 & $(.012, .062)$ & .062 \\
\hline Auto Oil & .029 & $(.023, .034)$ & .034 \\
\hline CARB city driving & .041 & $(.026, .055)$ & .055 \\
\hline CARB hwy driving & .033 & $(.017, .049)$ & .049 \\
\hline Oklahoma DOE & .047 & $(.040, .054)$ & .054 \\
\hline
\end{tabular}

Nonparametric Model

\begin{tabular}{|l|c|c|c|}
\hline Data Set & $\delta_{h}$ & $\begin{array}{c}90 \% \text { CONFIDENCE } \\
\text { INTERVAL }\end{array}$ & $\begin{array}{c}\text { 95\% UPPER } \\
\text { CONF. BOUND }\end{array}$ \\
\hline Sacramento City & .023 & $(.010, .036)$ & .036 \\
\hline Sacramento County & .028 & $(.004, .057)$ & .057 \\
\hline Auto Oil & .031 & $(.026, .036)$ & .036 \\
\hline CARB city driving & .043 & $(.015, .061)$ & .061 \\
\hline CARB hwy driving & .044 & $(.003, .050)$ & .050 \\
\hline Oklahoma DOE & .048 & $(.038, .059)$ & .059 \\
\hline
\end{tabular}

The dynamometer data sets are the most helpful in assessing the effect of CaRFG on fuel economy in that the large number of unavoidable extraneous factors that are nuisances in on the road testing because they cannot be replicated from one time period to the next, such as speed, traffic, weather, terrain, route, and fill-up precision, are eliminated. The only systematic difference in dynamometer testing between the mileage measured for a particular vehicle with conventional fuel and its mileage measured with CaRFG is the fuel formulation. Random variation is controlled through the use of professional drivers performing rigidly defined EPA driving protocols of changes in speed; measurements of fuel consumed and miles traveled are extremely accurate and unbiased.

The results of applying the statistical estimation methods of the previous section to the dynamometer data sets are presented in Table XIII. The normal model point estimates of $\delta$ are obtained from eqs. (18) and (25); the normal confidence intervals are obtained from eqs. (18), (19), (22), and (26); and the normal upper confidence bounds are obtained 
from eqs. (18), (19), (24), and (27). The nonparametric results are based on the $\log$ differences, $Z^{*}$, of eq. (14). The nonparametric point estimates are obtained from eqs. (30), (31) and (32); the nonparametric confidence intervals are obtained from eqs. (33) and (36); and the nonparametric upper confidence bounds are obtained from eqs. (34) and (36). All calculations were performed with Microsoft Excel spreadsheets, which are displayed in Appendix 2.

The energy content (BTU/gal) was measured for all the tests. For the on the road tests, which required substantial quantities of fuel over a long period of time, average energy content values were calculated for conventional fuel use. This was not necessary for CaRFG, since a single batch of CaRFG was used. The hypothesis that the mileage reduction due to CaRFG was consistent with the associated energy content reduction was tested for the two Sacramento on the road data sets and the three dynamometer data sets. These results are presented in Table XIV. P-values, which measure the plausibility of the hypothesis of consistency, are given for both the normal and the nonparametric model methods. P-values for the normal model were calculated from eq. (28). Nonparametric model P-values were calculated with Stata software. [19]

TABLE XIV. Assessing Consistency of CaRFG Mileage Reduction
and Energy Content Reduction

Normal Model

\begin{tabular}{|l|c|c|c|}
\hline Data Set & $\Delta_{\mathrm{EC}}$ & $\hat{\delta}$ & P-VALUE \\
\hline Sacramento City & .045 & .021 & 1. \\
\hline Sacramento County & .043 & .037 & .63 \\
\hline Auto Oil & .030 & .029 & .67 \\
\hline CARB city driving & .045 & .041 & .66 \\
\hline CARB hwy driving & .045 & .033 & .87 \\
\hline Oklahoma DOE & .055 & .047 & .97 \\
\hline
\end{tabular}

Nonparametric Model

\begin{tabular}{|l|c|c|c|}
\hline Data Set & $\Delta_{\mathrm{EC}}$ & $\hat{\delta}_{\mathrm{h}}$ & P-VALUE \\
\hline Sacramento City & .045 & .023 & .999 \\
\hline Sacramento County & .043 & .028 & .50 \\
\hline Auto Oil & .030 & .031 & .40 \\
\hline CARB city driving & .045 & .043 & .50 \\
\hline CARB hwy driving & .045 & .044 & .50 \\
\hline Oklahoma DOE & .055 & .048 & .89 \\
\hline
\end{tabular}

$\Delta_{\mathrm{EC}}$ denotes the energy content reduction

Discussion. All the statistical inferences presented in Tables XIII and XIV are based on models developed in the previous section and must be interpreted in the context of the underlying assumptions made. The normal model is based on the assumptions of a common intrinsic mileage reduction factor, $\delta$, for all vehicles, a common measure of 
relative mileage variability, $\sigma$, for all vehicles, and approximate normality of the difference in $\log$ mileage, $\mathrm{Z}$ or $\mathrm{Z}^{*}$. The nonparametric model is based on the assumptions of a common intrinsic mileage reduction factor, $\delta$, for all vehicles, and continuous, symmetric probability distributions, not necessarily the same for each vehicle, for the difference in $\log$ mileage, $\mathrm{Z}$ or $\mathrm{Z}^{*}$. Both models have strong theoretical foundations; however, the pervasive assumption that the intrinsic mileage factor does not vary from vehicle to vehicle, an assumption crucial to the development of confidence intervals and bounds, is an assumption that cannot be tested from the available data, because of a lack of replications of mileage measurements for each vehicle studied. Thus, whatever variations in the $\delta_{i}$ that may exist from vehicle to vehicle are in effect absorbed into $\sigma$ in the normal model and into the arbitrary distributions of $Z$ or $Z^{*}$ in the nonparametric model. The point estimates $\delta$ and $\partial_{h}$ are then estimates, or best guesses, of the common $\delta$ if indeed the assumption of a single $\delta$ is correct, and are estimates of the mean of the distribution of the $\delta$ 's if the assumption of a common $\delta$ is incorrect. If the common $\delta$ assumption is incorrect, the quality of $\delta$ or $\delta_{h}$ as an estimate of the mean of the distribution of the $\delta$ 's depends on how representative of the California population of vehicles is the sample of tested vehicles. If the common $\delta$ assumption is correct, the representativeness of the tested vehicles is not an issue.

Confidence intervals and confidence bounds put limits on the uncertainty of point estimates. Such uncertainty is unavoidable due to statistical variation in the data. The confidence level, e.g., $95 \%$, reflects the degree of confidence in the statistical method used to generate the interval or bound. For example, the $95 \%$ upper confidence bound, $\tilde{\delta}=$ 0.057 , for $\delta$ based on the nonparametric model analysis and the Sacramento County data set has the interpretation that, under the nonparametric model assumptions (common $\delta$ and continuous, symmetric $Z$ ), we have $95 \%$ confidence that the true value of $\delta$ is no greater than 0.057 . To say our level of confidence is $95 \%$ means that if (1) the nonparametric model assumptions are satisfied, and (2) we could apply this nonparametric model method to many similar data sets and compute a $\tilde{\delta}_{h}$ each time, then $95 \%$ of these $\tilde{\delta}_{h}$ 's would be an upper bound for $\delta$, i.e., greater than $\delta$. The caveat here is that if the nonparametric model assumptions are not valid, then the nominal confidence coefficient, $95 \%$, may not be achieved. Moreover, if the common $\delta$ assumption is not correct, then the confidence bound ought to be interpreted as bounding the mean of the distribution of $\delta$ 's; but again, the achieved confidence level need not be the nominal level.

It is apparent from Table XIII that remarkably consistent results have been obtained, whether the normal model or the nonparametric model is used, and regardless of the data set analyzed: point estimates are in the 2 to $4 \%$ range, $90 \%$ confidence intervals in the 0 to $6 \%$ vicinity, and $95 \%$ upper confidence bounds around $6 \%$ or less. Furthermore, as Table XIV attests, the estimated reductions in mileage are quite consistent with the associated reductions in energy content. The somewhat high point estimates for the Oklahoma study are to be expected, because of the similarly high energy content reduction due to the use of a 1988 conventional fuel formulation with relatively high $(117,900$ BTU/gal) energy content

The P-values in Table XIV quantify the plausibility of the hypothesis that the mileage reduction is consistent with the energy content reduction. For example, $P=0.999$ for the nonparametric model and the Sacramento City data set has the following interpretation: if the nonparametric model assumptions are satisfied, and if the true mileage reduction factor is no greater than the energy content reduction, then the probability that the nonparametric point estimator $\tilde{\delta}_{\mathrm{h}}$ would exceed the value calculated from the data set 
(namely 0.023 ) is 0.999 . Hence it is quite plausible (there is a $99.9 \%$ chance) of observing data like we saw, if the hypothesis of consistency is correct. Typically, a P-value greater than 0.10 is considered sufficient evidence to support the null hypothesis. All the Table XIV P-values comfortably exceed 0.10 .

From Tables XIII and XIV it is clear that the statistical method used to analyze the data has little bearing on the results. So it is mostly of academic interest to post-check for reasonableness of the normal model. For a given data set, consider the normal model residuals,

for on the road tests (based on mileage) or

$$
D_{i}=Z_{i}-\hat{\beta} \text {, }
$$

$$
D_{i}=Z_{i}^{*}-\hat{\beta} \text {, }
$$

for dynamometer tests (based on gallonage). The standard error of $D_{i}$ is

$$
\text { S.E. }\left(D_{i}\right)=\hat{\sigma} \sqrt{r_{i}-a} \text {, }
$$

for on the road tests, and

for dynamometer tests, where

$$
\operatorname{S.E} .\left(D_{i}\right)=\hat{\sigma}^{*} \sqrt{r_{i}^{*}-a^{*}}
$$

$$
\mathrm{a}=\sum_{\mathrm{i}} \frac{1}{\mathrm{r}_{\mathrm{i}}}
$$

and

$$
a^{*}=\sum_{i} \frac{1}{r_{i}^{*}}
$$

The studentized residuals $D_{i} /$ S.E. $\left(D_{i}\right)$, if the normal model is applicable, should be approximately standard normally distributed. The Shapiro-Wilk test of normality has been invoked for the data sets with a large enough number of vehicles to give meaningful results, namely the Sacramento City, Sacramento County, and the Auto Oil data sets. The computed P-values, obtained from Stata software [19], are $\mathbf{P}=0.01,0.02$, and 0.001 , respectively. That is, there is scant support for the normal model. However, it is interesting to note that the auto oil data set of 32 vehicles contains two vehicles whose mileage actually improved with CaRFG. If these two vehicles are removed as outliers, the P-value for analysis of the remaining 30 vehicles is $P=0.40$. Thus there is strong support for the normal model restricted to those vehicles showing mileage reduction in the dynamometer testing.

The Auto Oil dynamometer data set is probably the best available in terms of providing reliable mileage data that are relevant to the California vehicle population. If the modeling assumption of a common $\delta$ is abandoned, it is instructive to fit a distribution to the collection of Auto Oil individual vehicle mileage reduction estimates. This fit will not necessarily represent the actual distribution of California vehicle $\delta$ 's because the selection of Auto Oil vehicles most definitely was not a random sample from the Califomia population, although the selection was diverse in that it captured a range of automobile types and ages. Moreover, if in truth the distribution is degenerate, i.e., $\delta$ is the same for all vehicles, the fit is unnecessary and misleading. Thus, as an illustrative exercise of what might be done if a random sample of vehicles were available, we fit a distribution to the Auto Oil individual vehicle mileage reduction estimates, $1-\exp \left(-Z_{\mathrm{i}}^{*}\right)$. For simplicity we remove the two outlier vehicles with improved mileage with CaRFG and fit a normal distribution to the remaining 30 individual estimates. The normal fit is good (the ShapiroWilk P-value is 0.37 ), with an estimated mean of $\mu_{\mathrm{f}}=0.0326$ and an estimated standard deviation of $\sigma_{\mathrm{f}}=0.0132$. Important features of the vehicle population are then easily calculated. For example, the percentage of vehicles with $\delta$ greater than p, e.g., $p=0.05$, would be estimated by $100\left\{1-\Phi\left(\left[p-\mu_{f}\right] / \sigma_{f}\right)\right\} \%$, and the percentage with $\delta$ approximately equal to $p$ by $100\left\{\Phi\left(\left[p+0.005-\mu_{f}\right] / \sigma_{f}\right)-\Phi\left(\left[p-0.005-\mu_{f}\right] / \sigma_{f}\right)\right\} \%$. We emphasize that these formulas are only illustrative of a method; the existing data are insufficient to justify 
that a fit is appropriate or that the given fit is representative.

\section{Resolution of Results with Individual Mileage Records}

Tables XIII and XIV show the effect of CaRFG on mileage to be in the 2 to $4 \%$ range and consistent with the energy content reduction. Yet there has been a perception among the media and the public that the mileage reduction is much greater, say in the 10 to $15 \%$ range, or more. An explanation for this misperception is that individual motorists will experience large fluctuations in their mileage from fill-up to fill-up, including dramatic reductions, even if there is no change in fuel formulation; a large reduction may be interpreted as the result of CaRFG, when in fact it is the inevitable consequence of random variation. The random variation in mileage from fill-up to fill-up, or one time period to the next, is due to a number of uncontrolled factors, such as terrain, route, speed, traffic, weather, number of passengers, energy content of the fuel, and fill-up precision. The mileage reduction effect of CaRFG is masked by these bigger players and is nearly impossible to detect in an individual vehicle's mileage history. Only through dynamometer testing, where extraneous factors are controlled, or on the road testing with a large number of vehicles, where extraneous factors essentially cancel out, can the CaRFG mileage reduction effect be reliably estimated.

In this section we will model the mileage history for an individual vehicle and illustrate the tendency for large fluctuations in recorded mileage. Figures 1 through 4 show the meticulously recorded mileage histories of four vehicles. On the horizontal axis are the fill-up numbers indexed sequentially in time, and on the vertical axis are the corresponding recorded mileages in mpg. It is apparent from each figure that mileage varies considerably over time, with swings of $20 \%$ or more occurring occasionally from one fill-up to the next. Figure 1 depicts the mileage record of a 1993 Honda Prelude and Figure 2 portrays that of a 1970 Cadillac on its second engine. These vehicles are privately owned and driven by individuals who work at the California Energy Commission. The 1990 Ford 15 passenger van of Figure 3 is used exclusively as a commute vehicle in a Lawrence Livermore National Laboratory van pool. It is driven each work day, nearly always by the same driver, over the same route, a 50 mile round trip between Danville and Livermore. Yet its mileage time history still exhibits considerable variability. The most extreme degree of variation we have encountered is shown in Figure 4, which chronicles the mileage history of a Sacramento police car (from the Sacramento City data base). The mileages in this figure are averaged over ten consecutive fill-ups, yet still show remarkable variation.

We model the recorded mileage over time for a particular vehicle by the normal model method detailed earlier. Let $\mathrm{X}$ denote the recorded mileage for a fill-up of $\mathrm{N}$ gallons, and define

$$
\mathrm{H}=\log \mathrm{X} \text {. }
$$

From eqs. (1) and (2) and large sample statistical theory, it follows that $\mathrm{H}$ is distributed approximately as $\mathcal{X}(\log \mu, \sigma / \sqrt{\mathrm{N}})$, where $\mu$ is the intrinsic mean mpg for the vehicle and $\sigma$ is a parameter that characterizes the relative variation in recorded mileage from gallon to gallon. [16] The parameters $\mu$ and $\sigma$ have unknown values which must be estimated by a sample, namely $\mathrm{H}_{1}, \ldots, \mathrm{H}_{\mathrm{k}}$, which is the sequential time history of recorded mileages over $k$ fill-ups. Let $N_{i}$ denote the number of gallons in fill-up $i$, and define

$$
\theta=\log \mu \text {. }
$$

The likelihood function of the sample $h_{1}, \ldots, h_{k}$, assuming independence, is

which is maximized by

$$
L=\prod_{i=1}^{k} \frac{\sqrt{N_{i}}}{\sigma \sqrt{2 \pi}} \exp \left\{-\frac{N_{i}}{2 \sigma^{2}}\left(h_{i}-\theta\right)^{2}\right\}
$$


and

$$
\hat{\theta}=\sum_{i=1}^{k} \frac{N_{i}}{N} h_{i}
$$

$$
\hat{\sigma}^{2}=\frac{1}{k} \sum_{i=1}^{k} N_{i}\left(h_{i}-\hat{\theta}\right)^{2}
$$

where

$$
\mathrm{N} .=\sum_{\mathrm{i}=1}^{\mathbf{k}} \mathrm{N}_{\mathrm{i}} \text {. }
$$

We wish to compare the measured mileage for a particular vehicle in two consecutive time periods. Let $\mathrm{X}$ denote the mileage based on $\mathbf{N}$ gallons consumed in time period 1, and let $\mathrm{Y}$ denote the mileage based on $\mathrm{N}$ gallons consumed in time period 2. The assumption of the same number of gallons for both periods is made for convenience in graphical display and tabulation. If $N$ is small, say $N=20$, the time periods would correspond to consecutive fill-ups. For larger $N$, the time periods would involve averages over a number of fill-ups: e.g., $N=50$ would involve about 3 fill-ups, and $N=500$ nearly a year's worth of fill-ups. We wish to compare consecutive recorded mileages for two situations, one in which there is no change in fuel formulation from period 1 to period 2 , and the other in which there is an intrinsic reduction of magnitude $\delta$ from time period 1 to time period 2 , i.e., the mean mpg shifts from $\mu$ to $\mu(1-\delta)$ from period 1 to period 2 . Thus, $\delta=0.03$ would be a reduction that we believe is expected if a batch of conventional fuel is used in time period 1 and a batch of CaRFG is used in time period 2 , and $\delta=0.10$, say, would be a reduction of the magnitude suspected by some, which would be appropriate if CaRFG were in fact reducing mileage significantly for the vehicle, or if a systematic change in driving patterns or vehicle operating efficiency occurred between the two time periods. If the normal distribution model is valid, then the probability that the recorded mileage drops by a large amount, say at least $20 \%$, from time period 1 to time period 2 is estimated by

$$
\mathrm{P}\{\mathrm{Y} \leq 0.80\} \approx \Phi\left(\sqrt{\frac{N}{2}} \frac{\log (0.80)-\log (1-\delta)}{\hat{\sigma}}\right),
$$

since a $20 \%$ reduction means that $(X-Y) / X$ is at least 0.20 , and since $\log X$ being approximately $\mathcal{X}(\log \mu, \sigma / \sqrt{N})$ and $\log Y$ being approximately $\mathcal{N}(\log \mu(1-\delta), \sigma / \sqrt{N})$ implies that $\log \mathrm{Y} / \mathrm{X}$ is approximately $\mathcal{X}(\log (1-\delta), \sigma \sqrt{2} / \sqrt{N})$. If there is no change in fuel formulation, then $\delta=0$ and the $\log (1-\delta)$ term vanishes. More generally, the probability, $\mathrm{G}(\Delta, \delta, \sigma, N)$, of a drop in recorded mileage of at least $\Delta$ percent is estimated by

$$
\delta, \sigma, N)=P\left\{\frac{Y}{X} \leq 1-\frac{\Delta}{100}\right\} \approx \Phi\left(\sqrt{\frac{N}{2}} \frac{\log \left(1-\frac{\Delta}{100}\right)-\log (1-\delta)}{\hat{\sigma}}\right) .
$$

Estimation of $\hat{\sigma}$ from available vehicle time histories shows $\hat{\sigma}$ to range from about 0.15 for low variation driving pattems, like a van pool, to 0.85 for high variation driving patterns, like a police car. Calculations of $\hat{\sigma}$ have been made from 24 vehicle time histories extracted from the Sacramento County data set and for the vehicles of the four figures. As an illustration, the calculation of $\hat{\sigma}=0.272$ is presented in Appendix 2 for the Cadillac of Figure 2. In addition, Shapiro-Wilk tests of normality of the sequential log mileage records, $H_{1}, \ldots, H_{k}$, have been performed with Stata software [19] for the above 28 vehicles. The results along with the associated $\hat{\sigma}$ estimates are presented in Table XV. P-values of at least 0.10 show support for the normality assumption. The normality assumption appears adequate for the carefully recorded Honda Prelude, Cadillac, van pool, and police car time histories as well as for many of the Sacramento County histories. Recording inaccuracies and systematic changes in driving patterns may explain the lack of 
normality for certain vehicles.

Various probabilities $G(\Delta, \delta, \sigma, N)$, calculated from eq. (50), are plotted and tabulated as percentages in Figures 5 and 6 and Tables XVI and XVII. The number of gallons, $\mathrm{N}$, in each time period (the batch size) ranges from 10 to 100 in the figures and 10 to 500 in the tables. The percentage reduction, $\Delta$, in mpg experienced from batch 1 to batch 2 is taken to be $20 \%$ in the figures and ranges from $10 \%$ to $40 \%$ in the tables. The intrinsic mileage reduction factor, $\delta$, from batch 1 to batch 2 is allowed to be 0 (no reduction), 0.03 (the estimated CaRFG effect), 0.06 (the upper bound CaRFG effect), and 0.10 (a large effect). The relative variation in recorded mileage from gallon to gallon as estimated by $\hat{\sigma}$ is given two representative values, $\hat{\sigma}=0.20$, for a low variation driving pattern and $\hat{\sigma}=0.60$ for a high variation driving pattern. One inescapable conclusion from the figures

TABLE XV. Estimated $\sigma$ and Shapiro-Wilk Test of Normality P-Values

\begin{tabular}{|r|c|c|c|}
\hline Vehicle ID & $\mathbf{N}$ & $\hat{\sigma}$ & P-VALUE \\
\hline 102905 & 31 & 0.158 & 0.90812 \\
\hline 107013 & 26 & 0.155 & 0.15523 \\
\hline 107015 & 34 & 0.193 & 0.0119 \\
\hline 107101 & 47 & 0.272 & 0.00864 \\
\hline 107103 & 29 & 0.236 & 0.00029 \\
\hline $107116 \mathrm{a}$ & 106 & 0.260 & 0.09576 \\
\hline $107116 \mathrm{~b}$ & 40 & 0.187 & 0.19292 \\
\hline 107117 & 32 & 0.202 & 0.07420 \\
\hline 107121 & 57 & 0.304 & 0.02585 \\
\hline 107608 & 55 & 0.613 & 0.18589 \\
\hline 107805 & 26 & 0.253 & 0.01555 \\
\hline 110002 & 23 & 0.195 & 0.73702 \\
\hline $110006 \mathrm{a}$ & 46 & 0.148 & 0.00007 \\
\hline $110006 \mathrm{~b}$ & 40 & 0.190 & 0.26711 \\
\hline 110012 & 41 & 0.329 & 0.00006 \\
\hline 110206 & 29 & 0.399 & 0.06678 \\
\hline 110904 & 42 & 0.327 & 0.00000 \\
\hline 110922 & 52 & 0.158 & 0.40119 \\
\hline 132008 & 182 & 0.467 & 0.41135 \\
\hline $132102 \mathrm{a}$ & 37 & 0.265 & 0.16997 \\
\hline $132102 \mathrm{~b}$ & 22 & 0.281 & 0.04623 \\
\hline $134005 \mathrm{a}$ & 84 & 0.498 & 0.00444 \\
\hline $134005 \mathrm{~b}$ & 96 & 0.646 & 0.00321 \\
\hline 134305 & 56 & 0.385 & 0.03984 \\
\hline Prelude & 53 & 0.349 & 0.38464 \\
\hline Cadillac & 97 & 0.272 & 0.17906 \\
\hline Van Pool & 98 & 0.256 & 0.10035 \\
\hline Police Car & 36 & 0.842 & 0.37306 \\
\hline & & & \\
\hline
\end{tabular}


and tables is that a dramatic reduction in recorded mileage from one fill-up to the next is quite possible, even if there is no change in the fuel formulation. For example, it is seen from Table XVI and Figure 5 that $\mathrm{G}(20 \%, 0,0.20,20)=5.7 \%$, i.e., there is about a $6 \%$ chance that a reduction in mileage of $20 \%$ or more will be experienced from one 20 gallon fill-up to the next, even if there is no difference in the fuel formulation and one is driving under low variation conditions. (Also note that there is a similar chance of experiencing a $20 \%$ increase in mileage.) If the first fill-up is conventional fuel and the second is CaRFG, and $\delta=0.03$, then the probability of this dramatic reduction is estimated to be $\mathrm{G}(20 \%$, $0.03,0.20,20)=8.7 \%$. Under high variation driving conditions these probabilities are substantially higher: $18.1 \%$ if there is no difference in fuel formulation, and $21.6 \%$ if there is a $3 \%$ intrinsic mileage reduction factor. None of these probabilities is negligible. The

TABLE XVI. Probability Second Batch Gets Delta (\%) Lower Mileage Than First Batch, Based on Number of Gallons in Each Batch, Difference in Intrinsic Fuel Economy from Batch to Batch, and Mileage Variation in Driving

\begin{tabular}{|c|c|c|c|c|c|}
\hline & & \multicolumn{2}{|c|}{ LOW VARIATION } & \multicolumn{2}{|c|}{ HIGH VARIATION } \\
\hline DELTA (\%) & GALLONS & NODIFF & $3 \%$ DIFF & NO DIFF & 3\% DIFF \\
\hline 10 & 20 & $22.8 \%$ & $29.8 \%$ & $33.4 \%$ & $38.0 \%$ \\
\hline 10 & 30 & $18.1 \%$ & $25.8 \%$ & $29.9 \%$ & $35.4 \%$ \\
\hline 10 & 40 & $14.6 \%$ & $22.7 \%$ & $27.1 \%$ & $33.3 \%$ \\
\hline 10 & 50 & $11.9 \%$ & $20.1 \%$ & $24.8 \%$ & $31.4 \%$ \\
\hline 10 & 75 & $7.5 \%$ & $15.3 \%$ & $20.2 \%$ & $27.7 \%$ \\
\hline 10 & 100 & $4.8 \%$ & $11.8 \%$ & $16.8 \%$ & $24.7 \%$ \\
\hline 10 & 500 & $0.0098 \%$ & $0.40 \%$ & $1.6 \%$ & $6.3 \%$ \\
\hline 20 & 20 & $5.7 \%$ & $8.7 \%$ & $18.1 \%$ & $21.6 \%$ \\
\hline 20 & 30 & $2.7 \%$ & $4.8 \%$ & $13.2 \%$ & $16.8 \%$ \\
\hline 20 & 40 & $1.3 \%$ & $2.7 \%$ & $9.9 \%$ & $13.3 \%$ \\
\hline 20 & 50 & $0.63 \%$ & $1.6 \%$ & $7.5 \%$ & $10.7 \%$ \\
\hline 20 & 75 & $0.11 \%$ & $0.42 \%$ & $3.9 \%$ & $6.4 \%$ \\
\hline 20 & 100 & $0.021 \%$ & $0.12 \%$ & $2.1 \%$ & $3.9 \%$ \\
\hline 20 & 500 & $0 \%$ & $0 \%$ & $0.00026 \%$ & $0.0042 \%$ \\
\hline 30 & 20 & $0.58 \%$ & $1.1 \%$ & $7.3 \%$ & $9.1 \%$ \\
\hline 30 & 30 & $0.10 \%$ & $0.24 \%$ & $3.7 \%$ & $5.1 \%$ \\
\hline 30 & 40 & $0.018 \%$ & $0.055 \%$ & $2.0 \%$ & $3.0 \%$ \\
\hline 30 & 50 & $0.0033 \%$ & $0.013 \%$ & $1.1 \%$ & $1.8 \%$ \\
\hline 30 & 75 & $0.00005 \%$ & $0.00040 \%$ & $0.24 \%$ & $0.50 \%$ \\
\hline 30 & 100 & $0 \%$ & $0.00001 \%$ & $0.057 \%$ & $0.15 \%$ \\
\hline 30 & 500 & $0 \%$ & $0 \%$ & $0 \%$ & $0 \%$ \\
\hline 40 & 20 & $0.015 \%$ & $0.034 \%$ & $1.9 \%$ & $2.5 \%$ \\
\hline 40 & 30 & $0.00049 \%$ & $0.0016 \%$ & $0.53 \%$ & $0.82 \%$ \\
\hline 40 & 40 & $0.00002 \%$ & $0.00008 \%$ & $0.16 \%$ & $0.28 \%$ \\
\hline 40 & 50 & $0 \%$ & $0 \%$ & $0.049 \%$ & $0.097 \%$ \\
\hline 40 & 75 & $0 \%$ & $0 \%$ & $0.0027 \%$ & $0.0073 \%$ \\
\hline 40 & 100 & $0 \%$ & $0 \%$ & $0.00016 \%$ & $0.00058 \%$ \\
\hline 40 & 500 & $0 \%$ & $0 \%$ & $0 \%$ & $0 \%$ \\
\hline
\end{tabular}


message is that motorists experience occasional dramatic drops in mileage as a fact of life, whether there is any change in fuel formulation or not. Even when we compare large batches of fuel, say 50 gallons (about 3 fill-ups), the probabilities are nonnegligible. For example, $\mathrm{G}(20 \%, 0,0.20,50)=0.6 \%$; hence nearly one in a hundred 50 gallon comparisons show a $20 \%$ reduction. The impact of occasional substantial reductions in experienced mileage is perhaps best understood in the context of the California vehicle population, whose size is approximately 20 million. Vehicles may experience dramatic changes in mileage, but their drivers must actually calculate, i.e., record, their mileage in order to perceive a problem. Figures 7 and 8 and Tables XVIII and XIX provide the number of California motorists expected to record a dramatic reduction in mileage, as a

TABLE XVII. Probability Second Batch Gets Delta (\%) Lower Mileage Than First Batch, Based on Number of Gallons in Each Batch, Difference in Intrinsic Fuel Economy from Batch to Batch, and Mileage Variation in Driving

\begin{tabular}{|c|c|c|c|c|c|}
\hline & & \multicolumn{2}{|c|}{ LOW VARIATION } & \multicolumn{2}{|c|}{ HIGH VARIATION } \\
\hline DELTA (\%) & GALLONS & $6 \%$ DIFF & $10 \%$ DIFF & 6\% DIFF & $10 \%$ DIFF \\
\hline 10 & 20 & $37.9 \%$ & $50.0 \%$ & $43.0 \%$ & $50.0 \%$ \\
\hline 10 & 30 & $35.3 \%$ & $50.0 \%$ & $41.4 \%$ & $50.0 \%$ \\
\hline 10 & 40 & $33.2 \%$ & $50.0 \%$ & $40.1 \%$ & $50.0 \%$ \\
\hline 10 & 50 & $31.3 \%$ & $50.0 \%$ & $38.9 \%$ & $50.0 \%$ \\
\hline 10 & 75 & $27.6 \%$ & $50.0 \%$ & $36.6 \%$ & $50.0 \%$ \\
\hline 10 & 100 & $24.6 \%$ & $50.0 \%$ & $34.6 \%$ & $50.0 \%$ \\
\hline 10 & 500 & $6.2 \%$ & $50.0 \%$ & $18.7 \%$ & $50.0 \%$ \\
\hline 20 & 20 & $12.7 \%$ & $20.2 \%$ & $25.5 \%$ & $31.5 \%$ \\
\hline 20 & 30 & $8.1 \%$ & $15.4 \%$ & $21.0 \%$ & $27.8 \%$ \\
\hline 20 & 40 & $5.3 \%$ & $11.9 \%$ & $17.6 \%$ & $24.8 \%$ \\
\hline 20 & 50 & $3.6 \%$ & $9.4 \%$ & $14.9 \%$ & $22.4 \%$ \\
\hline 20 & 75 & $1.4 \%$ & $5.3 \%$ & $10.1 \%$ & $17.6 \%$ \\
\hline 20 & 100 & $0.54 \%$ & $3.1 \%$ & $7.0 \%$ & $14.1 \%$ \\
\hline 20 & 500 & $0 \%$ & $0.0016 \%$ & $0.050 \%$ & $0.81 \%$ \\
\hline 30 & 20 & $1.9 \%$ & $3.8 \%$ & $11.4 \%$ & $15.2 \%$ \\
\hline 30 & 30 & $0.53 \%$ & $1.5 \%$ & $7.0 \%$ & $10.4 \%$ \\
\hline 30 & 40 & $0.16 \%$ & $0.60 \%$ & $4.4 \%$ & $7.3 \%$ \\
\hline 30 & 50 & $0.049 \%$ & $0.25 \%$ & $2.9 \%$ & $5.2 \%$ \\
\hline 30 & 75 & $0.0027 \%$ & $0.029 \%$ & $1.0 \%$ & $2.3 \%$ \\
\hline 30 & 100 & $0.00016 \%$ & $0.0035 \%$ & $0.36 \%$ & $1.1 \%$ \\
\hline 30 & 500 & $0 \%$ & $0 \%$ & $0 \%$ & $0.00001 \%$ \\
\hline 40 & 20 & $0.075 \%$ & $0.21 \%$ & $3.3 \%$ & $4.9 \%$ \\
\hline 40 & 30 & $0.0051 \%$ & $0.022 \%$ & $1.2 \%$ & $2.1 \%$ \\
\hline 40 & 40 & $0.00036 \%$ & $0.0025 \%$ & $0.48 \%$ & $1.0 \%$ \\
\hline 40 & 50 & $0.00003 \%$ & $0.00029 \%$ & $0.19 \%$ & $0.44 \%$ \\
\hline 40 & 75 & $0 \%$ & $0 \%$ & $0.019 \%$ & $0.067 \%$ \\
\hline 40 & 100 & $0 \%$ & $0 \%$ & $0.0021 \%$ & $0.011 \%$ \\
\hline 40 & 500 & $0 \%$ & $0 \%$ & $0 \%$ & $0 \%$ \\
\hline
\end{tabular}


function of the percentage of motorists making mileage calculations. These numbers, $E(\Delta$, $\delta, \sigma, N)$, are given by

$$
\mathrm{E}(\Delta, \delta, \sigma, N),=(\mathrm{V} / 100) \mathrm{G}(\Delta, \delta, \sigma, N),
$$

where $\mathrm{V}=20000000$ is the California vehicle population size. $E(\Delta, \delta, \sigma, N)$ is the expected number of California motorists who would both experience and record a mileage reduction of at least $\Delta$ percent in comparing two consecutive batches of $\mathrm{N}$ gallons of fuel, if $\delta$ is the intrinsic mileage reduction effect between the two batches, $\sigma$ is the relative mileage variation parameter, and exactly $1 \%$ of all motorists record their mileage. We can only conjecture what percentage of California motorists actually record their mileage. If the

TABLE XVIII. Expected Number of Motorists Recording Second Batch to Get Delta (\%) Lower Mileage Than First Batch, Based on Number of Gallons in Each Batch, Difference in Intrinsic Fuel Economy from Batch to Batch, and Mileage Variation in Driving, Per One Percent of California Population Recording Mileage

\begin{tabular}{|c|c|c|c|c|c|}
\hline & & \multicolumn{2}{|c|}{ LOW VARIATION } & \multicolumn{2}{|c|}{ HIGH VARIATION } \\
\hline DELTA (\%) & GALLONS & NO DIFF & $3 \%$ DIFF & NO DIFF & $3 \%$ DIFF \\
\hline 10 & 20 & 45626 & 59637 & 66710 & 75977 \\
\hline 10 & 30 & 36153 & 51656 & 59833 & 70803 \\
\hline 10 & 40 & 29206 & 45385 & 54299 & 66542 \\
\hline 10 & 50 & 23881 & 40236 & 49644 & 62875 \\
\hline 10 & 75 & 14910 & 30507 & 40487 & 55375 \\
\hline 10 & 100 & 9573 & 23630 & 33615 & 49413 \\
\hline 10 & 500 & 20 & 809 & 3150 & 12629 \\
\hline 20 & 20 & 11460 & 17305 & 36231 & 43150 \\
\hline 20 & 30 & 5330 & 9518 & 26454 & 33534 \\
\hline 20 & 40 & 2565 & 5400 & 19763 & 26594 \\
\hline 20 & 50 & 1260 & 3122 & 14976 & 21358 \\
\hline 20 & 75 & 225 & 833 & 7771 & 12768 \\
\hline 20 & 100 & 42 & 231 & 4165 & 7858 \\
\hline 20 & 500 & $\overline{0}$ & 0 & 1 & 8 \\
\hline 30 & 20 & 1167 & 2107 & 14536 & 18294 \\
\hline 30 & 30 & 201 & $\overline{473}$ & 7453 & 10287 \\
\hline 30 & 40 & 36 & 111 & 3947 & 5965 \\
\hline 30 & 50 & 7 & 27 & 2132 & 3523 \\
\hline 30 & 75 & 0 & 1 & 481 & 991 \\
\hline 30 & 100 & 0 & 0 & 113 & 290 \\
\hline 30 & 500 & 0 & 0 & 0 & 0 \\
\hline 40 & 20 & 30 & 68 & 3703 & 4987 \\
\hline 40 & 30 & 1 & 3 & 1065 & 1631 \\
\hline 40 & 40 & 0 & 0 & 319 & 555 \\
\hline 40 & 50 & 0 & 0 & 98 & 193 \\
\hline 40 & 75 & 0 & 0 & 5 & 15 \\
\hline 40 & 100 & 0 & 0 & $\overline{0}$ & 1 \\
\hline 40 & 500 & 0 & 0 & $\overline{0}$ & 0 \\
\hline
\end{tabular}


recording percentage is $2 \%$, then the $\mathrm{E}(\Delta, \delta, \sigma, \mathrm{N})$ values should be multiplied by 2 ; if the recording percentage is $3 \%$, then the $\mathrm{E}(\Delta, \delta, \sigma, N)$ values should be multiplied by 3 , etc. To illustrate the use of these figures and tables, consider the scenario described earlier: a $20 \%$ reduction in mileage from one 20 gallon batch to the next, with no difference in fuel formulation, and low variation driving. From Table XVIII we see that $\mathrm{E}(20 \%, 0,0.20,20)$ $=11460$. Hence for every one percent who record mileage, about 11500 Califomia motorists would be expected to record a $20 \%$ reduction in their mileage from one fill-up to the next, even if there is no change in fuel formulation and low variation driving conditions prevail. If, as some believe, $\delta=0.10$, this number is seen from Table XIX to climb to around 40000 . Viewing the recording of a dramatic reduction as a potential complaint to be

TABLE XIX. Expected Number of Motorists Recording Second Batch to Get Delta (\%) Lower Mileage Than First Batch, Based on Number of Gallons in Each Batch, Difference in Intrinsic Fuel Economy from Batch to Batch, and Mileage Variation in Driving, Per One Percent of California Population Reconding Mileage

\begin{tabular}{|c|c|c|c|c|c|}
\hline & & \multicolumn{2}{|c|}{ LOW VARIATION } & \multicolumn{2}{|c|}{ HIGH VARIATION } \\
\hline DELTA (\% & GALLONS & $6 \%$ DIFF & $10 \%$ DIFF & $6 \%$ DIFF & $10 \%$ DIFF \\
\hline 10 & 20 & 75847 & 100000 & 85909 & 100000 \\
\hline 10 & 30 & 70648 & 100000 & 82788 & 100000 \\
\hline 10 & 40 & 66367 & 100000 & 80177 & 100000 \\
\hline 10 & 50 & 62684 & 100000 & 77894 & 100000 \\
\hline 10 & $\overline{75}$ & 55155 & 100000 & 73101 & 100000 \\
\hline 10 & 100 & 49173 & 100000 & 69139 & 100000 \\
\hline 10 & 500 & 12419 & 100000 & 37474 & 100000 \\
\hline 20 & 20 & 25415 & 40493 & 51030 & 63063 \\
\hline 20 & 30 & 16253 & 30771 & 42005 & 55592 \\
\hline 20 & 40 & 10681 & 23886 & 35181 & 49649 \\
\hline 20 & 50 & 7138 & 18789 & 29788 & 44708 \\
\hline 20 & 75 & 2723 & 10679 & 20233 & 35177 \\
\hline 20 & 100 & 1078 & 6256 & 14098 & 28228 \\
\hline 20 & 500 & 0 & 3 & 100 & 1621 \\
\hline 30 & 20 & 3711 & 7556 & 22878 & 30490 \\
\hline 30 & 30 & 1068 & 2952 & 14048 & 20891 \\
\hline 30 & 40 & 320 & 1197 & 8875 & 14679 \\
\hline 30 & 50 & 98 & 496 & 5705 & 10475 \\
\hline 30 & 75 & 5 & 58 & 1977 & 4694 \\
\hline 30 & 100 & 0 & 7 & 712 & 2178 \\
\hline 30 & 500 & 0 & 0 & 0 & 0 \\
\hline 40 & 20 & 150 & $\overline{414}$ & 6683 & 9786 \\
\hline 40 & 30 & 10 & 45 & 2478 & 4263 \\
\hline 40 & 40 & 1 & 5 & 954 & 1923 \\
\hline 40 & 50 & 0 & 1 & 376 & 886 \\
\hline 40 & 75 & $\overline{0}$ & 0 & 39 & 135 \\
\hline 40 & 100 & 0 & 0 & 4 & 21 \\
\hline 40 & 500 & $\overline{0}$ & $\overline{0}$ & 0 & 0 \\
\hline
\end{tabular}


voiced publicly, it is clear that the enormity of the California vehicle population and the nonnegligility of the probabilities $G(\Delta, \delta, \sigma, N)$ combine to create some rather significant numbers of recorded problems, whether or not there is in fact an issue in terms of an unacceptably large intrinsic mileage reduction factor, $\delta$. Since the introduction of CaRFG has been made a fuel economy issue, the percentage of motorists who record mileage has undoubtedly increased. Novice recorders who are unaccustomed to the usual variations in mileage will look for an explanation for a recorded dramatic drop in mileage. Our contention is that the intrinsic mileage reduction due to CaRFG is modest and is masked by considerable random variation caused by a number of uncontrolled factors. We offer as anecdotal evidence Figures 1, 2, and 3. Each of these time histories begins with conventional fuel and ends with CaRFG. The locations of the shift points are anything but apparent. (The switch to CaRFG occurs at fill-up number 47 for the Honda, fill-up number 78 for the Cadillac, and fill-up number 69 for the Ford van.) 


\section{ADDITIONAL FACTORS}

A number of additional factors besides the nominal fuel composition and corresponding energy content affects fuel economy. Vehicle parameters and driving conditions have a significant effect on vehicle fuel economy. This effect results in considerable deviations from the average fuel economy for any vehicle, and makes it difficult to evaluate fuel economy with accuracy. The purpose of this section is to give an estimate of the expected changes in fuel economy that result from changes in vehicle parameters and driving conditions.

Changes in fuel economy are evaluated with HVEC, a vehicle evaluation code that has been developed at LLNL $[22,23]$. HVEC has been validated against vehicular data and results from other codes. HVEC calculates vehicle fuel economy by simulating a secondby-second drive of the vehicle along the EPA Urban and Highway driving cycles.

An "average" vehicle is selected for the analysis, with the characteristics listed in Table XX. An engine performance map was selected from the literature, corresponding to a current 4-cylinder engine [24]. This vehicle is evaluated with HVEC, and then some parameters are changed to reflect common driving conditions that result in changes in fuel economy, including weight changes resulting from adding passengers, turning on the air conditioner, driving against a head wind, and driving faster in the highway. The results are given in Table XXI.

TABLE XX. Vehicle Characteristics for Fuel Economy Sensitivity Analysis.

\begin{tabular}{|l|c|}
\hline \multicolumn{1}{|c|}{ VEHICLE PARAMETER } & VALUE \\
\hline & \\
\hline Empty vehicle weight, $\mathrm{kg}$ & 1200 \\
\hline Frontal area, $\mathrm{m}^{2}$. & 2.2 \\
\hline Aerodynamic drag coefficient & 0.3 \\
\hline Coefficient of rolling friction & 0.01 \\
\hline Transmission efficiency & 0.94 \\
\hline Transmission gears & 5 \\
\hline Accessory load, $\mathrm{W}$ & 1000 \\
\hline
\end{tabular}

TABLE XXI. Fuel Economy and Changes in Fuel Economy with Respect to the Base Case "Average" Vehicle Described in TABLE XII. Results Obtained from HVEC.

\begin{tabular}{|l|c|c|}
\hline \multicolumn{1}{|c|}{ VEHICLE DESCRIPTION } & FUEL ECONOMY & CHANGE \\
\hline & mpg & $\%$ \\
\hline Base case vehicle & 28.7 & -- \\
\hline Base case with two 70 kg passengers added & 28.0 & -2.4 \\
\hline Base case with 2000 W accessories (A/C on) & 26.7 & -7.0 \\
\hline Base case driven against a 10 mph head wind & 26.9 & -6.2 \\
\hline Base case driven 25\% faster in highway cycle & 25.0 & -13.0 \\
\hline
\end{tabular}

The Environmental Protection Agency has also evaluated changes in fuel economy due to driving conditions [25]. Their results are shown in Table XXII. The conditions used by 
EPA for calculating the fuel economy losses listed in Table XXII ane not indicated with detail. [25] All the information available is listed in the table. Lack of the precise data used in generating Table XXI makes it impossible to compare these results with the HVEC results shown in Table XXI. However, both sets of results show that common driving conditions can result in very large changes in fuel economy, and these changes dwarf the $\sim 3 \%$ change in fuel economy due to the change in fuel energy content.

TABLE XXII. Average and Maximum Fuel Economy Reduction Resulting from Effects Listed [25].

\begin{tabular}{|l|l|c|c|}
\hline \multicolumn{1}{|c|}{ EFFECT } & \multicolumn{1}{c|}{ CONDITIONS } & \multicolumn{2}{c|}{ FUEL ECONOMY REDUCTION \% } \\
\hline & & AVERAGE & MAXIMUM \\
\hline & & & \\
\hline Temperature & $20^{\circ} \mathrm{F}$ vs. $70^{\circ} \mathrm{F}$ & 5.3 & 13 \\
\hline Head wind & $20 \mathrm{mph}$ & 2.3 & 6 \\
\hline Hills/Mountains & $7 \%$ grade & 1.9 & 25 \\
\hline Poor road conditions & Gravel, snow, etc. & 4.3 & 50 \\
\hline Traffic congestion & 20 vs. 27 mph & 10.6 & 15 \\
\hline Highway speed & 70 vs. $55 \mathrm{mph}$ & $\mathrm{N} / \mathrm{A}$ & 25 \\
\hline Acceleration rate & "Hard" vs. "Easy" & $<1$ & 10 \\
\hline Wheel alignment & $1 / 2$ inch & $<1$ & 4 \\
\hline Tire type & Non-radial vs. radial & 3.3 & 6 \\
\hline Tire pressure & 15 psi vs. 26 psi & 3.3 & N/A \\
\hline Air conditioning & Extreme heat & 21 & 20 \\
\hline Defroster & Extreme use & Analogous to A/C on some vehicles \\
\hline Idling/warm-up & Winter vs. summer & Variable & Unknown but likely small \\
\hline Windows & Open vs. closed & \multicolumn{2}{|c|}{} \\
\hline
\end{tabular}




\section{CONCLUSIONS}

Fuel economy data contained in the 1996 California Air Resources Boand (CARB) report on the performance and compatibility of California Reformulated Gasoline (CaRFG) has been examined and reanalyzed by two additional statistical methodologies. Additional, more recent data obtained from outside sources and not analyzed by CARB has also been analyzed by these two statistical approaches. No new experimental data was generated by this review. Within the assumptions of the analysis, point estimates for the reduction in fuel economy using CaRFG as compared to conventional, non-reformulated gasoline were $2-4 \%$, with a $95 \%$ upper confidence bound of $6 \%$. Many additional factors affect mileage in addition to the fuel: variation in energy among ostensibly identical fuels, reproducibility of tank fill-up, speed, terrain, traffic, wind and weather, road conditions, number of passengers, type of vehicle, vehicle maintenance. The relative effect of some of these additional factors were estimated from the literature and from a vehicle evaluation code; in most cases they can easily be expected to exceed the reduction due to using CaRFG. Thus, substantial variations in fuel economy are routine and inevitable, even if there is no change in fuel reformulation. This additional analysis confirms the conclusion reached by CARB with respect to fuel economy. 


\section{ACKNOWLEDGMENTS}

This work was performed at the request of the California Legislature under the auspices of the U.S. Department of Energy (DOE) by Lawrence Livermore National Laboratory (LLNL) under Contract No. W-7405-Eng-48. We would like to thank J. R. Smith, D. Flowers, and C. Westbrook for valued contributions. 


\section{REFERENCES}

1. A. M. Hochhauser, J. D. Benson, V. R. Burns, R. A. Gorse, Jr., W. J. Koehl, L. J. Painter, R. M. Reuter, and J. A. Rutherford, "Fuel Composition Effects on Automotive Fuel Economy - Auto/Oil Air Quality Improvement Research Program", SAE Paper No. 930138 (1993).

2. J. E. Orban, M. J. Murphy, and M. C. Matthews, "Vehicle Fuel Economy - The CleanFleet Alternative Fuels Project", SAE Paper No. 950396 (1995).

3. S. Beaton, G. A. Bishop, Y. Zhang, L. L. Ashbaugh, D. R. Lawson, and D. H. Stedman, "On-Road Vehicle Emissions: Regulations, Costs, and Benefits," Science 268, pages 991-993 (May, 1995).

4. M. D. Gurney, "Effects of a California Phase 2 Reformulated Gasoline on Exhaust Emissions and Vehicle Performance," NIPER/BDM-0251, National Institute for Petroleum and Energy Research, Bartlesville, OK (September, 1996).

5. "Gasoline Reformulation and Vehicle Technology Effects on Exhaust Emissions", Auto/Oil Air Quality Improvement Research Program, Technical Bulletin No. 17 (August, 1995).

6. "Technical Specifications, Backgrounder 6," Cleaner Buming Gasoline, California Air Resources Board, Sacramento, CA.

7. "Comparison of Federal and California Reformulated Gasoline," Fact Sheet 3", Cleaner Burning Gasoline, California Air Resources Board, Sacramento, CA.

8. L. M. Gibbs, "Gasoline Specifications, Regulations, and Properties," Automotive Engineering (October, 1996), pages 35-40.

9. "Fuel Economy Impact Analysis of RFG,", EPA 420-F-95-003, US EPA Office of Mobile Sources, EPA National Vehicle and Fuel Emissions Laboratory, Ann Arbor, MI (August, 1995).

10. "California Reformulated Gasoline: Performance and Compatibility Test Program: Report of the Performance Subcommittee of the California Reformulated Gasoline Advisory Committee", California Environmental Protection Agency, Air Resources Board (March, 1996.

11. "Toxicological and Performance Aspects of Oxygenated Motor Vehicle Fuels", Committee on Toxicological and Performance Aspects of Oxygenated and Reformulated Motor Vehicle Fuels, Board on Environmental Studies and Toxicology, Commission on Life Sciences, National Research Council, National Academy Press (June, 1996).

12. Barry Shiller, California State Automobile Association, San Francisco, CA, letter to Jeffery Richardson (Dec 13, 1996).

13. Automobile Club of Southern California, Los Angeles, CA, internal report from Steve Mazor to Steve Lenzi (April 5, 1996).

14. D. Oswalt, A. Hirsch, and J. Martin, California Environmental Protection Agency News Release 96-25 (October 10, 1996). 
15. Consumer Reports November 1996, pages 54-57.

16. C. R. Rao. Linear Statistical Inference and Its Applications, 2 nd ed. John Wiley \& Sons, New York. 1973.

17. M. Hollander \& D. A. Wolfe. Nomparametric Statistical Methods. John Wiley \& Sons, New York. 1973.

18. "Response to Media Allegations Concerning Cleaner-Burning Gasoline." ARB article dated 6-13-96 on website, www.arb.ca.gov/html/cbgpub.htm.

19. Stata 5.0. Stata Corporation, 702 University Drive East, College Station, TX 77840.

20. www.arb.ca.gov/pub/rfg

21. Statistical Analysis of Fuel Economy Data. Appendix 39 of Reference [10]. March 1996.

22. S. M. Aceves and J. R. Smith, 1995, "A Hybrid Vehicle Evaluation Code and Its Application to Vehicle Design," SAE paper 950491.

23. S. M. Aceves and J. R. Smith, 1996, "Lean-Burn Hydrogen Spark-Ignited Engines: The Mechanical Equivalent to the Fuel Cell," Proceedings of the $18^{\text {th }}$ Annual Fall Technical Conference of the ASME Internal Combustion Engine Division, ICE-Vol. 273, Alternative Fuels, Edited by J.A. Caton, pp.23-32.

24. M. W. Thomson, A. R. Frelund, M. Pallas, and K. D. Miller, 1987, “General Motors 2.3L Quad 4 Engine," SAE Paper 870353.

25. Environmental Protection Agency, 1995, "Fuel Economy Impact Analysis of RFG," Report EPA 420-F-95-003, EPA Office of Mobile Sources, available at the internet as http://www.epa.gov/OMSWWW/rfgecon.htm 


\section{FIGURE CAPTIONS}

Figure 1. Mileage Time History of a 1993 Honda Prelude

Figure 2. Mileage Time History of a 1970 Cadiliac

Figure 3. Mileage Time History of a 199015 Passenger Ford Van

Figure 4. Mileage Time History of a Sacramento City Police Car

Figure 5. Probability Second Batch Gets 20\% Lower Mileage Than First Batch,

Based on Number of Gallons in Each Batch, Difference in Intrinsic Fuel Economy from Batch to Batch, and Mileage Variation in Driving

Figure 6. Probability Second Batch Gets 20\% Lower Mileage Than First Batch, Based on Number of Gallons in Each Batch, Difference in Intrinsic Fuel Economy from Batch to Batch, and Mileage Variation in Driving

Figure 7. Expected Number of Motorists Recording Second Batch to Get 20\% Lower Mileage Than First Batch, Based on Number of Gallons in Each Batch, Difference in Intrinsic Fuel Economy from Batch to Batch, and Mileage Variation in Driving, Per One Percent of California Population Recording Mileage

Figure 8. Expected Number of Motorists Recording Second Batch to Get 20\% Lower Mileage Than First Batch, Based on Number of Gallons in Each Batch, Difference in Intrinsic Fuel Economy from Batch to Batch, and Mileage Variation in Driving, Per One Percent of California Population Recording Mileage 
prelude

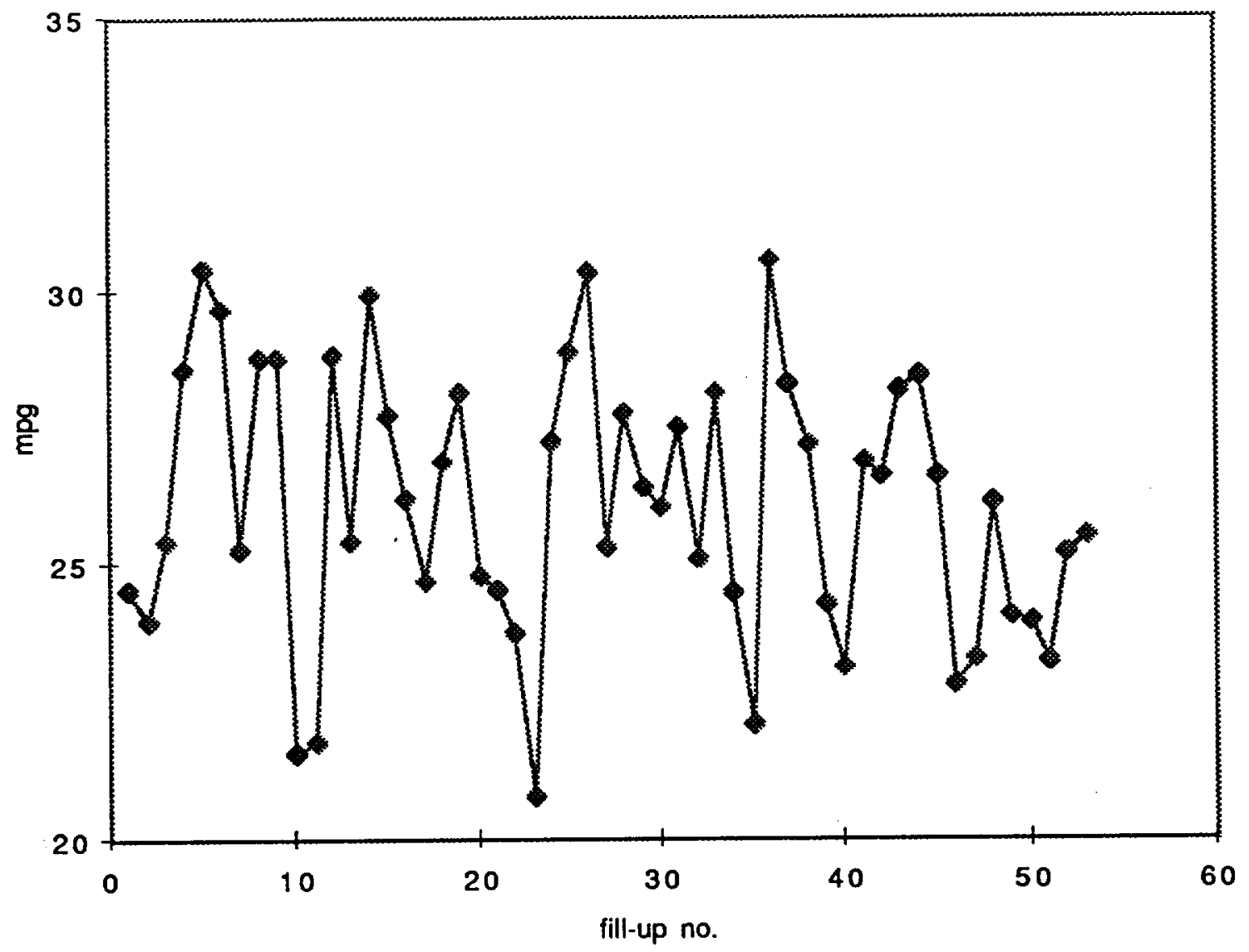

FIGURE 1 
cadillac

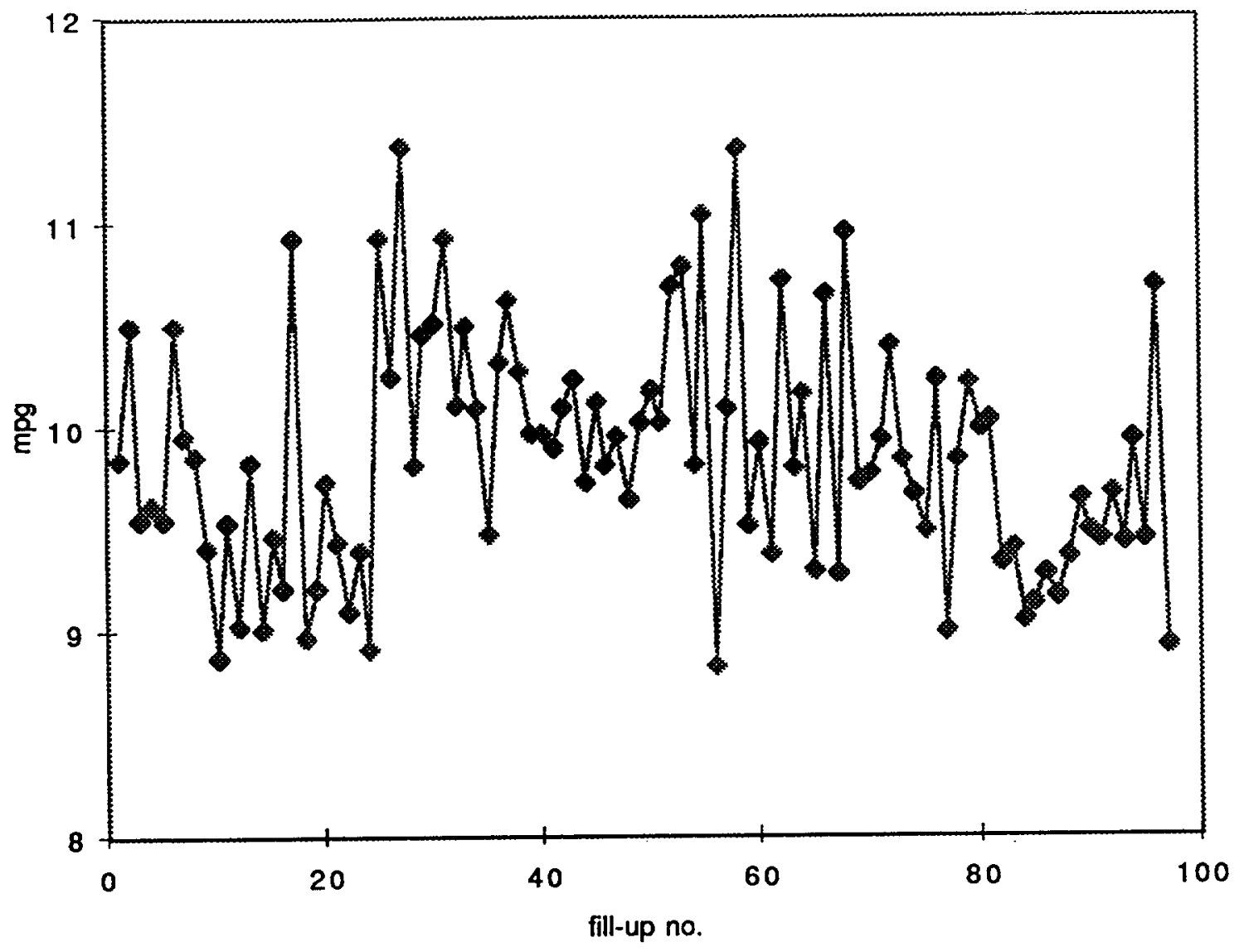

FIGURE 2 
van pool

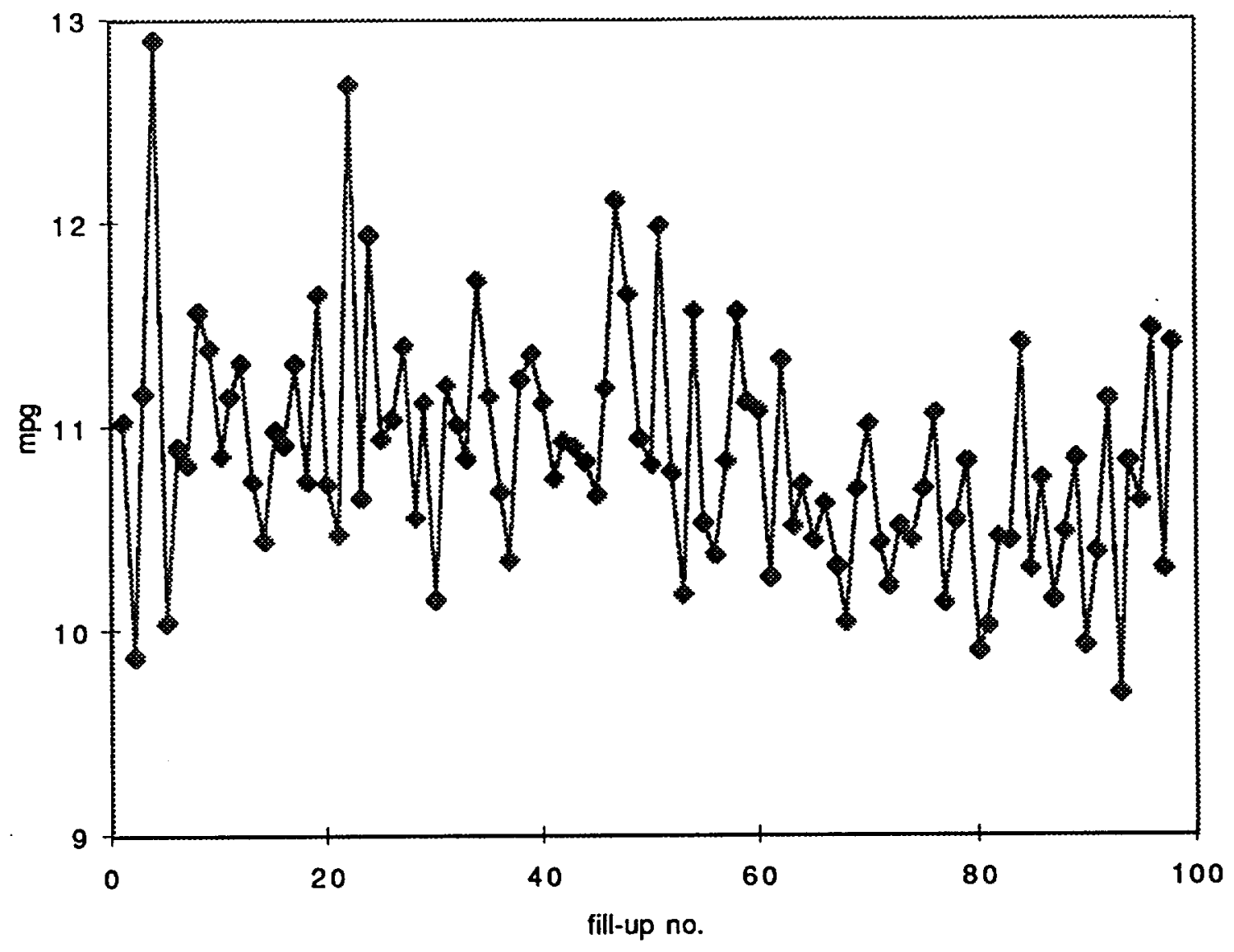

FIGURE 3 
police car

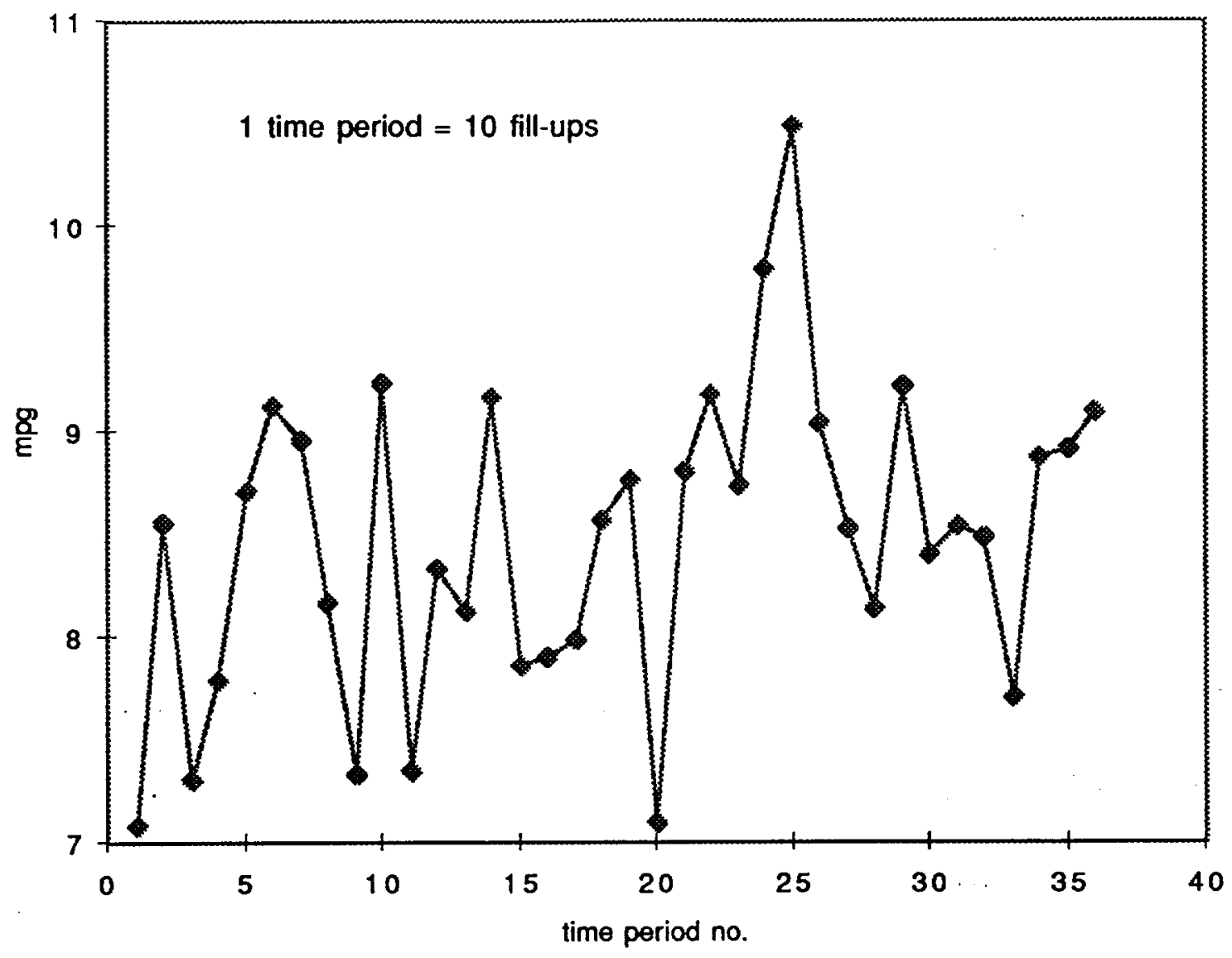

FIGURE 4 


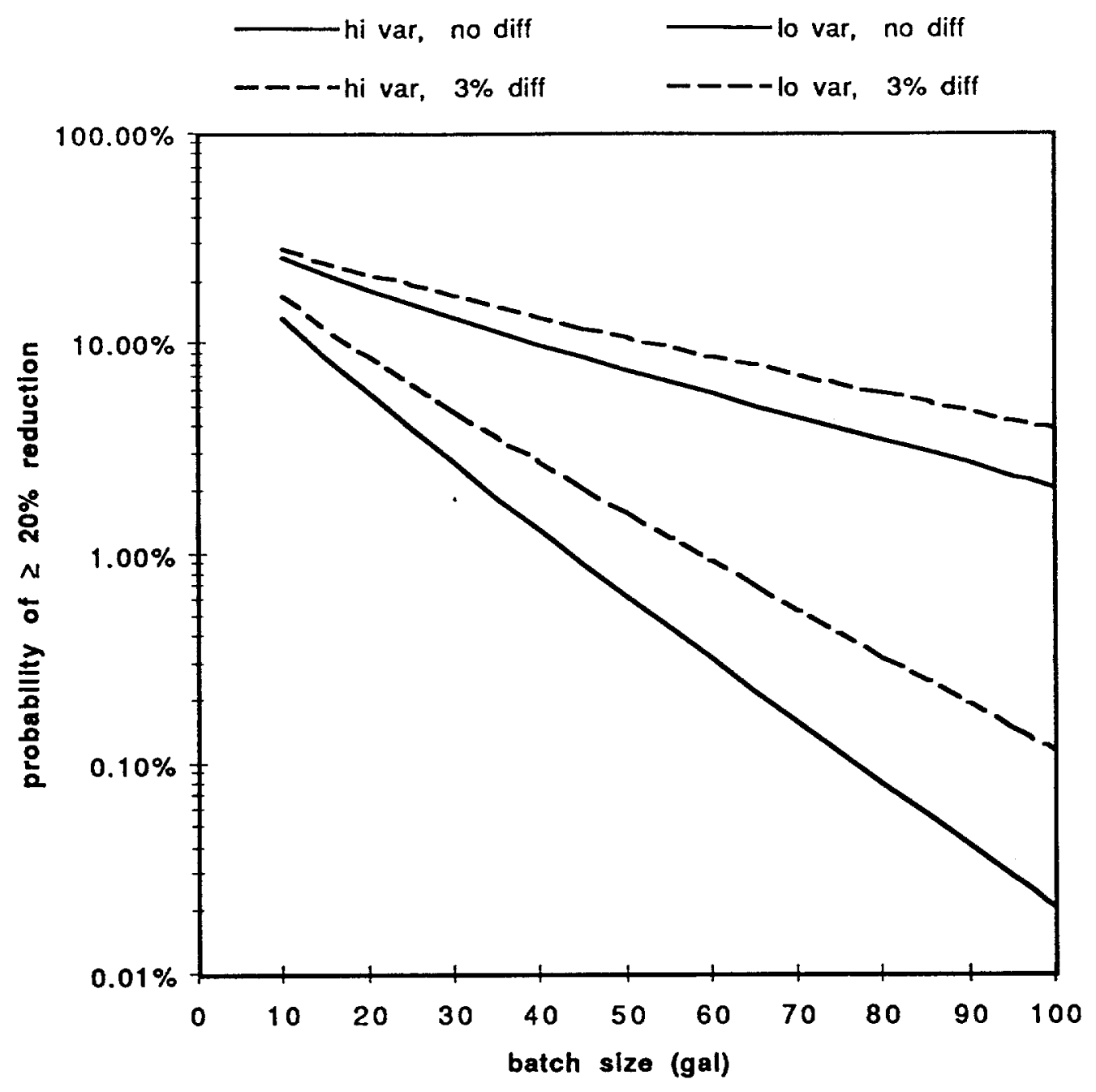

FIGURE 5 

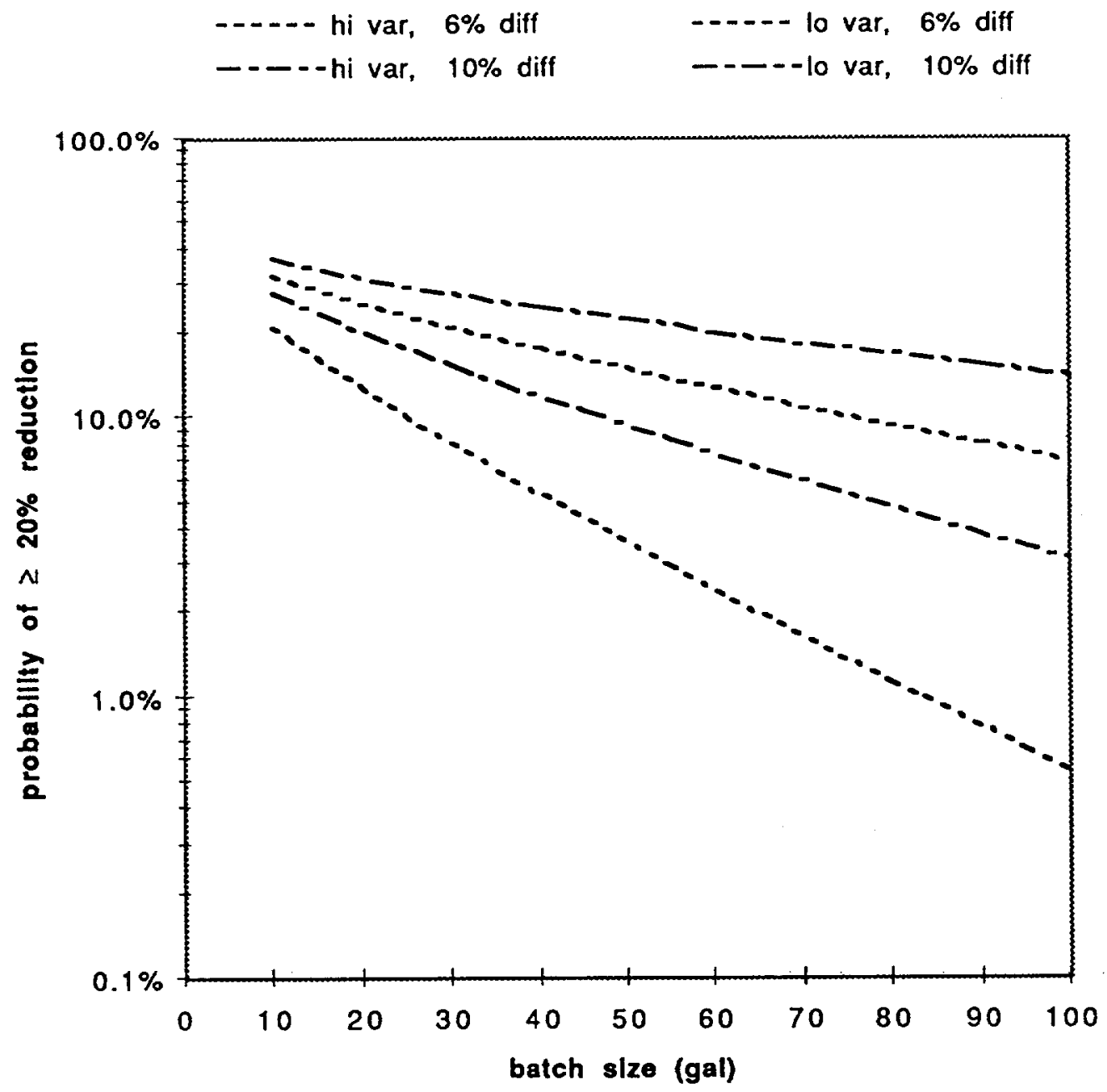

FIGURE 6 


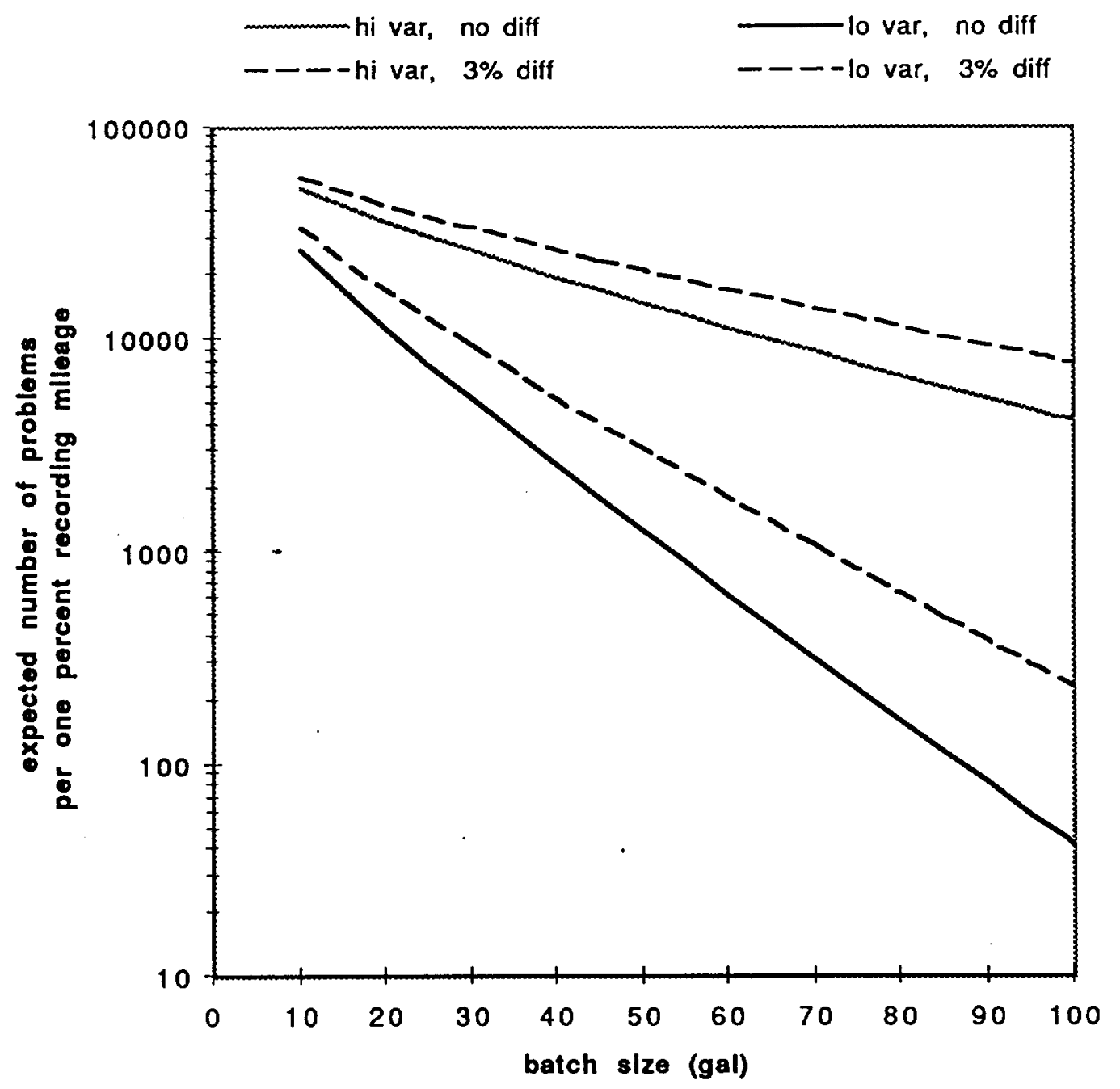

FIGURE 7 


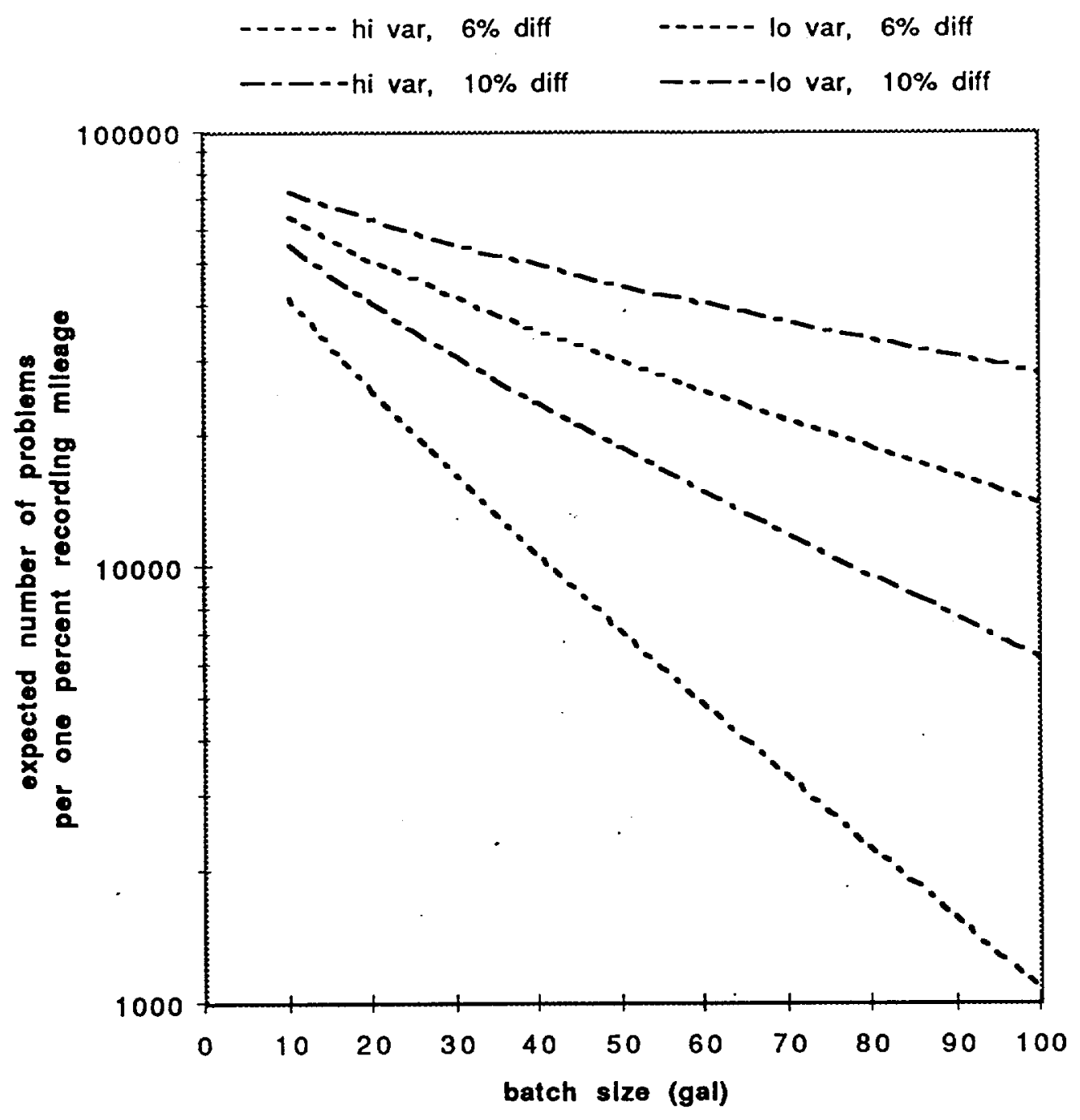

FIGURE 8 


\section{APPENDIX 1.}

\section{ANALYZING THE CONTROL VEHICLE DATA.}

The Sacramento City and Sacramento County data sets include control vehicles which used conventional fuel in both 1994 and 1995. We show here that there is no significant mileage change effect from 1994 to 1995 for the control vehicles, whether the normal model or the nonparametric model is used. As a result the control vehicle data are used for the normal model merely to help in the estimation of the relative mileage variation parameter, $\sigma$; the control vehicle data are not used at all for the nonparametric model.

Let $W_{j}$ denote the log mileage difference for control vehicle $j$,

$$
W_{j}=\log U_{j}-\log V_{j} \text {, }
$$

where $U_{j}$ is the 1994 mileage based on $K_{j}$ gallons, and $V_{j}$ is the 1995 mileage based on $L_{j}$ gallons, $\mathrm{j}=1, \cdots, \mathrm{C}$. Define

$$
s_{j}=1 / K_{j}+1 / L_{i}
$$

The normal model has $W_{j}$ distributed as $\mathcal{N}\left(\dot{\lambda}, v_{s_{j}} \sigma\right)$, where $\lambda$ is the intrinsic mileage change effect from 1994 to 1995 . We wish to test the hypothesis

$\mathrm{H}_{0}: \lambda=0$ (there is no mileage change effect from 1994 to 1995)

against the alternative

$\mathrm{H}_{1}: \lambda \neq 0 \quad$ (there is a mileage change effect from 1994 to 1995 ).

The maximum likelihood estimates of $\lambda$ and $\sigma$ based on $w_{1}, \ldots, w_{c}$ are

$$
\hat{\lambda}=\frac{\sum_{\mathrm{j}} \mathrm{w}_{\mathrm{j}} / \mathrm{s}_{\mathrm{j}}}{\sum_{\mathrm{j}} 1 / \mathrm{s}_{\mathrm{j}}}
$$

and

$$
\hat{\sigma}^{2}=\frac{1}{\mathrm{C}} \sum_{\mathrm{j}} \frac{1}{\mathrm{~s}_{\mathrm{j}}}\left(\mathrm{w}_{\mathrm{j}}-\hat{\lambda}\right)^{2} \text {. }
$$

The standard error of $\hat{\lambda}$ is

$$
\text { S.E. }(\hat{\lambda})=\hat{\sigma} / \sqrt{\sum_{j s_{j}} \frac{1}{1}} \text {. }
$$

The P-value of the control vehicle data for this hypothesis is therefore

$$
P=2\left[1-\Phi\left(\frac{|\hat{\lambda}|}{\text { S.E. }(\hat{\lambda})}\right)\right] \text {. }
$$

The hypothesis of no mileage change effect is accepted at significance level $\alpha$ if $P \geq \alpha$. Since $P$ is calculated to be $P=0.20$ for the Sacramento City control vehicles and $P=0.72$ for the Sacramento County control vehicles (see Appendix 2), it is judicious, since each $P$ exceeds the usual nominal cutoff of 0.10 , to accept $\mathrm{H}_{0}$ and claim that there is no significant mileage change effect from 1994 to 1995 for either set of control vehicles under the normal model.

Consider now the nonparametric model, which assumes $W_{j}$ to be distributed as

$$
\mathrm{W}_{\mathrm{j}}=\lambda+\mathrm{e}_{\mathrm{j}}
$$

where $e_{i}$ has an unspecified continuous distribution symmetric about 0 . The P-values for the Wilcoxon signed rank test of $H_{0}$ are computed from Stata software [19] to be $P=0.19$ for the Sacramento City control vehicles and $P=0.97$ for the Sacramento County control vehicles. Thus we accept $\mathrm{H}_{0}$ and claim that there is no significant mileage change effect from 1994 to 1995 for either set of control vehicles under the nonparametric model. 


\section{APPENDIX 2A}

\section{FUEL ECONOMY ANALYSIS OF SACRAMENTO CITY FLEET}

Note: all vehicles with less than 1000 miles in either year have been removed

\begin{tabular}{|c|c|c|c|c|c|c|c|c|c|c|c|c|c|c|}
\hline $\begin{array}{l}1994 \\
\mathrm{mpg}\end{array}$ & \begin{tabular}{|l|}
994 \\
iles
\end{tabular} & $\begin{array}{c}1995 \\
\mathrm{mpg}\end{array}$ & \begin{tabular}{|l|l|}
95 \\
iles
\end{tabular} & $\begin{array}{c}1994 \\
\mathrm{gal}\end{array}$ & $\begin{array}{c}1995 \\
\text { gal }\end{array}$ & or & og & weight & $n$ & sdel & a & al & & it \\
\hline 8.49 & 295 & 7.7 & 23 & 977 & 886.1 & 2552 & 11 & 66 & 35 & 25. & 443 & & & 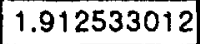 \\
\hline 8.29 & 35 & 29 & 86 & 6.9 & 6.5 & 05 & & 62 & 0 & & & & & 0 \\
\hline 8.88 & 22 & 25 & 08 & 5.8 & 7.6 & 157 & 57 & 264 & 31 & 935 & 27452 & & 29 & 43 \\
\hline 8.32 & 56 & 69 & 69 & 12.5 & 525.8 & & & 814 & 37 & 106 & 238 & 155 & 892 & 5834 \\
\hline 8.6 & 003 & 7 & 93 & & 1 & & & 151 & & & & & & \\
\hline 7.59 & 976 & .42 & 91 & 1314.4 & 1319.5 & 5312 & 534 & 7287 & 0.00 & 3113 & $0.5 \mathrm{~s}$ & 226 & 6821 & 0.528042306 \\
\hline 7. & 237 & & & & & & & & & & & & & \\
\hline 7.73 & 8782 & 7.8 & 994 & 1136.1 & 332.6 & 121. & 4871 & 77252 & $-9.17466 \mathrm{E} \cdot 04$ & 34292 & 0.0 & 47417 & 0.02090859 & 1354655 \\
\hline 8.35 & 861 & 43 & 63 & 0.5 & 849.7 & & -0.6 & & -0.0 & & & & 358 & \\
\hline 7.95 & 598 & .12 & 532 & 1333.1 & 1297 & 254 . & 226 & 1905 & -0.0 & 647 & 234 & 937 & 095 & 0778 \\
\hline 9.01 & 99 & 45 & 76 & 355 & 8.5 & 565 & 967 & 12 & & & & & & \\
\hline 8.55 & 43 & 8.5 & 51 & 12 & 888.4 & 255 & 119 & 791 & 9.84 & 0.01 & 0.075334416 & 3024 & 9376 & 0.10974044 \\
\hline 8.4 & 9906 & 03 & 91 & 3 & 870.6 & 075 & 0.0 & 231 & 489 & 57 & & & & 934 \\
\hline 8.02 & 773 & \begin{tabular}{|l|l|}
8.41 \\
\end{tabular} & 760 & 4 & 922.7 & 7.8832294 & -0.047483052 & 0.019694834 & -0.000935171 & -0.040022473 & 0.79750855 & -0.811242634 & \begin{tabular}{|l|}
1.122547562 \\
\end{tabular} & 6159 \\
\hline 8.11 & 606 & 8.46 & 348 & 1307.8 & 1105 & 776 . & 1305 & 2294 & -0.0 & 0727 & 064 & 9785 & 867 & 172 \\
\hline 7.95 & 28 & .54 & 55 & 11.1 & 1083.7 & 893 & 9079 & 3983 & -0.00 & 285 & 49221 & 6999 & 3276 & 636 \\
\hline 9.47 & 5971 & 8.53 & 1023 & 630.5 & 119.9 & 100.7422042 & 0.104539546 & 0.003985073 & 0.000416598 & 0.112000124 & 1.263713015 & 1.021191807 & 962852 & 3167938 \\
\hline 8.29 & 196 & & 85 & 29.9 & 2.5 & 703 & 737 & 502 & $E-04$ & 158 & 0.00 & 3187 & 883 & 8597 \\
\hline 7.87 & 8839 & 7.71 & 9902 & 123.1 & 1284.3 & 99.1515037 & 0.020539875 & 0.023700717 & 0.00048681 & 0.028000454 & 0.469749996 & 0.622610564 & 0.252773906 & 71914 \\
\hline 8.47 & 760 & 8.26 & 92 & 88.4 & 882.8 & 414 & 921 & 468 & 948 & 65 & 676 & 321 & 659 & 0985 \\
\hline 8.57 & 8972 & 8.01 & 5999 & 1046.9 & 748.9 & 436.5872647 & 0.067576972 & 0.017270141 & 0.001167064 & 0.07503755 & 2.458263071 & 1.424286216 & 1.993739958 & 1.282677124 \\
\hline 8.85 & 009 & 8.23 & 306 & 69.9 & 73.8 & 710.1130991 & 0.072631444 & 0.02809004 & 0.00204022 & 023 & 4.5 & 871 & 596 & 3196 \\
\hline 87 & 93 & .51 & & & & & & & & & 0.486 & & 10 & \\
\hline
\end{tabular}




\begin{tabular}{|c|c|c|c|c|c|c|c|c|c|c|c|c|c|c|}
\hline $\begin{array}{l}1994 \\
\mathrm{mpg} \\
\end{array}$ & \begin{tabular}{|l|}
1994 \\
miles \\
\end{tabular} & \begin{tabular}{c|}
1995 \\
$\mathrm{mpg}$ \\
\end{tabular} & \begin{tabular}{|l|}
1995 \\
miles \\
\end{tabular} & $\begin{array}{c}1994 \\
\text { gal }\end{array}$ & $\begin{array}{c}995 \\
\mathrm{gal}\end{array}$ & or & $g$ & it & $n$ & sdel & a & al & 10 & $n$ \\
\hline 3.19 & 479 & 8.14 & 9779 & 791.1 & 1201.4 & 295 & 718 & 53 & 5548 & 97 & 61 & 39 & 57 & 0.1214950 \\
\hline 7.79 & 063 & 8.71 & 761 & 33.4 & 50.3 & 72 & 931 & 266 & 58 & 352 & 83 & 234 & 328 & 736 \\
\hline .32 & 536 & 10.7 & 426 & 17.8 & 880.9 & 32.6552359 & -0.036159981 & 0.01948803 & -0.000704687 & -0.028699403 & 405778302 & 578665383 & 644168524 & - \\
\hline 10.79 & 389 & 1.02 & 8103 & 796 & 735.3 & 34703 & 2024 & 665 & 904 & 446 & 71023356 & 3812 & 091 & 593 \\
\hline 10.7 & 593 & 10.75 & 5389 & 176.9 & 501.3 & 2199 & -0.004662013 & 0.013906517 & $-6.48324 \mathrm{E}-04$ & 0.002798566 & 0.00275337 & 0.047666729 & 0.00764083 & 4060 \\
\hline 10.75 & 575 & 11.32 & 10574 & 1076.7 & 934.1 & 500.1718072 & -0.051665318 & 0.019785364 & 1022217 & 0474 & 522 & 2779 & 1158 & 1.049643 \\
\hline 10.68 & 125 & 10.44 & 8603 & 41.7 & 824 & 957 & 251 & 226 & 637 & 383 & 5905 & 24898 & 2193 & 0.4 \\
\hline 10.38 & 8227 & 11.12 & 9102 & 792.6 & 818.5 & 402.6709081 & -0.068864411 & 0.015928508 & -0.001096907 & 0.061403832 & 1.518242728 & -1.11931854 & 1.909589112 & -1.255315 \\
\hline 10.51 & 327 & 10.87 & 11200 & 1077.7 & 10 & & 516 & & & & & & & \\
\hline 10.74 & 025 & 10.68 & 12774 & 1026.5 & 1196.1 & 552.414582 & 0.005602256 & 0.021851938 & 0.00012242 & 0.013062834 & 0.094262719 & 0.278902929 & 0.017337679 & 0. \\
\hline 10.72 & 228 & 10.44 & 5194 & 301.1 & 497.5 & 187.5748184 & 0.026466573 & 0.007419922 & 0.000 & 7152 & 3301 & 2343 & 2314 & 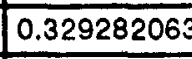 \\
\hline 11.16 & 74 & .09 & 4469 & 687.6 & 403 & & & & -04 & & & & 52 & \\
\hline 10.33 & 3608 & 10.05 & 2804 & 349.3 & 279 & 155.1085469 & 0.027479649 & 0.00613565 & 0.000168605 & 0.034940227 & 0.189359536 & 0.395299881 & 127286 & 0.3108938 \\
\hline 10.74 & 362 & 10.81 & 10726 & 1151 & 992.2 & & 543 & & & 336 & & 399 & 325 & \\
\hline 10.46 & 1407 & 10.65 & 10887 & 1090.5 & 1022.3 & 527.6496356 & -0.018001434 & 0.020872308 & -0.000375731 & -0.010540855 & 0.058626951 & -0.219953941 & 0985713 & 0.375632 \\
\hline 11.75 & 124 & 11.43 & 8225 & 861.6 & 719.6 & 915 & 763 & 824 & 281 & 341 & 764 & 881 & 9827 & 0. \\
\hline 10.08 & 625 & 10.65 & 12754 & 1153.3 & 1197.6 & 587.5163044 & 663 & 0462 & 8379 & 6051 & 5192 & 5556 & 5291 & -1 \\
\hline 10.49 & 011 & 10.74 & 10097 & 1240.3 & 940.1 & 534.767029 & -0.023 & 53852 & -0.00 & -0.016092088 & 754 & -0.338047558 & 0302 & -0.4 \\
\hline 10.44 & 231 & 10.57 & 7774 & 1075.8 & 735.5 & 398 & 375217 & 196 & 846 & 639 & 326 & 809 & 5522 & - \\
\hline 10.99 & 705 & 11.1 & 10953 & 1247 & 986.8 & 27729 & 934 & 949 & -0.0 & 3761 & 0.00 & 6233 & 0217 & -0 \\
\hline 10.76 & 1378 & 10.62 & 11149 & 1057.4 & 1049.8 & 526.7931473 & 0.013096539 & 0.020838428 & 0.000272911 & 0.020557118 & 0.222620194 & 0.428613032 & 0.090355209 & 0.2730610 \\
\hline 10.88 & 856 & 10.19 & 7100 & 997.8 & 696.8 & 10.2838664 & 0.065 & 0.016229654 & 0.001063357 & 0.072 & 3234 & 1.34 & 895 & \\
\hline 10.48 & 12070 & 11.06 & 8548 & 1151.7 & 772.9 & 462.5111348 & -0.053866317 & 0.018295615 & -0.000985517 & -0.046405739 & 0.996014292 & -0.906 & 3118 & -1.0 \\
\hline 10.59 & 1574 & 11.47 & 6164 & 148.6 & 537.4 & 16.4105539 & -0.079824772 & 4868 & -0.000367583 & 4193 & 276 & -0.709255958 & 7369 & -0.78 \\
\hline 10.64 & 479 & 10.87 & 11201 & 702.9 & 1030.5 & 417.8714953 & -0.021386217 & 9799 & 5351 & -0.013 & 5065 & -0.258594679 & 006 & -0.3 \\
\hline 10.38 & 3356 & 11.24 & 9430 & 323.3 & 839 & 233.3723651 & -0.079597967 & 0.009231542 & -0.000734812 & -0.072137388 & 1.214423757 & -1.001078697 & 1.478609104 & -1.104612 \\
\hline 10.62 & 565 & 11.15 & 10849 & 335.7 & 973 & 249.5882173 & -0.048700482 & 0.009872995 & -0.00048082 & 0.041239903 & .424482078 & -0.591851526 & 0.591957599 & -0.6989214 \\
\hline 11.27 & 4844 & 11.15 & 9015 & 429.8 & 808.5 & 280.6212549 & 0.01070483 & 0.011100573 & 0.00011 & 0.0181 & 0.092599985 & 0.27643 & 0.03215 & 0.1629007 \\
\hline 10.46 & 3687 & 10.63 & 8778 & 352.5 & 825.8 & 247.0461682 & -0.016121734 & 0.009772439 & -0.000157549 & -0.008661155 & 0.018532318 & -0.123665332 & 0.064209843 & -0.2 \\
\hline
\end{tabular}




\begin{tabular}{|c|c|c|c|c|c|c|c|c|c|c|c|c|c|c|}
\hline $\begin{array}{l}1994 \\
\mathrm{mpg}\end{array}$ & \begin{tabular}{|l|}
1994 \\
miles
\end{tabular} & $\begin{array}{c}1995 \\
\mathrm{mpg}\end{array}$ & $\begin{array}{l}1995 \\
\text { miles }\end{array}$ & $\begin{array}{c}1994 \\
\mathrm{gal} \\
\end{array}$ & $\begin{array}{c}1995 \\
\text { gal }\end{array}$ & gal factor & del log mpg & welght & term & sdel & sigma & std residual & sigmao & student res \\
\hline 10.35 & 2718 & 10.53 & 10603 & 262.6 & 1006.9 & 208.2803781 & -0.017241806 & 0.008238975 & -0.000142055 & -0.009781228 & 0.019926687 & $|-0.128233248|$ & 0.061917568 & -0.226042466 \\
\hline 10.27 & 5535 & 11.16 & 3793 & 538.9 & 339.9 & 208.4343537 & -0.083108933 & 0.008245066 & -0.000685239 & -0.075648354 & 1.192801755 & -0.992126906 & 1.439675829 & -1.08997227 \\
\hline 10.9 & 5552 & 10.91 & 11691 & 509.4 & 1071.6 & 345.27074 & -0.000917011 & 0.013657921 & $-1.25245 \mathrm{E}-04$ & 0.006543568 & 0.0147839 & 0.110453022 & 0.000290341 & -0.015478802 \\
\hline 11.52 & 5686 & 11.1 & 6986 & 493.6 & 629.4 & 276.6445592 & 0.037139547 & 0.010943266 & 0.000406428 & 0.044600126 & 0.550293391 & 0.673876391 & 0.381588552 & 0.561152318 \\
\hline 9.89 & 3852 & 10.8 & 9189 & 389.5 & 850.8 & 267.1826171 & -0.088021988 & 0.010568979 & -0.000930303 & -0.08056141 & 1.734052792 & -1.196228789 & 2.070096306 & -1.307008367 \\
\hline 10.77 & 8469 & 11.89 & 8860 & 786.4 & 745.2 & 382.6229303 & -0.09893322 & 0.015135467 & -0.0014974 & -0.091472641 & 3.201499428 & -1.625398322 & 3.745029802 & -1.757967054 \\
\hline 10.88 & 3366 & 10.62 & 8884 & 309.4 & 836.5 & 225.86011 & 0.024187226 & 0.008934379 & 0.000216098 & 0.031647804 & 0.226217763 & 0.432062371 & 0.132133107 & 0.330209008 \\
\hline 10.53 & 6015 & 10.99 & 10402 & 571.2 & 946.5 & 356.2237596 & 0.042757442 & 0.014091191 & -0.000602503 & -0.035296864 & 0.44380799 & -0.605174543 & 0.651247875 & -0.733088239 \\
\hline 8.36 & 10908 & 8.45 & 11121 & 1304.8 & 1316.1 & 655.21282 & -0.010708014 & 0.025918342 & -0.000277534 & -0.003247436 & 0.006909768 & -0.075511802 & 0.07512773 & -0.248990758 \\
\hline 61 & \begin{tabular}{|c|} 
in \\
contro \\
group \\
\end{tabular} & & & & & 3894 & & $\overline{1}$ & -0.007 & -0.03480413 & 0.93 & & 5218 & \\
\hline & & & & & & & & & aging effect & & 0.00584941 & 0.202153214 & control sigma & \\
\hline & & & & & & & & & & & std err $a \theta$ & p. value ae & & \\
\hline & & & & & & & & & & & & & & \\
\hline \begin{tabular}{|l|}
1994 \\
MPG \\
\end{tabular} & $\begin{array}{l}1894 \\
\text { miles } \\
\end{array}$ & $\begin{array}{l}1995 \\
\text { mpg } \\
\end{array}$ & \begin{tabular}{|l|}
1995 \\
miles \\
\end{tabular} & \begin{tabular}{|c|}
994 \\
gal \\
\end{tabular} & $\begin{array}{c}1995 \\
\text { gal }\end{array}$ & gal factor & del log mpg & wolght & torm & sdel & sigma & std resid & & student res \\
\hline \begin{tabular}{|l|}
9.72 \\
\end{tabular} & 1340 & 7.46 & 4500 & 137.9 & 603.2 & 112.2402915 & 0.264630204 & 0.005088992 & 0.001346701 & 0.243129925 & 6.634766093 & 2.339892476 & & 2.345869144 \\
\hline 8.65 & 9250 & 8.32 & 2564 & 1069.4 & 308.2 & 239.2487515 & 0.038897066 & 0.010847574 & 0.000421939 & 0.017396786 & 0.072408199 & 0.24444264 & & 0.245779329 \\
\hline 9.09 & 2463 & 9.01 & 4978 & 271 & 552.5 & 181.8184578 & 0.008839837 & 0.008243676 & 7.28727.E-04 & -0.012660443 & 0.029143102 & -0.155078283 & & .0 .15572147 \\
\hline 10.17 & 12582 & 8.86 & 8673 & 1237.2 & 978.9 & 546.4983891 & 0.137895445 & 0.024778319 & 0.003416817 & $0: 116395166$ & 7.403869794 & 2.471795168 & & 2.502999743 \\
\hline 8.22 & 7206 & 8.41 & 9644 & 876.6 & 1146.7 & 496.8107646 & -0.022851265 & 0.022525475 & -0.000514736 & -0.044351545 & 0.977256337 & -0.898022753 & & .0 .90831109 \\
\hline 8.2 & 8728 & 7.83 & 3792 & 1064.4 & 484.3 & 332.8526635 & 0.046171644 & 0.01509159 & 0.000696804 & 0.024671365 & 0.202599505 & 0.408886039 & & 0.412006777 \\
\hline 8.16 & 7610 & 8.04 & 9001 & 932.6 & 1119.5 & 508.7694069 & 0.014815086 & 0.023067681 & 0.00034175 & -0.006685194 & 0.022737829 & -0.136980136 & & -0.138587913 \\
\hline 8.73 & 6875 & 7.85 & 7007 & 787.5 & 892.6 & 418.3813463 & 0.106251838 & 0.018969473 & 0.002015541 & 0.084751558 & 3.005160685 & 1.574769308 & & 1.589921496 \\
\hline 8.38 & 7807 & 9.69 & 8934 & 931.6 & 922 & 463.3875701 & -0.145246511 & 0.021010062 & -0.003051638 & -0.166746791 & 12.88425614 & -3.260714447 & & -3.295517738 \\
\hline 7.79 & 6135 & 7.73 & 6535 & 787.5 & 845.4 & 407.7117398 & 0.007731997 & 0.018485711 & 0.000142931 & -0.013768282 & 0.07728812 & -0.252545402 & & -0.254912512 \\
\hline 10.56 & 4866 & 10.6 & 2299 & 460.8 & 216.9 & 147.4804781 & -0.003780723 & 0.006686787 & $-2.52809 E-04$ & -0.025281003 & 0.094259063 & -0.27889752 & & -0.279834687 \\
\hline 8.31 & $\longdiv { 3 7 1 2 }$ & 7.84 & 4171 & 446.7 & 532 & 242.8163891 & 0.058220775 & 0.011009332 & 0.000640972 & 0.036720495 & 0.327412342 & 0.519793227 & & 0.522678359 \\
\hline
\end{tabular}




\begin{tabular}{|c|c|c|c|c|c|c|c|c|c|c|c|c|c|}
\hline $\begin{array}{l}1994 \\
\mathrm{MPG}\end{array}$ & \begin{tabular}{|l|}
1994 \\
miles
\end{tabular} & \begin{tabular}{c|}
1995 \\
$\mathrm{mpg}$
\end{tabular} & \begin{tabular}{|l|}
1995 \\
miles
\end{tabular} & $\begin{array}{c}1994 \\
\text { gal }\end{array}$ & $\begin{array}{c}1995 \\
\mathrm{gal}\end{array}$ & gal factor & del $\log \mathrm{mpg}$ & welght & term & sdel & sigma & std resid & student res \\
\hline 8.29 & 2529 & 8.91 & 7393 & 305.1 & 829.7 & 223.0714399 & -0.072124272 & 0.010114093 & -0.000729472 & -0.093624552 & 1.955345363 & -1.270266458 & -1.276739397 \\
\hline 7.69 & 2502 & 7.71 & 8240 & 325.4 & 1068.7 & 249.447658 & -0.002597404 & 0.011309994 & $-2.93766 \mathrm{E}-04$ & -0.024097684 & 0.144853846 & -0.34573879 & .0 .347710685 \\
\hline 7.8 & 6761 & 8.24 & 7288 & 866.8 & 884.5 & 437.7802775 & -0.05487661 & 0.019849023 & -0.001089247 & -0.07637689 & 2.553760302 & -1.451687571 & .1 .46631295 \\
\hline 8.37 & 8999 & 7.84 & 5773 & 1075.1 & 736.4 & 437.0431355 & 0.06541505 & 0.019815601 & 0.001296239 & 0.04391477 & 0.842840775 & 0.833980434 & 0.84236821 \\
\hline 7.76 & 7355 & 7.26 & 9553 & 947.8 & 1315.8 & 550.9432939 & 0.066602505 & 0.024979852 & 0.001663721 & 0.045102226 & 1.120734778 & 0.961688709 & 0.973929952 \\
\hline 8.24 & 8189 & 8.23 & 9104 & 993.8 & 1106.2 & 523.495981 & 0.001214329 & 0.023735386 & 2.88226E-04 & -0.02028595 & 0.215428953 & -0.421633518 & -0.426728211 \\
\hline 7.91 & 6990 & 7.52 & 8267 & 883.7 & 1232.3 & 514.6424905 & 0.050561644 & 0.023333968 & 0.001179804 & 0.029061364 & 0.434647947 & 0.598896685 & 0.606008712 \\
\hline 8.64 & 6599 & 7.71 & 7818 & 763.8 & 1014 & 435.6469794 & 0.113884395 & 0.019752299 & 0.002249479 & 0.092384116 & 3.718170649 & 1.751651687 & 1.769211834 \\
\hline 8.95 & 7680 & 8.13 & 2731 & 858.1 & 335.9 & 241.4035092 & 0.096092609 & 0.010946271 & 0.00105176 & 0.074592329 & 1.34317288 & 1.052807694 & 1.058617059 \\
\hline 8.47 & 5248 & 8.65 & 3873 & 619.6 & 447.7 & 259.9034198 & -0.021028812 & 0.01178406 & -0.000247805 & -0.042529092 & 0.470093465 & -0.622838141 & -0.626540677 \\
\hline 9.16 & 5367 & 8.21 & 6613 & 585.9 & 805.5 & 339.1853169 & 0.109493255 & 0.015378713 & 0.001683865 & 0.087992976 & 2.626231776 & 1.472141713 & 1.483593795 \\
\hline 10.51 & 10325 & 10.33 & 7379 & 982.4 & 714.3 & 413.5842046 & 0.017274902 & 0.01875197 & 0.000323938 & -0.004225378 & 0.007384057 & -0.078060373 & .0 .078802723 \\
\hline 10.47 & 8302 & 10.18 & 5416 & 792.9 & 532 & 318.3808589 & 0.028089014 & 0.014435436 & 0.000405477 & 0.006588734 & 0.013821364 & 0.106796876 & 0.107576153 \\
\hline 10.42 & 8705 & 10.12 & 9932 & 835.4 & 981.4 & 451.2668208 & 0.029213372 & 0.020460505 & 0.00059772 & 0.007713093 & 0.026846676 & 0.148842978 & 0.150389452 \\
\hline 10.55 & 9883 & 10.27 & 10598 & 936.8 & 1031.9 & 491.0265251 & 0.026898836 & 0.022263216 & 0.000598855 & 0.005398556 & 0.014310679 & 0.108670885 & 0.109901148 \\
\hline 10.23 & 8920 & 10.39 & 9049 & 871.9 & 870.9 & 435.6998566 & -0.015619225 & 0.019754697 & -0.000306578 & -0.037019505 & 0.597102139 & -0.701951985 & -0.708989856 \\
\hline 9.48 & 5070 & 9.76 & 8339 & 534.8 & 854.4 & 328.9181687 & -0.029108084 & 0.014913199 & -0.000434095 & -0.050608364 & 0.842427348 & -0.833775868 & -0.840063414 \\
\hline 10.93 & 8798 & 10.7 & 8676 & 804.9 & 810.8 & 403.9196138 & 0.021267561 & 0.018313776 & 0.000389489 & -0.000232719 & 2.18755E-04 & -0.004248761 & .0 .004288209 \\
\hline 10.49 & 9487 & 10.25 & 10598 & 904.4 & 1034 & 482.4337598 & 0.023144717 & 0.021873619 & 0.000506259 & 0.001644437 & 0.001304585 & 0.032810981 & 0.033175825 \\
\hline 10.58 & 6131 & 10.37 & 8638 & 579.5 & 833 & 341.7511504 & 0.020048404 & 0.015495048 & 0.000310651 & -0.001451875 & 0.000720392 & -0.024381895 & -0.024573018 \\
\hline 10.45 & 9950 & 10.14 & 11123 & 952.2 & 1096.9 & 509.7204529 & 0.03011398 & 0.023110802 & 0.000695958 & 0.008613701 & 0.037819136 & 0.176660272 & 0.178737731 \\
\hline 10.6 & 10296 & 10.18 & 10409 & 971.3 & 1022.5 & 498.121301 & 0.04042899 & 0.022584895 & 0.000913084 & 0.01892871 & 0.178474907 & 0.383770577 & 0.388179102 \\
\hline 10.69 & 8584 & 10.68 & 9752 & 803 & 913.1 & 427.2590758 & 0.000935892 & 0.019371991 & 1.81301E-04 & -0.020564388 & 0.180685325 & -0.38613977 & -0.389935151 \\
\hline 12.9 & 9785 & 11.07 & 10082 & 758.5 & 910.7 & 413.8305476 & 0.152988565 & 0.018763139 & 0.002870546 & 0.131488285 & 7.154786311 & 2.429860977 & 2.452982778 \\
\hline 10.73 & 8551 & 10.81 & 7158 & 796.9 & 662.2 & 361.6662189 & -0.007428075 & 0.016398001 & -0.000121806 & -0.028928355 & 0.302660268 & -0.499759201 & -0.503907819 \\
\hline 10.52 & 10004 & 11.01 & 7904 & 951 & 717.9 & 409.0855653 & -0.045525743 & 0.018548001 & -0.000844412 & -0.067026023 & 1.8378119 & -1.231497749 & -1.243080032 \\
\hline 9.23 & 3682 & 10.53 & 2972 & 398.9 & 282.2 & 165.2761415 & -0.131769278 & 0.007493645 & -0.000987432 & -0.153269557 & 3.882593931 & -1.789963101 & -1.796707705 \\
\hline 10.23 & 4905 & 10.72 & 9378 & 479.5 & 874.8 & 309.7294543 & -0.046786576 & 0.01404318 & -0.000657032 & -0.068286855 & 1.44429775 & -1.091720486 & -1.099467794 \\
\hline 10.47 & 5722 & 9.91 & 10671 & 546.5 & 1076.8 & 362.5153699 & 0.054969677 & 0.016436501 & 0.000903509 & 0.033469397 & 0.406089909 & 0.578887526 & 0.583704431 \\
\hline
\end{tabular}




\begin{tabular}{|c|c|c|c|c|c|c|c|c|c|c|c|c|c|c|}
\hline $\begin{array}{c}1994 \\
\text { MPG }\end{array}$ & $\begin{array}{l}1994 \\
\text { miles }\end{array}$ & $\begin{array}{l}1995 \\
\mathrm{mpg}\end{array}$ & \begin{tabular}{l|}
1995 \\
miles
\end{tabular} & $\begin{array}{c}1994 \\
\text { gal }\end{array}$ & $\begin{array}{c}\begin{array}{c}1995 \\
\mathrm{gal}\end{array} \\
\end{array}$ & gal factor & del log $\mathrm{mpg}$ & welght & term & sdel & sigma & std resid & & student res \\
\hline 10.34 & 8895 & 10.36 & 10352 & 860.3 & 999.2 & 462.2811223 & -0.001932368 & 0.020959896 & $-4.05022 E-04$ & -0.023432647 & 0.253833467 & -0.457675362 & & -0.462548516 \\
\hline 11.7 & 11521 & 13.25 & 9733 & 984.7 & 734.6 & 420.7297272 & -0.124408711 & 0.019075949 & -0.002373214 & -0.14590899 & 8.957097527 & -2.718734161 & & -2.745042373 \\
\hline 8.45 & 1840 & 7.04 & 6401 & 217.8 & 909.2 & 175.7087489 & 0.182558271 & 0.007966661 & 0.00145438 & 0.161057992 & 4.557828129 & 1.939376214 & & 1.947147857 \\
\hline 7.51 & 10762 & 7.57 & 6305 & 1433 & 832.9 & 526.7424423 & -0.007957602 & 0.023882581 & -0.000190048 & -0.029457881 & 0.457089589 & -0.614163154 & & -0.621631089 \\
\hline 7.68 & 7897 & 7.38 & 9347 & 1028.3 & 1266.5 & 567.5187162 & 0.039845909 & 0.025731384 & 0.00102529 & 0.018345629 & 0.19100529 & 0.397013972 & & 0.402222568 \\
\hline 9.83 & 6249 & 10.11 & 9070 & 635.7 & 897.1 & 372.0553693 & -0.028086099 & 0.016869046 & -0.000473786 & -0.049586379 & 0.914813067 & -0.868858936 & & -0.876281388 \\
\hline 10.4 & 7312 & 10.35 & 3587 & 703.1 & 346.6 & 232.1562923 & 0.004819286 & 0.010526001 & 5.07278E-04 & -0.016680993 & 0.064598773 & -0.230884739 & & -0.232109564 \\
\hline 10.23 & 1877 & 10.49 & 11124 & 183.5 & 1060.4 & 156.4300989 & -0.025097842 & 0.007092564 & -0.000178008 & -0.046598122 & 0.339669968 & -0.529433805 & & -0.531321373 \\
\hline 12.47 & 1783 & 12.96 & 3572 & 143 & 275.6 & 94.14906832 & -0.038541931 & 0.004268733 & -0.000164525 & -0.060042211 & 0.339413708 & -0.529234054 & & -0.530367263 \\
\hline 10.15 & 1011 & 10.26 & 10935 & 99.6 & 1065.8 & 91.08776386 & -0.010779134 & 0.004129933 & $-4.45171 E-04$ & -0.032279414 & 0.094909858 & -0.279858662 & & -0.280438357 \\
\hline 10.49 & 8819 & 10.25 & 10676 & 840.7 & 1041.6 & 465.2144292 & 0.023144717 & 0.021092892 & 0.000488189 & 0.001644437 & 0.001258021 & 0.032220106 & & 0.032565385 \\
\hline 10.12 & 6112 & 10.1 & 12220 & 604 & 1209.9 & 402.8775566 & 0.00197824 & 0.018266529 & $3.61356 \mathrm{E} \cdot 04$ & -0.01952204 & 0.153540679 & -0.355954773 & & -0.35925103 \\
\hline 10 & 2866 & 9.83 & 10079 & 286.6 & 1025.3 & 223.9888559 & 0.017146159 & 0.010155688 & 0.000174131 & -0.004354121 & 0.004246463 & -0.059196602 & & -0.059499502 \\
\hline 11.05 & 8761 & 10.09 & 9909 & 792.9 & 982.1 & 438.7082197 & 0.090885594 & 0.019891096 & 0.001807814 & 0.069385314 & 2.112082542 & 1.320196375 & & 1.333525635 \\
\hline 10.18 & 2800 & 10.55 & 5819 & 275 & 551.6 & 183.510767 & -0.035700849 & 0.008320406 & -0.000297046 & -0.057201128 & 0.600441559 & -0.703912155 & & -0.706858974 \\
\hline 9.69 & 7153 & 10.3 & 10669 & 738.2 & 1035.8 & 431.0189177 & -0.061049469 & 0.019542462 & -0.001193057 & -0.082549749 & 2.93716163 & -1.556850877 & & -1.572289887 \\
\hline 10.34 & 6500 & 10.2 & 8820 & 628.6 & 864.7 & 363.9927811 & 0.013632149 & 0.016503487 & 0.000224978 & -0.007868131 & 0.022533877 & -0.136364415 & & -0.137503781 \\
\hline 10.3 & 5018 & 10.25 & 11204 & 487.2 & 1093.1 & 336.9982408 & 0.00486619 & 0.015279551 & 7.43532E-04 & -0.01663409 & 0.093245038 & -0.277393293 & & -0.279537115 \\
\hline 10.22 & 4372 & 9.88 & 12885 & 427.8 & 1304.1 & 322.1282869 & 0.033834073 & 0.014605345 & 0.000494158 & 0.012333793 & 0.049002947 & 0.201091721 & & 0.202576513 \\
\hline \multicolumn{2}{|c|}{10.76} & \multicolumn{2}{|c|}{7816} & \multicolumn{2}{|c|}{8.99} & 6189 & 726.4 & 688.4 & 353.4448403 & 0.179722706 & 0.016025242 & 0.0028801 & 0.158222427 & 8.848256986 \\
\hline \multirow{2}{*}{\multicolumn{2}{|c|}{61}} & \multirow{2}{*}{\multicolumn{2}{|c|}{ in test group }} & & & & & & 22055.50709 & & 1 & 0.02150028 & -0.019188762 & 1.24845889 \\
\hline & & & & & & & & & & & & 0.028960858 & & 0.00840651 \\
\hline \multicolumn{2}{|c|}{$\begin{array}{c}\text { NON- } \\
\text { PARAMETRK }\end{array}$} & \multicolumn{2}{|c|}{0.022786847} & \multicolumn{2}{|c|}{0.022529187} & delta & & & & & & & & \\
\hline \multicolumn{2}{|c|}{61} & & & & & & & & & $\begin{array}{l}\text { model with } \\
\text { aging }\end{array}$ & & & 1.106047684 & sigma:no agind \\
\hline \multicolumn{2}{|c|}{945.5} & \multicolumn{2}{|c|}{1891} & & & & & & & CA RFG effect & 0.028960858 & & 0.007447583 & \\
\hline \multicolumn{2}{|c|}{139.2219451} & & & & & & & & & std error & 0.010142939 & & & \\
\hline
\end{tabular}




\begin{tabular}{|c|c|c|c|c|c|c|c|c|c|c|c|}
\hline & & & & beta & & delta & & & & & \\
\hline CONFIDENCE & & 10 index & hl Index & $\begin{array}{l}\text { cont. interval } \\
\text { for rfg effect }\end{array}$ & & $\begin{array}{l}\text { conf. Interval } \\
\text { for ifg effect }\end{array}$ & & $\begin{array}{c}\text { model w/o } \\
\text { aging }\end{array}$ & beta & & \\
\hline 50 & 0.674490366 & 852 & 1040 & 0.018041323 & 0.028021612 & 0.017879553 & 0.027632649 & CA RFG effect & 0.02150028 & CA RFG BTU/g & 110400 \\
\hline 75 & 1.150349362 & 785 & 1107 & 0.01444412 & 0.031723273 & 0.014340305 & 0.031225369 & std error & 0.007447583 & conv BTU/g & 115500 \\
\hline 90 & 1.644853 & 717 & 1175 & 0.009907965 & 0.03636557 & 0.009859043 & 0.035712285 & & & & \\
\hline 95 & 1.959961082 & 673 & $\overline{1219}$ & 0.007731997 & 0.039744168 & 0.007702182 & 0.038964728 & delta & 0.021270796 & 0.045160396 & energy effect \\
\hline 99 & 2.575834515 & 587 & 1305 & 0.002874168 & 0.046750671 & 0.002870041 & 0.045674691 & & & 1 & $p$ value \\
\hline & & & & & & \multirow{9}{*}{\multicolumn{6}{|c|}{. }} \\
\hline & & & & & & & & & & & \\
\hline & & beta & & delta & & & & & & & \\
\hline CONFIDENCE & & $\begin{array}{c}\text { conf. interval } \\
\text { rfg effect }\end{array}$ & & $\begin{array}{c}\text { conf. interval } \\
\text { rfg effect }\end{array}$ & & & & & & & \\
\hline 50 & 0.674490366 & 0.016476957 & 0.026523602 & 0.016341954 & 0.026174941 & & & & & & \\
\hline 75 & 1.150349362 & 0.012932958 & 0.030067602 & 0.012849686 & 0.029620068 & & & & & & \\
\hline 90 & 1.644853 & 0.009250101 & 0.033750458 & 0.009207451 & 0.033187265 & & & & & & \\
\hline 95 & 1.959961082 & 0.006903308 & 0.036097252 & 0.006879535 & 0.035453515 & & & & & & \\
\hline 99 & 2.575834515 & 0.002316539 & 0.04068402 & 0.002313858 & 0.039867535 & & & & & & \\
\hline
\end{tabular}




\section{APPENDIX 2B.}

\section{FUEL ECONOMY ANALYSIS OF SACRAMENTO COUNTY FLEET}

NOTE: all vehicles with ridiculous mpg or less than 1000 miles in either year have been removed

\begin{tabular}{|c|c|c|c|c|c|c|c|c|c|c|c|c|c|c|}
\hline \begin{tabular}{|l|}
1994 \\
$\mathrm{mpg}$
\end{tabular} & \begin{tabular}{|l|l|}
1994 \\
miles \\
\end{tabular} & \begin{tabular}{|c|}
1995 \\
$\mathrm{mpg}$
\end{tabular} & \begin{tabular}{l|l|}
1995 \\
miles
\end{tabular} & $\begin{array}{c}1994 \\
\text { gal }\end{array}$ & $\begin{array}{c}1995 \\
\text { gal } \\
\end{array}$ & or & d & $t$ & term & sdel & sig & std & 0 & student \\
\hline 10.89 & 1139 & 13.63 & 2218 & 104.6 & 162.7 & 63.66786382 & -0.224428309 & 0.011357293 & -0.002548898 & -0.218668622 & 3.044340426 & 1479 & & \\
\hline 9.32 & 1209 & 97 & 854 & 129.7 & 36.3 & 89.26228365 & -0.067417955 & 0.016922914 & -0.00107349 & 0.061658268 & 0.339352179 & 0.451180425 & 0.405713208 & $-0.4933265\}$ \\
\hline 17.59 & 2086 & 17.9 & 914 & 8.6 & 8.7 & 3.8983694 & 0.017470154 & 0.013717396 & -0.000239645 & -0.011710467 & 0.010545461 & -0.079534896 & 0.023469866 & -0.11865341 \\
\hline 39.17 & 1175 & 37.14 & 1170 & 30 & 31.5 & 15.36585366 & 0.053216592 & 0.002741014 & 0.000145867 & 0.058976279 & 0.053445534 & 0.179052603 & 0.043516184 & 0.16156613 \\
\hline .28 & 5569 & 3.44 & 5087 & 453.5 & 378.5 & 206.3097957 & -0.090263412 & 0.036802252 & -0.003321897 & -0.084503726 & 1.473233417 & -0.940071114 & 1.68090568 & 1.00414535 \\
\hline 3.39 & 1516 & .77 & 385 & 5.4 & 8.5 & .83313468 & -0.270692197 & 0.003716286 & -0.00100597 & -0.26493251 & 1.462261788 & -0.936564071 & 1.526532645 & $-0.9569251 k$ \\
\hline 15.97 & 4959 & 16.69 & 3112 & 310.5 & 186.5 & 116.5155936 & -0.044097775 & 0.020784453 & -0.000916548 & -0.03 & 5673 & 143 & 577831 & .0 .36866646 \\
\hline 8.99 & 991 & 9.03 & 4384 & 110.2 & 485.5 & 89.81383247 & -0.004439519 & 0.016021301 & $-7.11269 \mathrm{E}-04$ & 0.001320168 & 0.000156531 & 0.009690043 & 0.00177017 & -0.03258616 \\
\hline 14.15 & 1937 & .15 & 14179 & 6.9 & 1002 & 120.4441127 & 0 & 0.021485236 & 0 & 0.005759687 & 0.003995612 & 0.048957202 & 0 & 0 \\
\hline 11.07 & 1031 & 10.89 & 4599 & 93.1 & 422.3 & 76.28275126 & 1639381 & 0.01360758 & 08 & 3497 & 8851 & 8156 & 0.020501523 & 0.11089653 \\
\hline 15.19 & 5062 & .17 & 1366 & 333.2 & 96.4 & 74.76834264 & 0.069510263 & $0: 013337435$ & 0.000927089 & 0.07526995 & 0.42360493 & 0.504086922 & 0.361256455 & $0.4655139 \varepsilon$ \\
\hline 15.07 & 3708 & 12.99 & 2695 & 246.1 & 207.5 & 112.5788139 & 0.148526182 & 0.020082197 & 0.002982732 & 0.154285869 & 2.679840644 & 1.267883682 & 2.483491644 & 1.22055197 \\
\hline 14.54 & \begin{tabular}{|l|}
2346 \\
\end{tabular} & 14.85 & 1970 & 161.3 & 132.7 & 72.80445578 & -0.021096393 & \begin{tabular}{|l|}
0.01298711 \\
\end{tabular} & -0.000 & 36706 & 0.017124668 & \begin{tabular}{|l|}
0.10135286 \\
\end{tabular} & 0.032402191 & $0.1394158 i$ \\
\hline 6.57 & 2193 & 8.48 & 1070 & 333.8 & 126.2 & 91.57730435 & -0.265196617 & 0.016335875 & -0.00416886 & -0.24943693 & 5.697828361 & -1.848756053 & 5.964000654 & $-1.8914452 i$ \\
\hline 21.36 & 1038 & 29.22 & 021 & 48.6 & 137.6 & 35.91493018 & -0.31 .3333392 & 0.006406629 & -0.002007411 & -0.307573705 & 3.397609293 & -1.427616785 & 3.52604936 & 1.4543506 \\
\hline 6.54 & 2989 & 7.44 & 6016 & 457 & 808.6 & 291.9802465 & -0.128933683 & 0.052084443 & -0.006715439 & -0.123173997 & 4.429875663 & -1.630124204 & 4.853848875 & -1.70634974 \\
\hline 8.63 & 2975 & 8.92 & 1481 & 344.7 & 167.2 & 112.5880836 & -0.033051441 & 0.02008385 & -0.0006638 & -0.027291755 & 0.083860094 & -0.224286224 & 0.122990973 & $-0.2716198 i$ \\
\hline 5.59 & 3435 & 5.82 & 2977 & 614.5 & 511.5 & 279.1445382 & -0.040320975 & 0.049794765 & -0.002007773 & .0 .034561288 & 0.333433297 & -0.447228437 & 0.453827884 & -0.52175968 \\
\hline 10.54 & 3696 & 8.29 & 4127 & 350.7 & 497.8 & 205.7495109 & 0.240127574 & 0.036702307 & 0.008813236 & 0.245887261 & 12.43972757 & 2.731683392 & 11.86377435 & 2.66769617 \\
\hline 10.2 & 1769 & 8.05 & 1004 & 173.4 & 124.7 & 72.53599463 & 0.236715629 & 0.012939221 & 0.003062916 & 0.242475316 & 4.264701486 & 1.599444763 & 4.064502882 & 1.56145202 \\
\hline 20.02 & 1790 & 19.09 & 1277 & 89.4 & 66.9 & 38.26525912 & 0.047567136 & 0.006825889 & 0.000324688 & 0.053326823 & 0.108816833 & 0.255489448 & 0.086580217 & 0.22789471 \\
\hline 14.98 & 4356 & 17.21 & 3403 & 290.8 & 197.7 & 117.6891709 & -0.138774632 & 0.0209938 & -0.002913407 & -0.133014945 & 2.082271638 & -1.117618596 & 2.266504956 & $-1.1660126 !$ \\
\hline 20.36 & 1452 & 18.8 & 2831 & 71.3 & 150.6 & 7575 & 0.079715322 & 0.008632006 & 0.000688103 & 0.085475009 & 0.353537516 & 0.460513834 & 0.307496946 & 0.42948231 \\
\hline 13.5 & 1266 & 13.16 & 5336 & 93.8 & 405.5 & 76.17844983 & 776 & 0.013588974 & 0.000346624 & 0.031267446 & 0.074476106 & 0.211365162 & 0.049565188 & $0.1724301 !$ \\
\hline
\end{tabular}




\begin{tabular}{|c|c|c|c|c|c|c|c|c|c|c|c|c|c|c|}
\hline \begin{tabular}{|l|}
1994 \\
$\mathrm{mpg}$ \\
\end{tabular} & \begin{tabular}{|l|}
1994 \\
miles \\
\end{tabular} & \begin{tabular}{|c|}
1995 \\
$\mathrm{mpg}$ \\
\end{tabular} & \begin{tabular}{|l|}
1995 \\
miles \\
\end{tabular} & $\begin{array}{c}1994 \\
\mathrm{gal} \\
\end{array}$ & $\begin{array}{c}1995 \\
\mathrm{gal}\end{array}$ & al factor & $\mathrm{mpg}$ & t & $\bar{n}$ & sdel & sigma & |al & $9 \mathrm{maO}$ & iudent \\
\hline 25.35 & 1402 & 21.63 & 1192 & 55.3 & 55.1 & 27.59990942 & 0.15869749 & 0.004923367 & 0.000781326 & 0.164457177 & 0.74647165 & 0.669162487 & 0.695100775 & $0.6457268 \mathrm{C}$ \\
\hline \begin{tabular}{|l|}
23.57 \\
\end{tabular} & 4188 & .28 & 2044 & 177.7 & 69.8 & 50.1149899 & -0.216929972 & 0.008939685 & -0.001939286 & 0.211170285 & 2.234772202 & -1.157821361 & 2.358341906 & -1.1894010 \\
\hline 10.41 & \begin{tabular}{|l|}
1856 \\
\end{tabular} & 10.59 & 3877 & 178.3 & 366.1 & 119.9038024 & -0.017143277 & 0.021388854 & -0.000366675 & -0.01138359 & 0.015537869 & -0.09654297 & 0.035238762 & -0.1453902 \\
\hline 6.23 & 1085 & 6.35 & 3579 & 174.2 & 563.6 & 133.0701003 & $=0.01907848$ & 0.023737503 & -0.000452875 & 0.013318793 & 0.023605339 & -0.118995366 & 0.048435973 & $-0.1704546 \varepsilon$ \\
\hline 7.06 & 1533 & 6.94 & 2759 & 217.1 & 397.6 & 140.4245323 & 0.017143277 & 0.025049412 & 0.000429429 & 0.022902964 & 0.073659092 & 0.210202612 & 0.041269639 & $0.1573404 \mathrm{C}$ \\
\hline \begin{tabular}{|l|}
6.72 \\
\end{tabular} & 1892 & 5.93 & 2278 & 281.5 & 384.1 & 162.4461388 & 0.125063942 & 0.028977702 & 0.003624066 & 0.130823628 & 2.780236708 & 1.291414963 & 2.540818347 & 1.23455867 \\
\hline 31.65 & 3276 & 24.03 & 3170 & 103.5 & 131.9 & 57.99341546 & 0.275435099 & 0.010345065 & 0.002849394 & 0.281194786 & 4.585568792 & 1.658523136 & 4.399641101 & 1.62455175 \\
\hline \begin{tabular}{|l|}
22.24 \\
\end{tabular} & 3154 & 22.26 & 1505 & 141.8 & 67.6 & 45.77688634 & -0.000898876 & 0.008165839 & $-7.34008 \mathrm{E}-05$ & 86081 & 0.001081592 & 0.02547163 & $3.69868 E-04$ & -0.00471025 \\
\hline 13.8 & 4513 & 13.59 & 15163 & 327 & 1115.7 & 252.8827199 & 0.015334364 & 0.045110091 & 0.000691735 & 0.021094051 & 0.112522437 & 0.259803198 & 0.05946353 & 0.18886447 \\
\hline \begin{tabular}{|l|}
9.82 \\
\end{tabular} & 2594 & 9.42 & 3790 & 264.2 & 402.3 & 159.4713578 & 0.041586034 & 0.02844705 & 0.001183 & 0.047345721 & 0.357473748 & 0.463070382 & \begin{tabular}{|l|}
0.27578948 \\
\end{tabular} & 0.40673708 \\
\hline \begin{tabular}{|l|}
6.42 \\
\end{tabular} & 5606 & 6.66 & \begin{tabular}{|l|}
7677 \\
\end{tabular} & 873.2 & 1152.7 & 496.8348092 & -0.036701367 & 0.088627106 & -0.003252736 & -0.03094168 & 0.475663467 & -0.534164259 & 0.669231683 & -0.6335970 \\
\hline 42.54 & 3450 & 30.02 & 4005 & 81.1 & 133.4 & 50.43701632 & 0.348580984 & 0.008997129 & 0.003136228 & 0.35434067 & 6.332736129 & 1.949039424 & 6.128536391 & $1.9173584 E$ \\
\hline 28.17 & 3141 & 34.66 & 2769 & 111.5 & 79.9 & 46.54571578 & -0.207328702 & 0.008302985 & -0.001721447 & -0.201569016 & 1.891155599 & -1.065095523 & 2.000776475 & -1.09552986 \\
\hline 5.1 & 1715 & 5.65 & 2411 & 336.3 & 426.7 & 188.0723591 & -0.102415005 & 0.033548996 & -0.003435921 & -0.096655319 & 1.757019112 & -1.026628155 & \begin{tabular}{|c|}
1.97265963 \\
\end{tabular} & -1.08780488 \\
\hline 23.22 & 973 & 29.35 & 2694 & 41.9 & 91.8 & 28.76903515 & -0.23427857 & 0.00513192 & -0.001202299 & -0.228518883 & 1.502344331 & -0.949313526 & 1.579030162 & $-0.9732404 i$ \\
\hline 26.64 & \begin{tabular}{|l|}
1649 \\
\end{tabular} & 23.91 & 1977 & 61.9 & 82.7 & 35.40200553 & 0.108117064 & 0.006315132 & 0.000682774 & 0.113876751 & 0.459090178 & 0.524775956 & 0.413824648 & $0.4982337 \mathrm{C}$ \\
\hline 36.47 & \begin{tabular}{|l|}
1138 \\
\end{tabular} & 44 & \begin{tabular}{|l|}
254 \\
\end{tabular} & 31.2 & 28.5 & 14.89447236 & -0.187699629 & 0.002656927 & -0.000498704 & -0.181939942 & 0.493038948 & 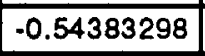 & 0.524749401 & -0.56104911 \\
\hline 8.69 & 1511 & 8.82 & 2288 & 173.9 & 259.4 & 104.1072236 & -0.014848931 & 0.018571005 & -0.00027576 & -0.009089244 & 0.008600751 & -0.071827891 & 0.022954679 & -0.11734396 \\
\hline 10.05 & 5045 & 9.72 & 4569 & 502 & 470.1 & 242.763296 & 0.033387016 & 0.043304953 & 0.001445823 & 0.039146703 & 0.372026095 & 0.472401894 & 0.270606508 & 0.40289701 \\
\hline \begin{tabular}{|l|}
9.07 \\
\end{tabular} & 3396 & 8.8 & 2120 & 374.4 & 240.9 & 146.5837153 & 0.030220543 & 0.026148108 & 0.00079021 & 0.035980229 & 0.189763894 & 0.337389621 & 0.133872151 & 0.28338055 \\
\hline 24.48 & 7497 & 24.08 & 6615 & 306.3 & 274.7 & 144.820327 & 0.016474837 & 0.025833549 & 0.000425604 & 0.022234524 & 0.071595413 & 0.20723711 & 0.039307171 & 0.15355388 \\
\hline \begin{tabular}{|l|}
22.52 \\
\end{tabular} & 1518 & 21.97 & 1672 & 67.4 & 76.1 & 35.74313589 & 0.024725917 & 0.006375984 & 0.000157652 & 0.030485604 & 0.033218671 & 0.141161431 & 0.021852315 & $0.1144916 \mathrm{C}$ \\
\hline 26.85 & 3855 & 22.88 & 556 & 143.6 & 24.3 & 20.78308517 & 0.160002654 & 0.003707358 & 0.000593187 & 0.165762341 & 0.571060027 & 0.585282863 & 0.532064634 & 0.56494624 \\
\hline \begin{tabular}{|l|}
19.88 \\
\end{tabular} & 7077 & 19.37 & 2632 & 356 & 135.9 & 98.35413702 & 0.025988724 & 0.01754475 & 0.000455966 & 0.031748411 & 0.099137191 & 0.243861495 & 0.066429738 & 0.19962098 \\
\hline 12.94 & 6748 & 13.3 & 6869 & 521.5 & 516.5 & 259.4939788 & -0.027440746 & 0.04628943 & -0.001270217 & -0.021681059 & 0.121979902 & -0.27050112 & 0.195397552 & $-0.3423611 !$ \\
\hline 51.95 & 4151 & 39.38 & 2721 & 79.9 & 69.1 & 37.0542953 & 0.277023644 & 0.006609873 & 0.001831091 & 0.282783331 & 2.963099059 & 1.333208313 & 2.843624418 & 1.30605373 \\
\hline & & & & & & & & & & & & & & \\
\hline 50 & $\begin{array}{l}\text { in } \\
\text { ontrol }\end{array}$ & & & & & 7 & & 1 & 8 & 84 & 121 & & & r \\
\hline
\end{tabular}




\begin{tabular}{|c|c|c|c|c|c|c|c|c|c|c|c|c|c|c|}
\hline & group & & & & & & & & & & & & & \\
\hline & & & & & & & & & aging effect & $S E$ of $a \theta->$ & 0.015944119 & 0.717918599 & $\begin{array}{c}<-p \text { value of } \\
2 \theta\end{array}$ & \\
\hline & & & & & & & & & & & & & & \\
\hline $\begin{array}{l}1994 \\
\text { mpg }\end{array}$ & \begin{tabular}{|l|}
1994 \\
miles \\
\end{tabular} & \begin{tabular}{|c|}
1995 \\
$\mathrm{mpg}$
\end{tabular} & \begin{tabular}{|l|}
1995 \\
miles \\
\end{tabular} & $994 \mathrm{gal}$ & $\begin{array}{c}1995 \\
\text { gal }\end{array}$ & gal factor & dell & weight & term & sdel & sigma & idual & & $\overrightarrow{\text { tudent res }}$ \\
\hline 5.05 & \begin{tabular}{|l|}
1805 \\
\end{tabular} & 5.79 & 2032 & 357.4 & 350.9 & 177.0600875 & -0.136744048 & 0.026422218 & -0.003613081 & -0.174936198 & 5.418512015 & -1.802872225 & & $-1.8271727 \S$ \\
\hline 7.93 & 2606 & 7.74 & 2550 & 328.6 & 329.5 & 164.5246923 & 0.024251348 & 0.024551594 & 0.000595409 & -0.013940801 & 0.031974707 & -0.138493125 & & -0.14022516 \\
\hline 17.4 & 2748 & 18.37 & 3537 & 157.9 & 192.5 & 86.74586187 & -0.054248693 & 0.01294486 & -0.000702242 & -0.092440843 & 0.741270226 & -0.666827046 & & -0.67118535 \\
\hline 22.38 & 1978 & 22.77 & 1029 & 88.4 & 45.2 & 29.90778443 & -0.017276177 & 0.004463061 & $-7.71046 \mathrm{E}-04$ & -0.055468327 & 0.092018335 & -0.234942786 & & -0.2354688 \\
\hline 6.23 & 2547 & 5.69 & 2038 & 408.8 & 358.2 & 190.9154628 & 0.090666085 & 0.02848982 & 0.00258306 & 0.052473935 & 0.525688374 & 0.561550882 & & $0.5697252 \mathrm{C}$ \\
\hline 4.36 & 1299 & 5.78 & 1318 & 297.9 & 228 & 129.1523103 & -0.281931625 & 0.019273065 & -0.005433686 & -0.320123775 & 13.23542947 & -2.817694775 & & $-2.8452464 \varepsilon$ \\
\hline 22.95 & 1889 & 23.96 & 2348 & 82.3 & 98 & 44.73322241 & -0.043067837 & 0.006675423 & -0.000287496 & -0.081259986 & 0.29538176 & -0.420936673 & & -0.42234871 \\
\hline 12.62 & 5795 & 12.66 & 2999 & 459.2 & 236.9 & 156.2770866 & -0.00316456 & 0.023320826 & $-7.38001 E-04$ & -0.041356709 & 0.267292796 & -0.400422575 & & -0.40517496 \\
\hline 5.32 & \begin{tabular}{|l|}
2941 \\
\end{tabular} & 4.94 & 2929 & 552.8 & 592.9 & 286.0741206 & 0.074107972 & 0.0426901 & 0.003163677 & 0.035915823 & 0.369020258 & 0.470489604 & & 0.48086565 \\
\hline 6.17 & 1950 & 6.62 & 2480 & 316 & 374.6 & 171.4068926 & $-0,070396532$ & 0.025578607 & -0.001800645 & -0.108588682 & 2.021144676 & -1.101092054 & & $-1.1154502 \varsigma$ \\
\hline 9.58 & \begin{tabular}{|l|}
496 \\
\end{tabular} & 9.29 & 1261 & 156.2 & 135.7 & 72.61507366 & 0.030739039 & 0.010836159 & 0.000333093 & .0 .00745311 & 0.004033684 & -0.049189892 & & $-0.0494585 !$ \\
\hline 6.63 & 4805 & 6.73 & 4633 & 724.7 & 688.4 & 353.0418796 & -0.014970339 & 0.052683525 & -0.00078869 & -0.053162489 & 0.997784695 & -0.773647892 & & .0 .79486944 \\
\hline 17.37 & 2828 & 18.71 & 5433 & 162.8 & 290.4 & 104.3184466 & -0.07431356 & 0.015567172 & -0.001156852 & -0.11250571 & 1.320414356 & -0.889979589 & & $-0.8969887 \xi$ \\
\hline 11.65 & 6160 & 11.87 & 3030 & 528.8 & 255.3 & 172.1752838 & -0.018708029 & 0.025693272 & -0.00048067 & -0.056900178 & 0.557439911 & -0.578261073 & & $-0.5858360 \epsilon$ \\
\hline 23.41 & 1948 & 20.92 & 4683 & 83.2 & 223.9 & 60.65932921 & 0.112457642 & 0.009052035 & 0.00101797 & 0.074265493 & 0.334558245 & 0.447982239 & & 0.45002368 \\
\hline 10.84 & 2609 & 7.94 & 3663 & 240.7 & 461.3 & 158.1693875 & 0.311329721 & 0.023603208 & 0.00734838 & 0.273137571 & 11.80008999 & 2.660526489 & & $2.6924919 \varepsilon$ \\
\hline 48.86 & 1461 & 50.71 & 1937 & 29.9 & 38.2 & 16.77209985 & -0.037164064 & 0.002502857 & $-9.30163 \mathrm{E}-04$ & -0.075356214 & 0.095241357 & -0.239021912 & & $-0.2393215 !$ \\
\hline 5.49 & 2398 & 6.81 & 1401 & 436.8 & 205.7 & 139.8439844 & -0.215463865 & 0.020868556 & -0.00449642 & -0.253656014 & 8.997754038 & -2.323228818 & & -2.34785616 \\
\hline 5.32 & 3121 & 6.07 & 2446 & 586.7 & 403 & 238.900778 & -0.131885302 & 0.035650544 & -0.004701783 & -0.170077451 & 6.910524994 & -2.03601254 & & 2.07330516 \\
\hline 24.62 & 1891 & 20.32 & 5760 & 76.8 & 283.5 & 60.42964197 & 0.191953498 & 0.009017759 & 0.00173099 & 0.153761349 & 1.42871097 & 0.92575724 & & 0.92995981 \\
\hline 28.94 & 4110 & 22.05 & 5150 & 142 & 233.6 & 88.31522897 & 0.271912119 & 0.013179053 & 0.003583544 & 0.23371997 & 4.824221526 & 1.701134094 & & $1.7124557 \mathrm{~g}$ \\
\hline 25.31 & 3462 & 21.34 & 4280 & 136.8 & 200.6 & 81.33396562 & 0.170616329 & 0.012137257 & 0.002070814 & 0.132424179 & 1.426285697 & 0.924971158 & & 0.93063608 \\
\hline 26.14 & 1085 & 17.73 & 1574 & 41.5 & 88.8 & 28.28242517 & 0.388208588 & 0.004220513 & 0.001638439 & 0.350016439 & 3.464922537 & 1.441689358 & & $1.4447413 E$ \\
\hline 27.46 & 1700 & 24.39 & 2688 & 61.9 & 110.2 & 39.63614178 & 0.118557188 & 0.005914799 & 0.000701242 & 0.080365039 & 0.255991584 & 0.39186617 & & 0.39303024 \\
\hline 35.76 & 3508 & 26.94 & 4637 & 98.1 & 172.1 & 62.48338268 & 0.283217779 & 0.009324233 & 0.002640789 & 0.24502563 & 3.75134979 & 1.500094809 & & 1.50713771 \\
\hline
\end{tabular}




\begin{tabular}{|c|c|c|c|c|c|c|c|c|c|c|c|c|c|}
\hline $\begin{array}{l}1994 \\
\text { mpg }\end{array}$ & \begin{tabular}{|l|}
1994 \\
miles
\end{tabular} & $\begin{array}{c}1995 \\
\mathrm{mpg}\end{array}$ & $\begin{array}{l}1995 \\
\text { miles }\end{array}$ & $1994 \mathrm{gal}$ & $\begin{array}{c}1995 \\
\text { gal }\end{array}$ & gal factor & del log $\mathrm{mpg}$ & weight & term & sdel & sigma & std residual & $\overline{e r}$ \\
\hline 18.44 & 1800 & 18.4 & 3000 & 97.6 & 163 & 61.04681504 & 0.002171554 & 0.009109858 & $1.97825 E-04$ & -0.036020596 & 0.079207225 & -0.217975322 & -0.211 \\
\hline 25.38 & 4302 & 24.54 & $\longdiv { 3 7 1 0 }$ & 169.5 & 151.2 & 79.91393826 & 0.033657023 & 0.01192535 & 0.000401372 & -0.004535127 & 0.00164362 & -0.031399708 & .0 .031 \\
\hline 12.21 & 5821 & 11.87 & 1812 & 476.7 & 152.7 & 115.6531459 & 0.02824108 & 0.017258619 & 0.000487402 & -0.00995107 & 0.011452413 & -0.082884522 & $\overline{.083}$ \\
\hline 12.16 & 1808 & 11.47 & 1004 & 148.7 & 87.5 & 55.08573243 & 0.058416945 & 0.008220301 & 0.000480205 & 0.020224796 & 0.022532398 & 0.11625955 & 0.116 \\
\hline 20.25 & 1296 & 17.84 & 1358 & 64 & 76.1 & 34.76374019 & 0.126711666 & 0.005187703 & 0.000657342 & 0.088519517 & 0.272398408 & 0.404228761 & 0.405 \\
\hline 7.84 & 5969 & 7.39 & 5514 & 761.4 & 746.1 & 376.8361791 & 0.059111099 & 0.056234287 & 0.003324071 & 0.02091895 & 0.16490444 & 0.314514811 & 0.323 \\
\hline 25.66 & 4541 & 23.97 & 5571 & 177 & 232.4 & 100.4758183 & 0.068130311 & 0.014993746 & 0.001021529 & 0.029938161 & 0.090055822 & 0.232423922 & 0.234 \\
\hline 32.66 & 993 & 23.5 & 3464 & 30.4 & 147.4 & 25.20224972 & 0.329150666 & 0.003760866 & 0.001237892 & 0.290958517 & 2.133543289 & 1.131294452 & 1.133 \\
\hline 11.1 & 1801 & 8.14 & 7418 & 162.3 & \begin{tabular}{|l|}
911.3 \\
\end{tabular} & 137.7645212 & 0.310154928 & 0.020558243 & 0.00637624 & 0.271962779 & 10.18958103 & 2.472310943 & 2.498 \\
\hline 7.42 & 3837 & 6.97 & 3432 & 517.1 & 492.4 & 252.2239128 & 0.062563832 & 0.037638721 & 0.002354823 & 0.024371683 & 0.149815689 & 0.299780635 & 0.305 \\
\hline 19.59 & 3303 & 20.12 & 1320 & 168.6 & 65.6 & 47.22527754 & -0.026695113 & 0.007047306 & -0.000188129 & -0.064887263 & 0.198835272 & -0.345359687 & -0.346 \\
\hline 19.92 & 2637 & 18.8 & 3875 & 132.4 & 206.1 & 80.61341211 & 0.057867382 & 0.012029731 & 0.000696129 & 0.019675233 & 0.031206644 & 0.136819645 & 0.137 \\
\hline 14.62 & 1295 & 16.37 & 4366 & 88.6 & 266.7 & 66.50610751 & -0.113059937 & 0,009924534 & -0.001122067 & -0.151252087 & 1.521473104 & -0.955338032 & -0.960 \\
\hline 18.22 & 3568 & 17.58 & 2595 & 195.8 & 147.6 & 84.15864881 & 0.035758 & 0.012558777 & 0.000449077 & -0.00243415 & 0.000498647 & -0.017295043 & 0.017 \\
\hline 12.73 & 5392 & 13.15 & 5110 & 423.6 & 388.6 & 202.6729377 & -0.032460346 & 0.030244357 & -0.000981742 & -0.070652496 & 1.011697731 & -0.779023064 & .0 .791 \\
\hline 26.6 & 1524 & 21.21 & 2609 & 57.3 & 123 & 39.08985025 & 0.226438447 & 0.005833277 & 0.001320878 & 0.188246298 & 1.385214068 & 0.911556043 & 0.914 \\
\hline 21.21 & 3166 & 19.06 & 3899 & 149.3 & 204.6 & 86.31472167 & 0.10688087 & 0.012880522 & 0.001376681 & 0.068688721 & 0.407244973 & 0.49425696 & 0.497 \\
\hline 22.05 & 3180 & 21.08 & 3250 & 144.2 & \begin{tabular}{|l|}
154.2 \\
\end{tabular} & 74.51621984 & 0.044987878 & 0.011119862 & 0.000500259 & 0.006795729 & 0.003441303 & 0.045434564 & 0.045 \\
\hline 21.91 & 3727 & 21.62 & 4438 & 170.1 & 205.3 & 93.02485349 & 0.013324341 & 0.013881858 & 0.000184967 & -0.024867808 & 0.057527303 & -0.185764162 & -0.187 \\
\hline 22.1 & 1452 & 20.86 & 2951 & 65.7 & 141.5 & 44.86751931 & 0.057744159 & 0.006695464 & 0.000386624 & 0.019552009 & 0.017152003 & 0.10143372 & 0.101 \\
\hline 29.74 & 4940 & 20.43 & 7090 & 166.1 & 347 & 112.330345 & 0.375488532 & 0.016762766 & 0.006294227 & 0.337296383 & 12.77969414 & 2.768759014 & 2.792 \\
\hline 22.65 & 2969 & 22.52 & 1736 & 131.1 & 77.1 & 48.54855908 & 0.005756049 & 0.007244776 & 4.17013E-04 & -0.032436101 & 0.05107797 & -0.175041789 & .0 .175 \\
\hline 13.04 & 1549 & 13.88 & 2094 & 118.8 & 150.9 & 66.46985539 & -0.062427399 & 0.009919124 & -0.000619225 & -0.100619548 & 0.672960322 & -0.635359689 & -0.638 \\
\hline 17.53 & 8955 & 17.27 & 3491 & 510.8 & 202.1 & 144.806677 & 0.014942807 & 0.021609125 & 0.000322901 & -0.023249343 & 0.078272634 & -0.216685525 & .0 .219 \\
\hline 19.38 & 1572 & 18.28 & 4086 & 81.1 & 223.5 & 59.50705844 & 0.05843404 & 0.008880084 & 0.000518899 & 0.020241891 & 0.024382074 & 0.120937295 & 0.121 \\
\hline 19.77 & 1054 & 19.07 & 8398 & 53.3 & 440.4 & 47.54571602 & 0.036049218 & 0.007095124 & 0.000255774 & -0.002142932 & 0.000218337 & 0.011444294 & -0.011 \\
\hline 19.33 & 7417 & 18.79 & 7795 & 383.7 & \begin{tabular}{|l|}
414.8 \\
\end{tabular} & 199.3221791 & 0.02833348 & 0.029744332 & 0.00084276 & -0.00985867 & 0.019372794 & -0.10780057 & .0 .109 \\
\hline 13.19 & 5366 & 14.43 & 1772 & 406.8 & 122.8 & 94.32598187 & -0.089850406 & 0.014076022 & -0.001264736 & -0.128042556 & 1.546464667 & -0.963152217 & -0.970 \\
\hline 15.74 & 8642 & 14.21 & 4307 & 549 & 303.1 & 195.2844737 & 0.102259301 & 0.029141796 & 0.00298002 & 0.064067151 & 0.801564627 & 0.693416545 & 0.703 \\
\hline
\end{tabular}




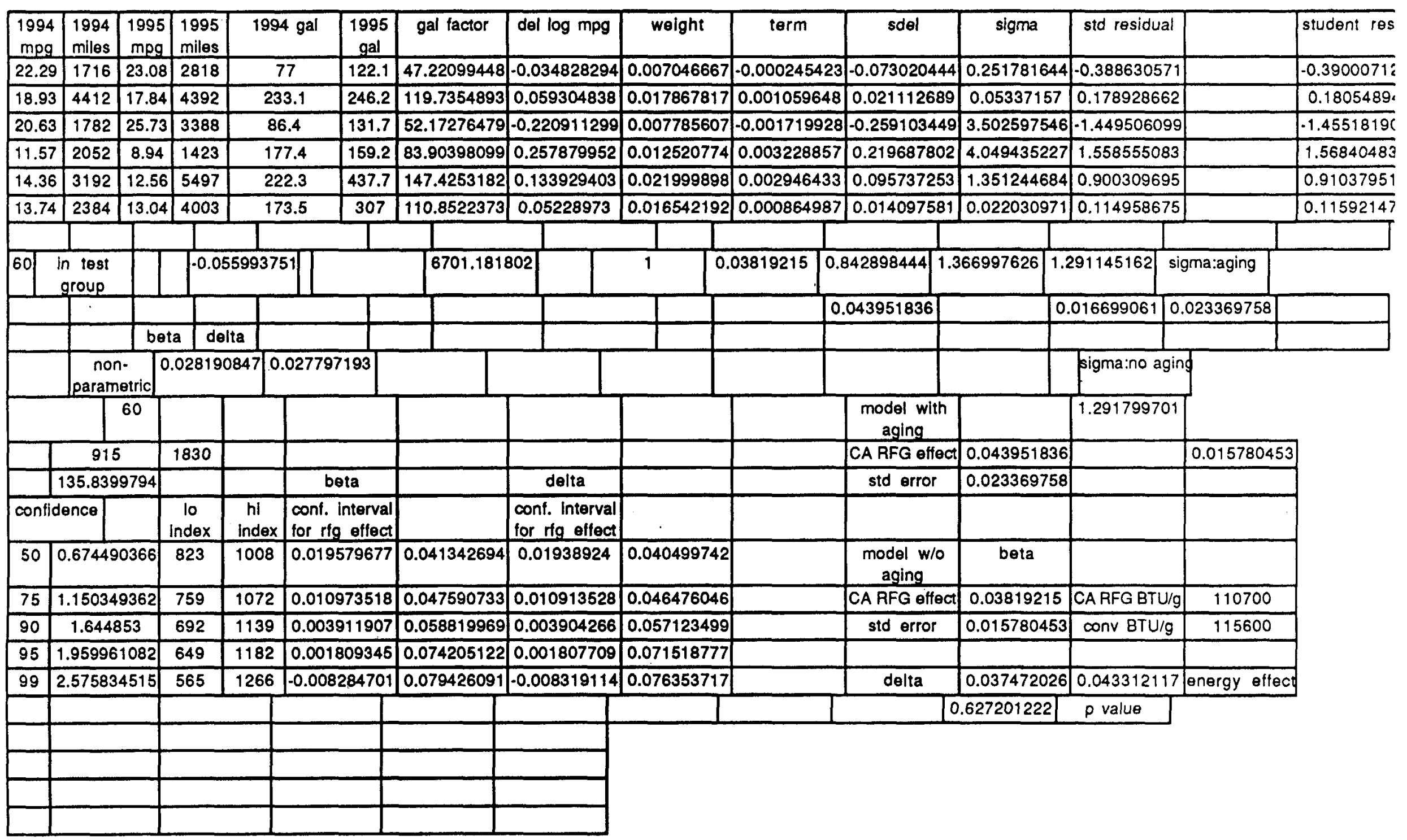




\begin{tabular}{|c|c|c|c|c|c|}
\hline & & beta & & delta & \\
\hline \multicolumn{2}{|c|}{ confidence } & $\begin{array}{c}\text { conf. Interval } \\
\text { for rfg effect }\end{array}$ & & $\begin{array}{c}\text { conf. Interval } \\
\text { for rfg effect }\end{array}$ & \\
\hline 50 & 0.674490366 & 0.027548386 & 0.048835913 & 0.02717239 & 0.047662617 \\
\hline 75 & 1.150349362 & 0.020039115 & 0.056345184 & 0.019839666 & 0.054787193 \\
\hline 90 & 1.644853 & 0.012235623 & 0.064148676 & 0.012161072 & 0.062134449 \\
\hline 95 & 1.959961082 & 0.007263075 & 0.069121224 & 0.007236762 & 0.066786455 \\
\hline 99 & 2.575834515 & -0.002455687 & 0.078839986 & -0.002458705 & 0.075812205 \\
\hline
\end{tabular}


APPENDIX 2C.

FUEL ECONOMY ANALYSIS OF AUTO OIL FLEET

NORMAL MODEL

\begin{tabular}{|c|c|c|c|c|c|c|c|c|c|c|c|}
\hline $\begin{array}{l}\text { idustry } \\
\text { mpg }\end{array}$ & miles & $\begin{array}{l}\mathrm{ig} \\
\mathrm{los}\end{array}$ & $\begin{array}{c}\text { ifg } \\
\text { miles }\end{array}$ & $\begin{array}{c}\text { mile } \\
\text { factor }\end{array}$ & 9 & woight & n & 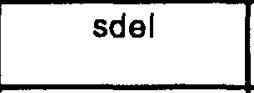 & a & std & stuo \\
\hline 22.64 & $22.19 \AA$ & 22.30 & 22.199 & 11.098 & -0.014247792 & 3125 & 45244 & 17765 & 69746 & $199 \mathrm{~g}$ & 6697 \\
\hline 16 & 96 & & & 98 & 88 & 125 & 781 & 431 & 091 & & 628 \\
\hline $21.4 \mathrm{~d}$ & $22.19 \mathrm{q}$ & 20.52 & 22.199 & $11.09 \mathrm{~g}$ & -0.041 & 125 & 2216 & 5345 & 5504 & 24 द & 7187 \\
\hline 21.54 & $9 \notin$ & 04 & & 11.098 & 284 & 125 & 3946 & 273 & 956 & $53 \pi$ & 9614 \\
\hline 11 & & 18.73 & & 11 & 242 & & 664 & 315 & 054 & 196 & 079 \\
\hline 19.73 & $22.19 \notin$ & 19.26 & 22 & 11.099 & 914 & 125 & 435 & 643 & $36 q$ & 029 & 7704 \\
\hline .00 & & 14.63 & & & & & & & 여 & & 530 \\
\hline 20.27 & $22.19 \AA$ & 19.39 & $22.19 q$ & 11.098 & -0.0 & 25 & 015 & 34 & & $02 €$ & 5039 \\
\hline 15.26 & & & & & & & & & & & 974 \\
\hline .07 & $22.19 q$ & 24.81 & 22. & 11.098 & & 25 & $07 €$ & 373 & & & -1 \\
\hline 22.51 & & 39 & & & & & & & & & 869 \\
\hline $19.5 d$ & 22.196 & 19.46 & & 11 & -0. & 25 & -04 & 68 & 303 & 377 & 5157 \\
\hline 77 & $\theta$ & 2 & & 99 & & & 214 & $5 g$ & 389 & 728 & 84 \\
\hline 20.72 & $22.19 \notin$ & 19.95 & 22 & 11 & 74 & 25 & 446 & 717 & 19 & 354 & 2088 \\
\hline 29.57 & 22.199 & 28.34 & 22 & 198 & & 25 & & 43 & & 55 & 29 \\
\hline 26.23 & $22.19 \mathrm{q}$ & 25.32 & & 11.098 & -0.03 & 125 & .0 .00 & 364 & 38 & 160 & 3148 \\
\hline .51 & & .04 & & & & & 399 & & 275 & 335 & 753 \\
\hline 26.63 & $22.19 \mathrm{q}$ & 27.39 & 22. & 11. & & 25 & & & $44 \mathrm{~g}$ & 867 & 3398 \\
\hline .84 & 99 & $21.4 \mathrm{~d}$ & & $9 q$ & 229 & 25 & 007 & $2 q$ & 34 & $37 q$ & 985 \\
\hline 26.19 & 22.199 & 25.37 & & & & & -0.001055721 & -0.004617504 & 624 & 797 & 409 \\
\hline 13 & 96 & 20.33 & 22 & 11. & 204 & & -0 & -0.0 & 024 & 112 & $14 \mathrm{~d}$ \\
\hline 93 & $9 q$ & $27.4 \mathrm{~A}$ & & 11.098 & $-0.05214871 \mathrm{~g}$ & 125 & -0.001629647 & -0.022983162 & 249 & -1.1 & 0637 \\
\hline 22.24 & 22.199 & 21.35 & $22.19 \mathrm{q}$ & 11.098 & $-0.0408407 \mathrm{~g}$ & 0.03125 & 0.001276273 & -0.011675173 & 0.001512765 & -0.57494 & -0.58414092 \\
\hline
\end{tabular}




\begin{tabular}{|c|c|c|c|c|c|c|c|c|c|c|c|}
\hline \begin{tabular}{|c|} 
industry \\
mpg
\end{tabular} & \begin{tabular}{|c|} 
industry \\
miles
\end{tabular} & $\begin{array}{c}\mathrm{rfg} \\
\text { miles } \\
\end{array}$ & $\begin{array}{l}\mathrm{rfg} \\
\text { miles }\end{array}$ & $\begin{array}{c}\text { mile } \\
\text { factor }\end{array}$ & del log mpg & weight & term & sdel & sigma & std residual & student resid \\
\hline 25.07 & 22.199 & 24.63 & 22.196 & 11.098 & -0.0177067 & 0.03125 & -0.000553334 & 0.011458857 & 0.001457227 & 0.564288854 & $0.57331804 \mathrm{~g}$ \\
\hline 20.02 & 22.198 & 19.25 & 22.196 & 11.098 & -0.039220713 & 0.03125 & -0.001225647 & -0.010055156 & $0.00112207 \mathrm{~g}$ & -0.495163927 & .0 .503087053 \\
\hline 24.39 & 22.196 & 23.62 & 22.199 & 11.098 & -0.032079401 & 0.03125 & .0 .001002481 & -0.002913845 & $9.42275 \mathrm{E}-04$ & -0.143491624 & -0.145787638 \\
\hline 26.09 & 22.196 & 24.67 & 22.199 & 11.098 & -0.052508607 & 0.03125 & -0.001640894 & -0.023343051 & 0.006047278 & -1.14952332 & .1 .167916863 \\
\hline 18.03 & 22.19 & 17.66 & 22.199 & 11.098 & -0.02018005 & 0.03125 & -0.000630627 & 0.008985 & 0.000896044 & 0.442488942 & 0.449569214 \\
\hline 27.71 & $22.19 \mathrm{q}$ & 27.29 & 22.199 & 11.099 & -0.015273024 & 0.03125 & -0.00047728 & 0.013892533 & 0.002141941 & 0.684134681 & 0.695081531 \\
\hline 19.56 & 22.19 q & 18.77 & 22.199 & 11.098 & -0.041226814 & 0.03125 & -0.001288338 & -0.01206125 & $0.0016144 \mathrm{~J}$ & -0.593953916 & -0.603457782 \\
\hline 17.15 & 22.196 & 16.50 & 22.199 & 11.098 & -0.038637793 & 0.03125 & -0.001207431 & -0.009472236 & 0.000995749 & -0.466458139 & -0.473921943 \\
\hline 13.40 & 22.199 & 13.87 & 22.19 & 11.098 & 0.034473527 & 0.03125 & 0.001077298 & 0.063639084 & 0.044946157 & 3.133892524 & 3.184037980 \\
\hline & & & & & & & & & & & \\
\hline \multirow[t]{7}{*}{32} & $\begin{array}{l}\text { n test } \\
\text { group }\end{array}$ & & & $\begin{array}{r}355.13 \\
6 \\
\end{array}$ & & 1 & -0.02916555 & $-3.60822 \mathrm{E}-1 \mathrm{~S}$ & 0.067649125 & & \\
\hline & & & beta & & & & & & 0.003589755 & & \\
\hline & & $\begin{array}{l}\text { CARFG } \\
\text { effect }\end{array}$ & \multicolumn{2}{|c|}{0.029165557} & 0.030768938 & $\begin{array}{l}\text { Pnergy } \\
\text { effect }\end{array}$ & & & & & \\
\hline & & $\begin{array}{l}\text { std } \\
\text { error }\end{array}$ & \multicolumn{2}{|c|}{0.003589759} & 0.672437755 & value & & & & & \\
\hline & delta & $\begin{array}{r}0.0287 \\
44347 \\
\end{array}$ & & $\begin{array}{l}\text { CARFG } \\
\text { BTU/g }\end{array}$ & $11137 d$ & & & & & & \\
\hline & & & & $\begin{array}{r}\text { cony } \\
\text { BTU/d }\end{array}$ & 114850 & & & & & & \\
\hline & & & beta & & delta & & & & & & \\
\hline \multicolumn{2}{|r|}{ confidence } & $\begin{array}{l}\text { conf. in } \\
\text { for } \mathrm{rgg}\end{array}$ & $\begin{array}{l}\text { terval } \\
\text { effect }\end{array}$ & & $\begin{array}{l}\text { conf. interval } \\
\text { for } \mathrm{rfg} \text { effect }\end{array}$ & & & & & & \\
\hline & 50 & \multicolumn{2}{|c|}{0.674490366} & 0.0267 & 0.03160 .0264 & 0.0311 & & & & & \\
\hline & 75 & \multicolumn{2}{|c|}{1.150349363} & 0.0250 & $0.03330 .024 \pi$ & 0.0327 & & & & & \\
\hline & 90 & \multicolumn{2}{|c|}{1.644853} & 0.0233 & 0.03510 .023 & 0.03446 & & & & & \\
\hline & 95 & \multicolumn{2}{|c|}{1.95996108} & 0.0221 & 0.03620 .0219 & 0.0356 & & & & & \\
\hline & 99 & \multicolumn{2}{|c|}{2.575834515} & 0.0199 & 0.03840 .0197 & 0.0377 & & & & & \\
\hline
\end{tabular}


APPENDIX 2D

FUEL ECONOMY ANALYSIS OF AUTO OIL FLEET

NONPARAMETRIC MODEL

\begin{tabular}{|c|c|c|c|c|}
\hline $\begin{array}{c}\text { industry } \\
\text { mpg }\end{array}$ & $\begin{array}{c}\text { industry } \\
\text { miles }\end{array}$ & rfg mpg & rfg miles & del log mpg \\
\hline 22.62 & 22.196 & 22.3 & 22.196 & 0.014247792 \\
\hline 24.16 & 22.196 & 22.84 & 22.196 & 0.056184988 \\
\hline 21.4 & 22.196 & 20.52 & 22.196 & 0.041990902 \\
\hline 21.54 & 22.196 & 21.04 & 22.196 & 0.023486284 \\
\hline 19.11 & 22.196 & 18.73 & 22.196 & 0.020085242 \\
\hline 19.73 & 22.196 & 19.26 & 22.196 & 0.024109914 \\
\hline 15 & 22.196 & 14.62 & 22.196 & 0.025659747 \\
\hline 20.27 & 22.196 & 19.39 & 22.196 & 0.044384491 \\
\hline 15.26 & 22.196 & 14.7 & 22.196 & 0.037387532 \\
\hline 26.07 & 22.196 & 24.81 & 22.196 & 0.04953843 \\
\hline 22.51 & 22.196 & 21.39 & 22.196 & 0.051036132 \\
\hline 19.5 & 22.196 & 19.46 & 22.196 & 0.002053389 \\
\hline 22.77 & 22.196 & 22.44 & 22.196 & 0.014598799 \\
\hline 20.72 & 22.196 & 19.95 & 22.196 & 0.037870274 \\
\hline 29.57 & 22.196 & 28.34 & 22.196 & 0.0424861 \\
\hline 26.23 & 22.196 & 25.32 & 22.196 & 0.035309197 \\
\hline 14.51 & 22.196 & 14.04 & 22.196 & 0.032927668 \\
\hline 26.63 & 22.196 & 27.39 & 22.196 & -0.028139583 \\
\hline 21.84 & 22.196 & 21.4 & 22.196 & 0.020352229 \\
\hline 26.19 & 22.196 & 25.32 & 22.196 & 0.033783061 \\
\hline 21.13 & 22.196 & 20.33 & 22.196 & 0.038596204 \\
\hline 28.93 & 22.196 & 27.46 & 22.196 & 0.052148719 \\
\hline 22.24 & 22.196 & 21.35 & 22.196 & 0.04084073 \\
\hline & & & & \\
\hline
\end{tabular}




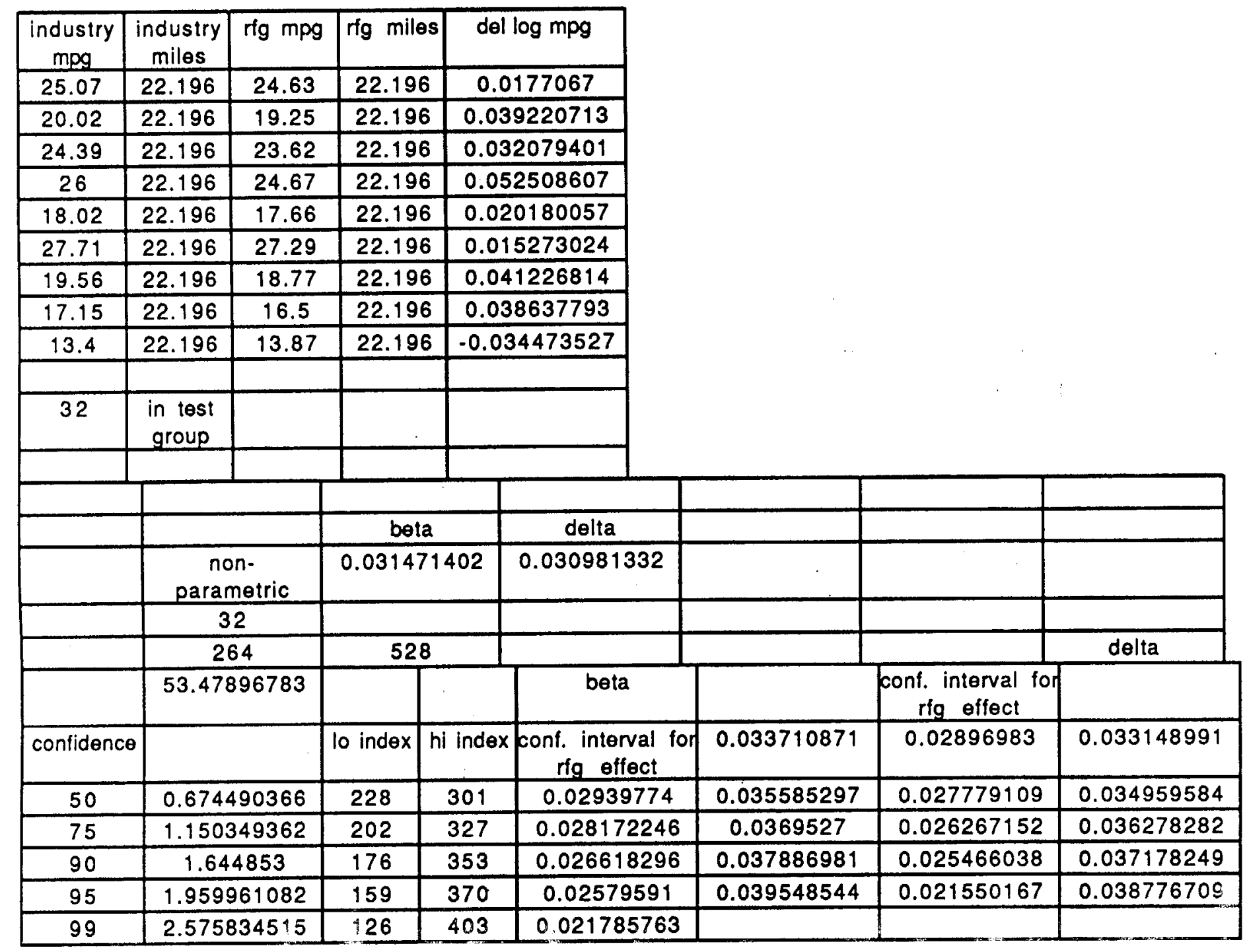


APPENDIX 2E

FUEL ECONOMY ANALYSIS OF CARB FLEET

CITY DRIVING

NORMAL MODEL

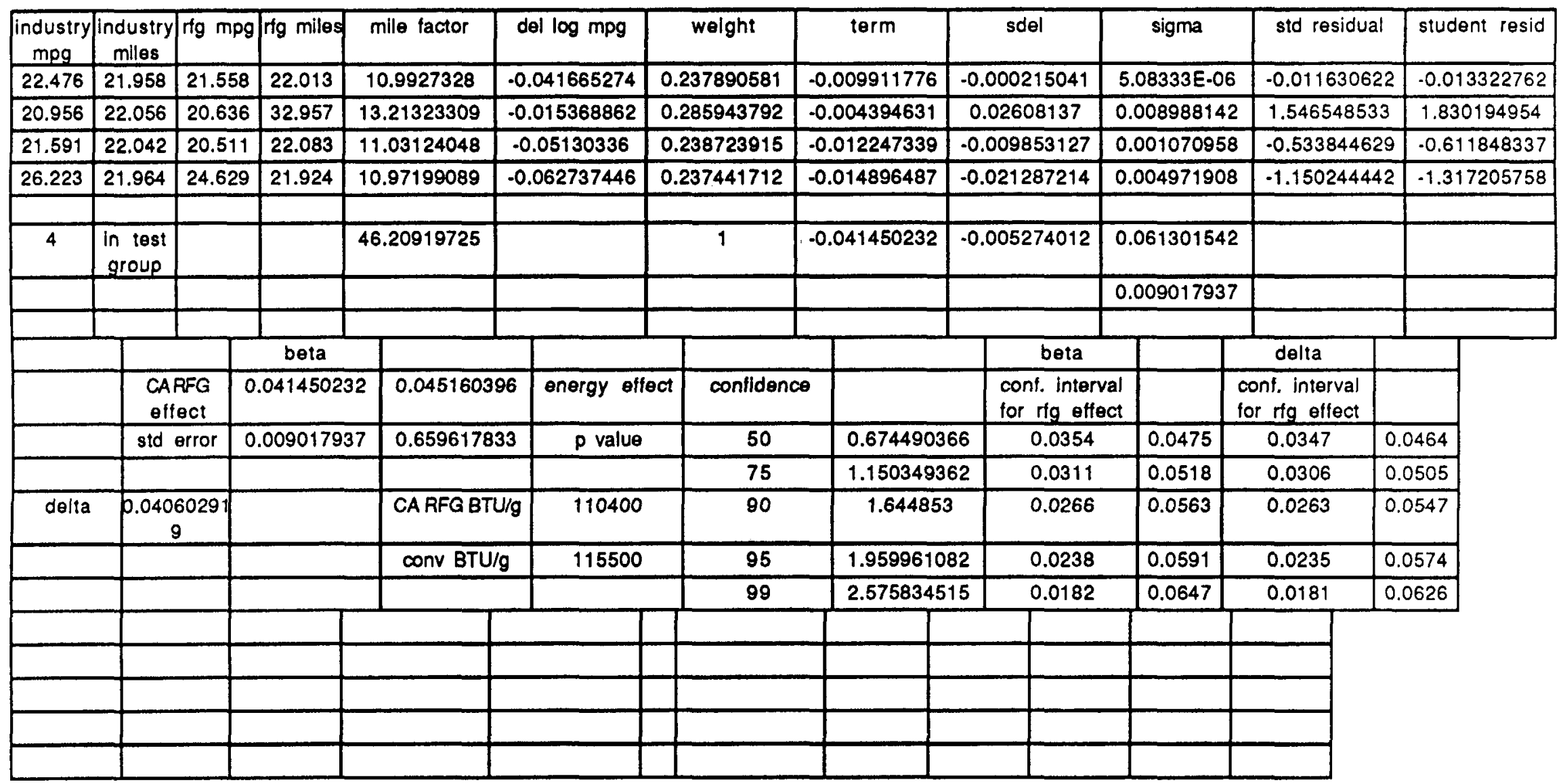




\begin{tabular}{|c|c|c|c|c|c|c|c|c|c|c|c|c|c|}
\hline city mpg & & & & & & & & & & & & \\
\hline & Taurus & Caravan & Lumina & Accord & & & d rfg & mpg rfg & d conv & mpg conv & reduction \\
\hline $\mathrm{d} \mathrm{ffg}$ & 22.013 & 32.957 & 22.083 & 21.924 & & Taurus & 22.013 & 21.558 & 21.958 & 22.476 & .0408 \\
\hline $\mathrm{mpg} \mathrm{rfg}$ & 21.558 & 20.636 & 20.511 & 24.629 & & Caravan & 32.957 & 20.636 & 22.056 & 20.956 & .0153 \\
\hline $\mathrm{d}$ conv & 21.958 & 22.056 & 22.042 & 21.964 & & Lumina & 22.083 & 20.511 & 22.042 & 21.591 & .0500 \\
\hline mpg conv & 22.476 & 20.956 & 21.591 & 26.223 & & Accord & 21.924 & 24.629 & 21.964 & 26.223 & .0608 \\
\hline reduction & .0408 & .0153 & .0500 & .0608 & & & & & & & \\
\hline
\end{tabular}


APPENDIX 2F

FUEL ECONOMY ANALYSIS OF CARB FLEET

HIGHWAY DRIVING

NORMAL MODEL

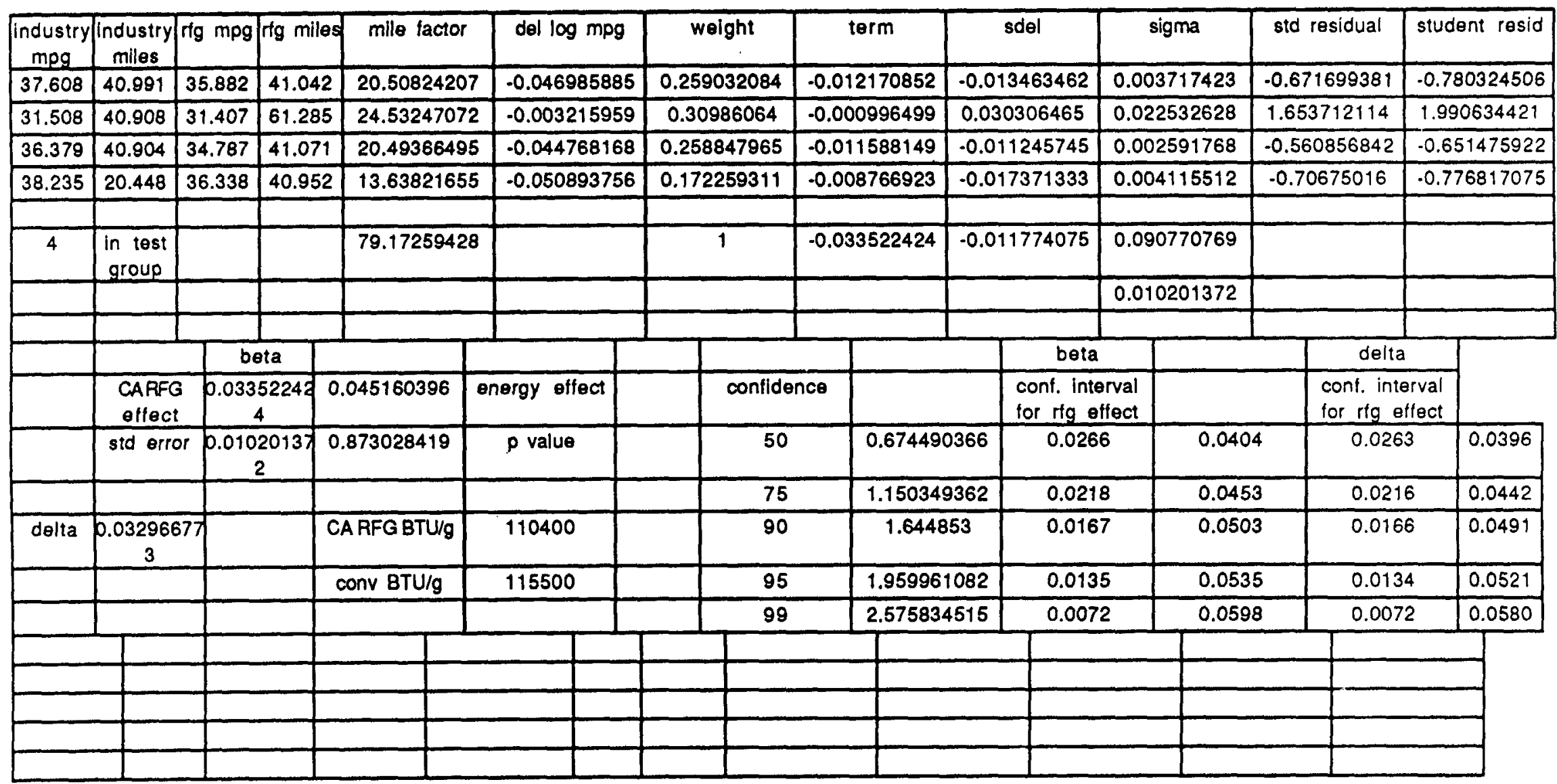




\begin{tabular}{|c|c|c|c|c|c|c|c|c|c|c|}
\hline hwy mpg & & & & & & & & & & \\
\hline & Taurus & Caravan & Lumina & Accord & & $d \mathrm{rg}$ & $\mathrm{mpg}$ rfg & $d$ conv & mpg conv & reduction \\
\hline$d r l g$ & 41.042 & 61.285 & 41.071 & 40.952 & Taurus & 41.042 & 35.882 & 40.991 & 37.608 & .0459 \\
\hline $\mathrm{mpg} \mathrm{rig}$ & 35.882 & 31.407 & 34.787 & 36.338 & Caravan & 61.285 & 31.407 & 40.908 & 31.508 & .0032 \\
\hline$d$ conv & 40.991 & 40.908 & 40.904 & 20.448 & Lumina & 41.071 & 34.787 & 40.904 & 36.379 & .0438 \\
\hline mpg conv & 37.608 & 31.508 & 36.379 & 38.235 & Accord & 40.952 & 36.338 & 20.448 & 38.235 & .0496 \\
\hline reduction & .0459 & .0032 & .0438 & .0496 & & & & & & \\
\hline
\end{tabular}


APPENDIX 2G

FUEL ECONOMY ANALYSIS OF CARB FLEET

CITY DRIVING

NONPARAMETRIC MODEL

\begin{tabular}{|c|c|c|c|c|c|c|}
\hline industry $\mathrm{mpg}$ & industry miles & $\mathrm{rfg} \mathrm{mpg}$ & rfg miles & del log mpg & & \\
\hline 22.476 & 21.958 & 21.558 & 22.013 & 0.041665274 & & \\
\hline 20.956 & 22.056 & 20.636 & 32.957 & 0.015368862 & & \\
\hline 21.591 & 22.042 & 20.511 & 22.083 & 0.05130336 & & \\
\hline 26.223 & 21.964 & 24.629 & 21.924 & 0.062737446 & & \\
\hline \multirow{3}{*}{4} & in test aroun & & & & & \\
\hline & & & & & & \\
\hline & 0.041665274 & 0.015368862 & 0.05130336 & 0.062737446 & & \\
\hline 0.041665274 & 0.041665274 & & & & & \\
\hline 0.015368862 & 0.028517068 & 0.015368862 & & & & \\
\hline 0.05130336 & 0.046484317 & 0.033336111 & 0.05130336 & & & \\
\hline 0.062737446 & 0.05220136 & 0.039053154 & 0.057020403 & 0.062737446 & & \\
\hline 0.015368862 & & & beta & & & \\
\hline 0.028517068 & & nonparametric & 0.0441 & & & \\
\hline 0.033336111 & & & & & & \\
\hline 0.039053154 & & & & $\begin{array}{c}88 \% \\
\text { confidence } \\
\text { interval for rfg } \\
\text { effect: }\end{array}$ & 0.0154 & 0.0627 \\
\hline 0.041665274 & & & & & & \\
\hline 0.046484317 & & & .. & $\begin{array}{l}94 \% \text { upper } \\
\text { bound for rfg }\end{array}$ & 0.0627 & \\
\hline
\end{tabular}




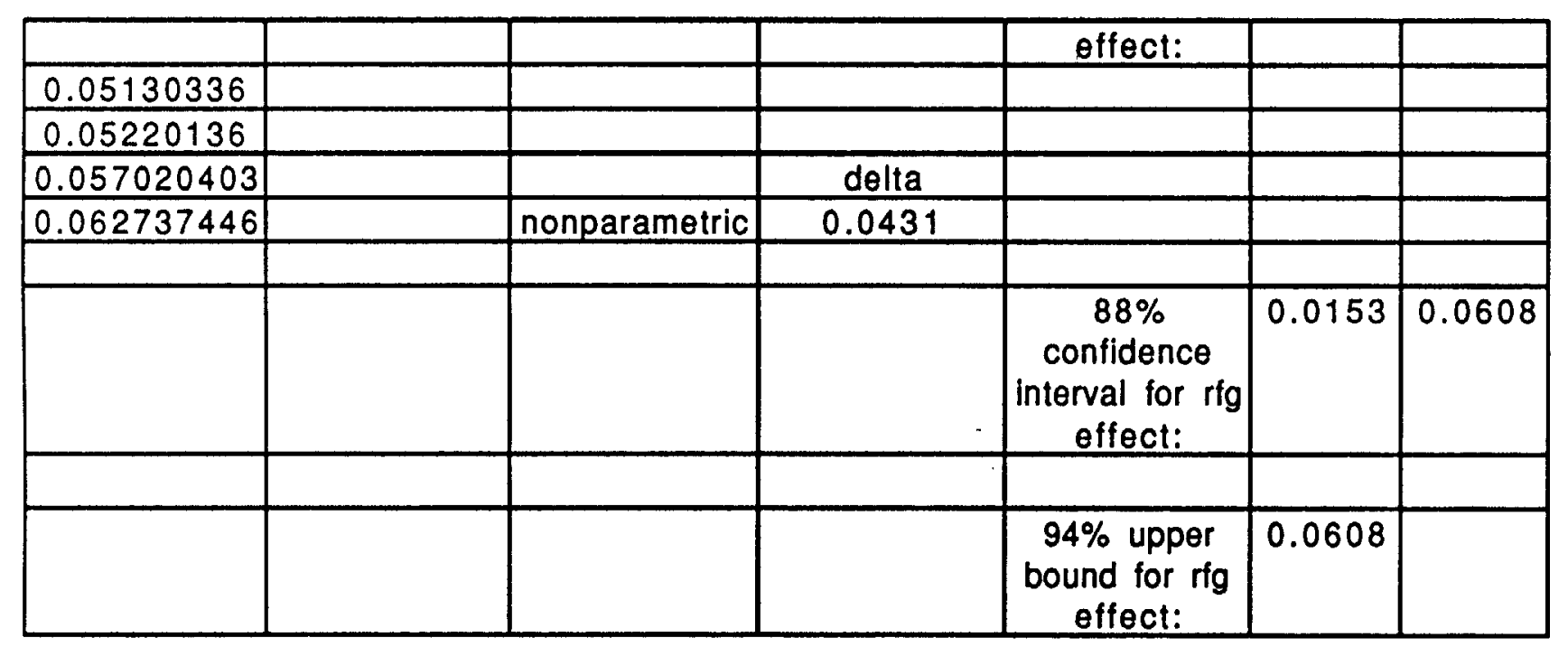




\section{APPENDIX 2H}

FUEL ECONOMY ANALYSIS OF CARB FLEET

HIGHWAY DRIVING

NON-PARAMETRIC MODEL

\begin{tabular}{|c|c|c|c|c|c|c|}
\hline industry $\mathrm{mpg}$ & industry miles & ifg $\mathrm{mpg}$ & ifg miles & del $\log \mathrm{mpg}$ & & \\
\hline 37.608 & 40.991 & 35.882 & 41.042 & 0.046985885 & & \\
\hline 31.508 & 40.908 & 31.407 & 61.285 & 0.003215959 & & \\
\hline 36.379 & 40.904 & 34.787 & 41.071 & 0.044768168 & & \\
\hline 38.235 & 20.448 & 36.338 & 40.952 & 0.050893756 & & \\
\hline$\overline{4}$ & in test group & & & & & \\
\hline & & & & & & \\
\hline & 0.046985885 & 0.003215959 & 0.044768168 & 0.050893756 & & \\
\hline 0.046985885 & 0.046985885 & & & & & \\
\hline 0.003215959 & 0.025100922 & 0.003215959 & & & & \\
\hline 0.044768168 & 0.045877027 & 0.023992064 & 0.044768168 & & & \\
\hline 0.050893756 & 0.048939821 & 0.027054858 & 0.047830962 & 0.050893756 & & \\
\hline 0.003215959 & & & beta & & & \\
\hline 0.023992064 & & nonparametric & 0.0453 & & & \\
\hline 0.025100922 & & & & & & \\
\hline 0.027054858 & & & & $\begin{array}{c}88 \% \\
\text { confidence } \\
\text { interval for rfg } \\
\text { effect: } \\
\end{array}$ & 0.0032 & 0.0509 \\
\hline 0.044768168 & & & & & & \\
\hline 0.045877027 & & & & $\begin{array}{c}94 \% \text { upper } \\
\text { bound for } \mathrm{rfg}\end{array}$ & 0.0509 & \\
\hline
\end{tabular}




\begin{tabular}{|c|c|c|c|c|c|}
\hline & & & effect: & & \\
\hline \multicolumn{6}{|l|}{0.046985885} \\
\hline \multicolumn{6}{|l|}{0.047830962} \\
\hline 0.048939821 & & delta & & & \\
\hline \multirow[t]{4}{*}{0.050893756} & nonparametric & 0.0443 & & & \\
\hline & & & & & \\
\hline & & & $\begin{array}{c}88 \% \\
\text { confidence } \\
\text { interval for } \mathrm{rg} \\
\text { effect: }\end{array}$ & 0.0032 & 0.0496 \\
\hline & & & $\begin{array}{c}94 \% \text { upper } \\
\text { bound for rfg } \\
\text { effect: }\end{array}$ & 0.0496 & \\
\hline
\end{tabular}




\section{APPENDIX 2I}

\section{FUEL ECONOMY ANALYSIS OF OKLAHOMA FLEET}

\section{NORMAL MODEL}

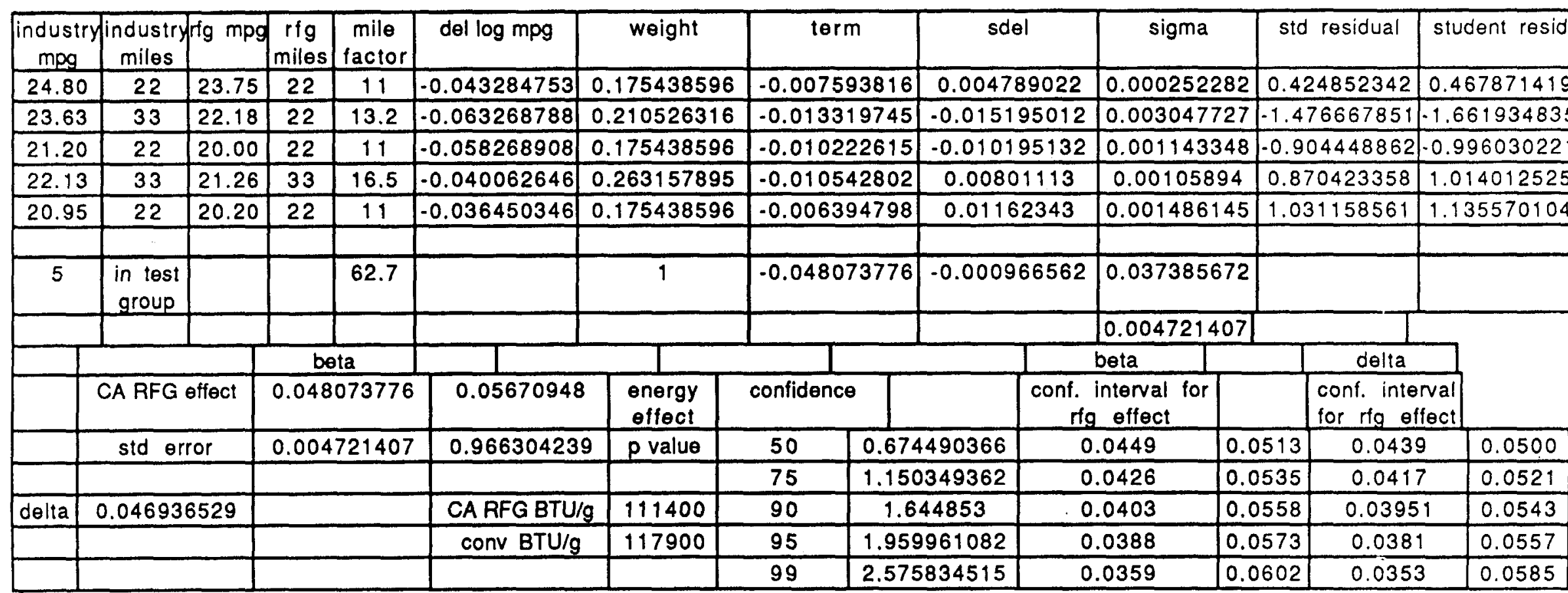


APPENDIX 2J

FUEL ECONOMY ANALYSIS OF OKLAHOMA DOE FLEET

NONPARAMETRIC MODEL

\begin{tabular}{|c|c|c|c|c|c|c|}
\hline industry mpg & industry miles & $\mathrm{rfg} \mathrm{mpg}$ & ifg miles & del log mpg & & \\
\hline 24.80 & 22 & 23.75 & 22 & 0.043284753 & & \\
\hline 23.63 & 33 & 22.18 & 22 & 0.063268788 & & \\
\hline 21.20 & 22 & 20.00 & 22 & 0.058268908 & & \\
\hline 22.13 & 33 & 21.26 & 33 & 0.040062646 & & \\
\hline 20.95 & 22 & 20.20 & 22 & 0.036450346 & & \\
\hline \multirow[t]{3}{*}{5} & in test group & & & & & \\
\hline & & & & & & \\
\hline & 0.043284753 & 0.063268788 & 0.058268908 & 0.040062646 & 0.036450346 & \\
\hline 0.043284753 & 0.043284753 & & & & & \\
\hline 0.063268788 & 0.053276771 & 0.063268788 & & & & \\
\hline 0.058268908 & 0.050776831 & 0.060768848 & 0.058268908 & & & \\
\hline 0.040062646 & 0.0416737 & 0.051665717 & 0.049165777 & 0.040062646 & & \\
\hline 0.036450346 & 0.03986755 & 0.049859567 & 0.047359627 & 0.038256496 & 0.036450346 & \\
\hline \multicolumn{7}{|l|}{0.036450346} \\
\hline 0.038256496 & & & beta & & & \\
\hline 0.03986755 & & nonparametric & 0.0492 & & & \\
\hline \multicolumn{7}{|l|}{0.040062646} \\
\hline 0.0416737 & & & & $\begin{array}{c}88 \% \\
\text { confidence } \\
\text { interval for } \mathrm{rg} \\
\text { effect: }\end{array}$ & 0.0383 & 0.0608 \\
\hline 0.043284753 & & & & & & \\
\hline
\end{tabular}




\begin{tabular}{|c|c|c|c|c|c|}
\hline 0.047359627 & & & $\begin{array}{c}94 \% \text { upper } \\
\text { bound for } \mathrm{rfg} \\
\text { effect: }\end{array}$ & 0.0608 & \\
\hline \multicolumn{6}{|l|}{0.049165777} \\
\hline \multicolumn{6}{|l|}{0.049859567} \\
\hline 0.050776831 & & delta & & & \\
\hline 0.051665717 & nonparametric & 0.0480 & & & \\
\hline \multicolumn{6}{|l|}{0.053276771} \\
\hline 0.058268908 & & & \begin{tabular}{|c|}
$88 \%$ \\
confidence \\
interval for $\mathrm{rg}$ \\
effect: \\
\end{tabular} & 0.03753 & 0.0590 \\
\hline \multicolumn{6}{|l|}{0.060768848} \\
\hline 0.063268788 & & & $\begin{array}{c}94 \% \text { upper } \\
\text { bound for rfg } \\
\text { effect: }\end{array}$ & 0.0590 & \\
\hline
\end{tabular}


APPENDIX 2K

\section{CADILLAC DIARY}

\begin{tabular}{|c|c|c|c|c|c|c|c|}
\hline fill-up & mpg & gallons & odometer & mpg & $\ln (\mathrm{mpg})$ & $\mathrm{c}^{*} f$ & term \\
\hline & & & 1198 & & & & \\
\hline 1 & 9.84295026 & 22.859 & 1423 & 9.84 & 2.286755489 & 52.27294373 & $9.55900 \mathrm{E}-04$ \\
\hline 2 & 10.50036973 & 20.285 & 1636 & 10.50 & 2.351410469 & 47.69836136 & 0.090245478 \\
\hline 3 & 9.54885137 & 21.678 & 1843 & 9.55 & 2.256420872 & 48.91469166 & 0.017349048 \\
\hline 4 & 9.614411497 & 19.762 & 2033 & 9.61 & 2.26326317 & 44.72660677 & 0.009090336 \\
\hline 5 & 9.550840204 & 22.197 & 2245 & 9.55 & 2.25662913 & 50.0903968 & 0.01750382 \\
\hline 6 & 10.49882754 & 18.764 & 2442 & 10.50 & 2.351263588 & 44.11910997 & 0.083111481 \\
\hline 7 & 9.949738435 & 19.498 & 2636 & 9.95 & 2.297546263 & 44.79755703 & 0.003212396 \\
\hline 8 & 9.854655087 & 22.223 & 2855 & 9.85 & 2.287943941 & 50.84497821 & 0.000232335 \\
\hline 9 & 9.400884191 & 19.679 & 3040 & 9.40 & 2.240803748 & 44.09677695 & 0.037937343 \\
\hline 10 & 8.884596813 & 20.710 & 3224 & 8.88 & 2.184319082 & 45.23724819 & 0.20872469 \\
\hline 11 & 9.530999339 & 21.194 & 3426 & 9.53 & 2.254549575 & 47.78292369 & 0.019279869 \\
\hline 12 & 9.02571108 & 20.497 & 3611 & 9.03 & 2.200077291 & 45.09498424 & 0.146815724 \\
\hline 13 & 9.831460674 & 19.224 & 3800 & 9.83 & 2.285587517 & 43.93813442 & $1.47841 E-04$ \\
\hline 14 & 9.014617626 & 40.157 & 4162 & 9.01 & 2.19884744 & 88.29911667 & 0.296056516 \\
\hline 15 & 9.465918055 & 21.551 & 4366 & 9.47 & 2.247697775 & 48.44013474 & 0.029523718 \\
\hline 16 & 9.206798867 & 16.944 & 4522 & 9.21 & 2.219942218 & 37.61470095 & 0.071079039 \\
\hline 17 & 10.92128028 & 18.496 & 4724 & 10.92 & 2.390713205 & 44.21863144 & 0.207831413 \\
\hline 18 & 8.977320454 & 38.096 & 5066 & 8.98 & 2.194701447 & 83.60934634 & 0.308640117 \\
\hline 19 & 9.214243897 & 39.287 & 5428 & 9.21 & 2.220750536 & 87.24662633 & 0.160718602 \\
\hline 20 & 9.726564438 & 20.151 & 5624 & 9.73 & 2.274860744 & 45.84071886 & 0.001955029 \\
\hline 21 & 9.431715334 & 20.993 & 5822 & 9.43 & 2.244077982 & 47.10992907 & 0.034659584 \\
\hline 22 & 9.104704097 & 20.429 & 6008 & 9.10 & 2.208791214 & 45.1233957 & 0.117747602 \\
\hline 23 & 9.39942614 & 20.214 & 6198 & 9.40 & 2.240648639 & 45.29247158 & 0.039244536 \\
\hline 24 & 8.924006507 & 21.515 & 6390 & 8.92 & 2.188745006 & 47.0908488 & 0.198139989 \\
\hline 25 & 10.92950469 & 20.129 & 6610 & 10.93 & 2.391465985 & 48.13781881 & 0.229404577 \\
\hline
\end{tabular}




\begin{tabular}{|c|c|c|c|c|c|c|c|}
\hline fill-up & $\mathrm{mpg}$ & gallons & odometer & $\mathrm{mpg}$ & $\ln (\mathrm{mpg})$ & $c^{* f}$ & term \\
\hline 26 & 10.2399832 & 19.043 & 6805 & 10.24 & 2.326299979 & 44.29973049 & 0.032938285 \\
\hline 27 & 11.3681891 & 19.968 & 7032 & 11.37 & 2.4308 .19025 & 48.5385943 & 0.426270525 \\
\hline 28 & 9.806313119 & 20.497 & 7233 & 9.81 & 2.283026374 & 46.79519159 & $5.81396 \mathrm{E}-04$ \\
\hline 29 & 10.44620911 & 21.156 & 7454 & 10.45 & 2.346239148 & 49.63703542 & 0.080091681 \\
\hline 30 & 10.50326272 & 22.374 & 7689 & 10.50 & 2.351685944 & 52.6166213 & 0.100363086 \\
\hline 31 & 10.93202523 & 21.405 & 7923 & 10.93 & 2.391696576 & 51.1942652 & 0.245001775 \\
\hline 32 & 10.1010101 & 20.691 & 8132 & 10.10 & 2.312635429 & 47.85073966 & 0.016134802 \\
\hline 33 & 10.49536304 & 22.105 & 8364 & 10.50 & 2.350933544 & 51.967386 & 0.0969 \\
\hline 34 & 10.09 & 21 & 5 & 10.09 & 2.31 & 50.61 & 0.1 \\
\hline 35 & 9.475 & 20 & 10 & 48 & 2.24 & 46.27 & 933 \\
\hline 36 & 10.3 & 20 & 11 & 31 & 2.33 & 47 & 0.0 \\
\hline 37 & 10.6 & 40 & 9 & 62 & 2.36 & 95 & 0.247 \\
\hline 38 & 10.26534073 & 21.821 & 9643 & 10.27 & 2.32 & 50.81 & 0.042 \\
\hline 39 & 9.968260266 & 20.164 & 9844 & 9.97 & 2.29 & 46.36 & 0.004 \\
\hline 40 & 9.96 & 21.276 & 10056 & 9.96 & 2.29 & 48.91 & 316 \\
\hline 41 & 9.899 & & 65 & 90 & 2.29 & 48. & 105 \\
\hline 42 & 10.08 & & 3 & 09 & 2.31 & 47. & \\
\hline 43 & 10.226 & 18 & 36 & 10.23 & 2.32 & 43.8 & 0.0 \\
\hline 44 & 9.7253 & 21 & 10876 & 9.73 & 2.274 & 49. & 0.1 \\
\hline 45 & 10.120 & 18.872 & 11067 & 10.12 & 2.314 & 43.681 & 0.01 \\
\hline 46 & 9.8072 & 20.393 & 11267 & 9.81 & 2.28 & 46.559 & 5.1 \\
\hline 47 & 9.952958653 & 20.195 & 11468 & 9.95 & 2.297869859 & 46.4054818 & 0.003497109 \\
\hline 48 & 9.644570645 & 20.426 & 11665 & 9.64 & 19513 & 46.29338692 & 0.006852006 \\
\hline 49 & 10.017 & 21.662 & 11882 & 10.02 & 2.30 & 499 & 801 \\
\hline 50 & 10.171 & & 12088 & 10.17 & 2.31 & 46.976 & 177 \\
\hline 51 & 10.01798099 & & 12283 & 10.02 & 2.304 & 44.85478741 & 1958 \\
\hline 52 & 10.68619474 & 18.435 & 12480 & 10.69 & 2.36 & 43.671 & 347 \\
\hline 53 & 10.7865 & 20 & 12699 & 10.79 & 2.37 & 48.28668726 & 0.177 \\
\hline 54 & 9.816370385 & 20.476 & 12900 & 9.82 & 2.284051439 & 46.76823727 & $8.89569 \mathrm{E}-0$ \\
\hline
\end{tabular}




\begin{tabular}{|c|c|c|c|c|c|c|c|}
\hline fill-up & $m p g$ & gallons & odometer & $\mathrm{mpg}$ & $\ln (\mathrm{mpg})$ & $c^{*} f$ & term \\
\hline 55 & 11.04337398 & 20.012 & 13121 & 11.04 & 2.401830608 & 48.06543413 & 0.2745067 \\
\hline 56 & 8.841189542 & 21.151 & 13308 & 8.84 & 2.179421431 & 46.09694269 & 0.234475786 \\
\hline 57 & 0.09715097 & 18.322 & 13493 & 10.10 & 2.312253301 & 42.36510499 & 0.013899113 \\
\hline 58 & 11.35442011 & 22.194 & & 11.35 & 2.429607105 & 53.9227001 & 3203 \\
\hline 59 & 9.525660964 & 20.576 & 13941 & 9.53 & 2.253989311 & 46.37808407 & 9533 \\
\hline 60 & 927705936 & 19.642 & 14136 & 9.93 & 2.295329428 & 45.08486062 & 0.002 \\
\hline 61 & 381 & 21. & & 38 & 2.23 & 47.72352702 & 3245 \\
\hline 62 & 10.72322736 & 21.169 & 14563 & 10.72 & 2.37241217 & 50.22159323 & 0.162 \\
\hline 63 & 9.804841434 & 21.316 & 14772 & 9.80 & 2.28 & 48.66 & -04 \\
\hline 64 & & 20 & 84 & 15 & 2.31 & 48.39 & 274 \\
\hline 65 & 9.289919058 & 21.744 & 15186 & 9.29 & 2.22892984 & 48.46585044 & 5622 \\
\hline 66 & 10.65 & & & & 7278 & 0088 & 429 \\
\hline 67 & 9.28 & & & 9.28 & 2.2 & 2474 & 806 \\
\hline 68 & 10.9 & 18 & 781 & 10.95 & 2.39 & 45.02 & 537 \\
\hline 69 & 9.7 & & & & 2.27 & 0964 & 377 \\
\hline 70 & 9.7712 & & & 77 & 2.2 & 53.42 & 877 \\
\hline 71 & 538 & & & 94 & 2.29 & 16238 & 349 \\
\hline 72 & 10. & 20 & & 10.40 & 2.34 & 38465 & 739 \\
\hline 73 & 9.842105263 & & & 34 & 2.28 & 2312 & -04 \\
\hline 74 & 9.6 & & & & 2.2 & 5549 & 903 \\
\hline 75 & 9. & 19 & & 9 & 2.2 & 0743 & \\
\hline 76 & 10.229 & 18. & 45 & 10.23 & 2.3 & 42.27886969 & 6411 \\
\hline 77 & & & & & 2.1 & 8015 & 3766 \\
\hline 78 & 9.83 & & 17 & 4 & 2.2 & 9239 & .04 \\
\hline 79 & 10.21015067 & 20.176 & 923 & 10.21 & 2.3 & 46.87656309 & 3412 \\
\hline 80 & 9.992046132 & 20.116 & 18124 & 9.99 & 8939 & 46.30279536 & 67562 \\
\hline 81 & 10.03923967 & 19.623 & 321 & 10.04 & 01381 & 45.2604766 & 31778 \\
\hline 82 & 9.336338132 & & & & 2.23 & 48.57199455 & 016 \\
\hline 83 & 9.400892288 & 18.828 & 18701 & 9.40 & 2.240804609 & 42.18986918 & 0.036295354 \\
\hline
\end{tabular}




\begin{tabular}{|c|c|c|c|c|c|c|c|}
\hline fill-up & $\mathrm{mpg}$ & gallons & odometer & $\mathrm{mpg}$ & $\ln (\mathrm{mpg})$ & $\mathrm{c}^{*} f$ & term \\
\hline 84 & 9.055708219 & 16.012 & 18846 & 9.06 & 2.203395301 & 35.28076556 & 0.105874096 \\
\hline 85 & 9.147735935 & 19.677 & 19.026 & 9.15 & 2.21350641 & 43.55516563 & 0.09976301 \\
\hline 86 & 9.287320364 & 40.916 & 19406 & 9.29 & 2.228650068 & 91.18744619 & 0.128589952 \\
\hline 87 & 9.169199595 & 19.740 & 19587 & 9.17 & 2.215849997 & 43.74087895 & 0.09360269 \\
\hline 88 & 9.363769803 & 19.757 & 19772 & 9.36 & 2.236847966 & 44.19340527 & 0.045259894 \\
\hline 89 & 9.638731514 & 40.773 & 20165 & 9.64 & 2.265789514 & 92.38303586 & 0.014596983 \\
\hline 90 & 9.494482936 & 19.485 & 20350 & 9.49 & 2.250710886 & 43.85510162 & 0.022524233 \\
\hline 91 & 9.444388627 & 19.906 & 20538 & 9.44 & 2.245420769 & 44.69734583 & 0.030728653 \\
\hline 92 & 9.676125539 & 19.946 & 20731 & 9.68 & 2.269661567 & 45.27066961 & 0.004517217 \\
\hline 93 & 9.43632987 & 19.923 & 20919 & 9.44 & 2.24456712 & 44.71851072 & 0.032105837 \\
\hline 94 & 9.939033762 & 19.519 & 21113 & 9.94 & 2.296469809 & 44.8247942 & 0.002699084 \\
\hline 95 & 9.447081955 & 20.853 & 21310 & 9.45 & 2.245705906 & 46.82970526 & 0.031724989 \\
\hline 96 & 10.68469254 & 18.344 & 21506 & 10.68 & 2.368812114 & 43.45348941 & 0.129748409 \\
\hline 97 & 8.935485793 & 16.787 & 21656 & 8.94 & 2.190030517 & 36.76404228 & 0.150483894 \\
\hline & & & & & & & \\
\hline & & total miles & 20458 & & 2079.082 & 2.284710564 & 0.272 \\
\hline & & avg mpg & 9.839919734 & & 97 & 9.822842725 & sigma hat \\
\hline
\end{tabular}




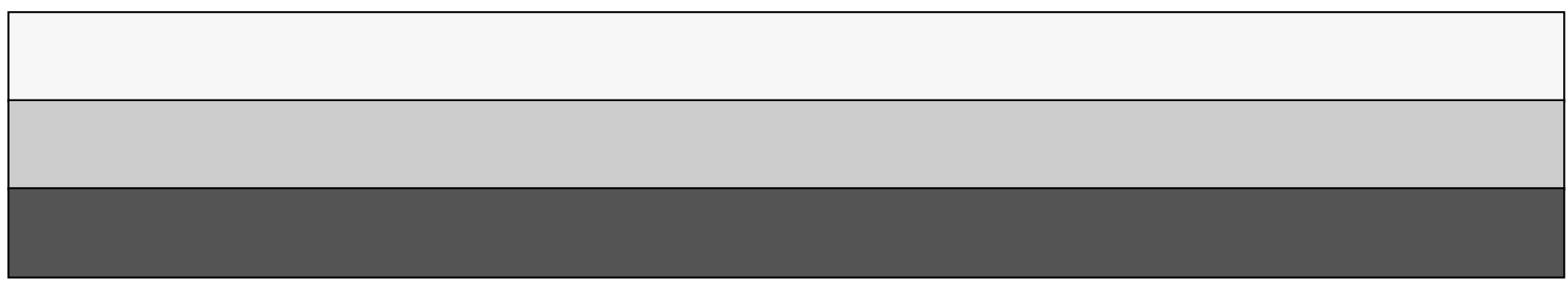

